\title{
OTROS MATERIALES UTILIZADOS PARA \\ LA ENSEÑANZA DE LA MEDICINA EN \\ EL REAL COLEGIO DE CIRUGÍA DE \\ SAN CARLOS DE MADRID (1788-1826)
}

\section{Carlos Manuel da Costa Carballo}

Escuela Universitaria de Biblioteconomía y Documentación, U.C.M.

\section{RESUMEN}

En este trabajo hemos analizado, aplicando las herramientas básicas de la documentación, como son el análisis, la indización, la clasificación, un fondo documental histórico que en otra época fue utilizado como material docente en el Real Colegio de Cirugía de San Carlos de Madrid.

PALABRAS CLAVE: análisis documental, indización, clasficación, Real colegio de cirugía de Madrid, juntas literarias.

\section{SUMMARY}

In this work we have analyzed, applying the basic tools of the documentation, like they are the analysis, indexing, classification, a historical documental collection that was used as educational material in the Royal College of Surgery of San Carlos from Madrid in another time.

KEY WORDS: documental analysis, indexing, classification, Royal college of surgery of Madrid, literary meetings.

Dedicado a la prof ${ }^{a}$. Dra. Dña. Elvira Arquiola Llopis (In Memoriam)

Siempre que iniciamos el estudio de la enseñanza de una ciencia nos ocupamos, entre otros aspectos relevantes, del análisis de las fuentes de conocimiento que se utilizaron, o se utilizan, para adquirir las nociones teóricoprácticas de esa ciencia, es decir, los libros o manuales de texto que se reco- 
mendaban, los apuntes que tomaban los alumnos en las explicaciones a las que asistían, etc. Es lo más lógico.

Sin embargo, y ateniéndonos ya estrictamente a la enseñanza de la medicina, siempre hubo otros materiales en los que se podía embeber la ciencia médica. Recordemos brevísimamente la transmisión oral de conocimientos, la antiloguía grecorromana, las akroaesis alejandrinas, los comentarios de texto de los alumnos árabes, la lectio/quaestio/disputatio del mundo medieval, sin contar, por supuesto, con los libros de texto.

Teniendo es cuenta lo que acabamos de comentar, lo que pretendemos con este trabajo es analizar esos otros materiales documentarios que pueden haber servido para que los estudiantes de medicina de finales del siglo XVIII y principios del XIX adquirieran más conocimientos, en principio teóricos.

Varios son estos materiales: las censuras de libros, las lecciones magistrales impartidas en los actos y discursos inaugurales de los diferentes cursos académicos, las historias clínicas que debían hacer los colegiales en las salas de los enfermos, las Juntas Literarias de los Jueves.

Algunos de estos temas ya fueron analizados por mí en mi tesis doctoral ${ }^{1}$. Sin embargo, en ella no traté el tema de las Juntas Literarias por razones de contenidos, pero creo que ha llegado el momento de analizar este tipo de producción científica que estuvo vigente durante casi toda la vida del Colegio (1788-1836) y a las que los alumnos tenían obligación de asistir.

Estas Juntas Literarias, no obstante, tienen un antecedente que fue el establecimiento de unas Juntas en las que un Colegial expondría un tema médico razonado y fundamentado con experimentos que reafirmaran lo que había argumentado con cierto rigor científico. Esto se puede ver en el Art. II de los Estatutos del Real Colegio de Profesores Cirujanos de Madrid (1747).

Por lo tanto, ¿cuáles son los objetivos que perseguimos con este trabajo?:

1. Catalogar las Juntas Literarias de los Jueves analizando los documentos correspondientes y elaborando los índices que sean necesarios. Este aspecto lo tocaremos al final del trabajo.

2. Hacer un estudio temático de los contenidos, teóricos y prácticos, intentando ver si eran temas relevantes o simplemente meras consultas.

3. Intentar analizar las repercusiones que estos actos tuvieron en la vida académica del Colegio.

1 Costa Carballo, C. M. da (1991), La enseñanza de la Medicina a finales del Siglo XVIII en las Instituciones Docentes ubicadas en el Hospital General de Madrid, Universidad Complutense de Madrid. 
4. Comprobar si los alumnos participaban por obligación (Ordenanzas) o por interés, o si no participaban.

5. Averiguar si estos documentos pudieron haber influido en la mejora de la calidad docente del Colegio.

Empezando por éste último punto, no cabe duda que fueron los cirujanos del Siglo XVIII los que auspiciaron el cambio. ¿Qué es lo que aportaron, en último extremo, los cirujanos del siglo XVIII?. A través de las Ordenanzas podemos responder a esta pregunta.

En primer lugar, con la erección del Colegio de Cirujanos pretendían «...poner la Cirugía, y Anatomía en Madrid en el mismo grado de cultura, perfecciòn, y estimaciòn, que actualmente lograban estas Facultades en la Corte de Paris» ${ }^{2}$. Creo que no puede estar más claro, pero para acallar los posibles ataques que pudieran venir del otro sector sanitario, el de los médicos, decían un poco más adelante que esto beneficiaría a España: "Y respecto de que utilidad de esta Fundaciòn no traia perjuicio à nadie, ni en comùn, ni en particular, sino singular beneficio, y utilidad, no solo à todo el publico de esta nuestra Corte, sino tambien à toda España» ${ }^{3}$.

La metodología para llevar a cabo ese fin era la observación y la experiencia, pero que ilustraremos en este momento con las palabras siguientes: «El Colegio intenta, como Hypocrates, trabajar por el camino de la Observaciòn, y Experiencia, cultivar, y adelantar la Cirugia, y sus Operaciones por medio de la Disseccion Anatomica, que es tan necesaria, ofreciendo continuamente à Dios reverentes sacrificios por los aciertos, que se ha de dignar concederle para la feliz curacion de las enfermedades» ${ }^{4}$.

Se establecieron una especie de juntas literarias en las que los colegiales debían exponer un tema médico razonado y fundamentado solidamente con experimentos que confirmasen lo que se intentaba argumentar.

Concedieron una gran importancia a las disecciones anatómicas y pretendieron que los colegiales informasen de su práctica diaria para que de esta forma se pudiera aprender todo aquello que resultase más oportuno para curar a los enfermos.

2 Estatutos del Real Colegio de Profesores Cirujanos de Madrid, aprobados por S.M., Madrid, Imprenta de Don Juan Zùñiga. En adelante: Estatutos del Real Colegio.

3 Ibidem.

4 Estatutos del Real Colegio, p. 6, estatuto XXIV. 
Así mismo debían celar por buscar una continua perfección en todo lo que rodeaba al acto quirúrgico, que es la interpretación a las palabras que podemos leer a continuación: «...adelantaràn, y perfeccionaràn las Operaciones de Cirugia» 5 .

Pero ¿dónde debía de realizarse todo esto?, pues hasta ahora la enseñanza era exclusivamente teórica: a la cabecera del enfermo. La práctica diaria a la cabecera del enfermo era la base de esta nueva concepción del arte, y si no veamos el siguiente párrafo que aunque es un poco extenso creo que encierra la filosofía de la nueva medicina: "...la càthedra que da mas luz a la medicina, es la cabecera del enfermo; el cathedratico, que sin huecos y ruidosos conceptos te explicarà su dictamen, serà la naturaleza; y quien te acabarà de inclinar la balanza de tu mala o buena opiniòn serà el propio desengaño, despues de haber peregrinado por los peligrosos mares de varias, y distintas enfermedades, que la pràctica ofrece» ${ }^{6}$.

Cabecera del enfermo, observación y experiencia (que por tal podríamos entender la palabra desengaño que aparece en el párrafo anterior) es la manera de hacer medicina que constantemente vemos referida en cualquier parte.

Como en cualquiera de las instituciones docentes borbónicas, en el Real Colegio de Medicina de Madrid, institución docente paralela en el tiempo al Real Estudio de Medicina práctica, se instauró como método docente para esta enseñanza práctica las Juntas Literarias con el encargo de realizar: «...los exercicios literarios en que principalmente debe ocuparse este Cuerpo para facilitar los posibles adelantamientos de la ciencia, y el que con sus disertaciones, y las observaciones practicas que se hagan en las Enfermerias destinadas para la enseñanza, y por cada uno de los individuos del Colegio, pueda formarse dentro de pocos años un Cuerpo de doctrina practica que se haga recomendable»?.

De la lectura del artículo siguiente se desprende que no tenían un lugar de ubicación, por lo que estas sesiones se celebrarían en la Real Academia: «...congregandose por ahora, y hasta que se elija sitio proporcionado, en la Sala de la Academia Medica Matritense» ${ }^{8}$.

5 Estatutos del Real Colegio, p. 4, estatuto V.

6 GRANJEL, L. S. (1979), Medicina española del siglo XVIII, Universidad de Salamanca, Colección Historia General de la Medicina española, vol. IV, p. 33.

7 Real Cedula y Reglamento que S. M. manda observar para el Gobierno y Direccion del Real Colegio de Medicina de Madrid, de Orden Superior, Madrid, Imprenta Real, 1795, p. 2, sign.: 614.2 N891. En adelante: Real Cedula.

8 Real Cedula, Cap. II, art. 6, p. 8. 
La Academia se había fundado en el año 1734 y estaba ubicada en la calle de la Montera con salida a la calle de los Negros ${ }^{9}$.

Tampoco podemos olvidar como método docente empleado por los profesores de las diferentes instituciones docentes las clases que impartían ellos mismos, y para los objetivos que perseguimos en este trabajo, fue Josef Ribes el máximo representante en esta faceta. La metodología empleada por Ribes para impartir sus clases teóricas tenía una doble vertiente:

- de un lado, se basa en la experiencia personal vivida por él mismo en su práctica cotidiana;

- de otro lado, está la experiencia ajena de los más diversos autores bien porque ha leído sus obras y hace referencias a ellas, o bien porque se apoya en informaciones que saca de las obras para buscar aquello que sea de utilidad para el aprendizaje de sus alumnos.

Veamos estos aspectos con algunos ejemplos. Ribes refiere de vez en cuando casos prácticos vividos por otros profesores o por él mismo para ilustrar más a estos aprendices de médicos que le escuchaban en las aulas. Veamos uno de estos casos, un caso de lepra que dice Ribes que acaeció en el Colegio de San Carlos, caso que no fue objeto de una sesión en las Juntas Literarias de los Jueves, que se recogían en las Memorias y Censuras de las Juntas Literarias aunque fue un caso extraordinario, pero no por ello vamos a dudar de la palabra de nuestro profesor en el sentido de que el caso no lo he encontrado referenciado, por el momento, en ninguna obra consultada: «...la practica que se ha observado en la enfermeria de este Colegio solo con un leproso que se presentó fue lo siguiente. En este enfermo se puso en practica el sublimado corrosibo habiendo limpiado antes las primeras vias con un purgante suave pues en estos nunca debemos usar de los gastricos, y se observó que los caracteres que se manifestaban de lepra cesaron; y el enfermo andaba por si solo, lo que no habia podido antes por la gran laxitud en que se hallaba (...)».

Cualquier tarea que emprendían tenía una profunda carga docente. Parece como que estaban en todo instante intentando justificarse ante alguien o ante algo, o más bien podemos decir que su lucha por recuperar esa posición social que hacía tantos siglos les fue arrebatada a los cirujanos les obligaba de continuo a demostrar sus cualidades docentes y su gran profesionalidad y valga

9 Mariscal García, N. (1934), «La Academia y su tiempo. Historia de dos siglos», El Siglo Médico, año 81, 29 de diciembre, pp.709-755. 
como ejemplo una prueba más de esto, como son los casos clínicos que se presentaban en las Juntas Literarias de los jueves que al quedar escritas y archivadas podían ser utilizadas para ilustrar más aún el temario teórico de las clases. Ribes las utilizó en algunas ocasiones como cuando explica el tema de la escrófula y dice al respecto: «...y tambien nos podemos valer del muriate de cal, y ha surtido buenos efectos como se demostro en una junta de observacion D.Ignacio Lacava en el Colegio de San Carlos de Madrid,...», recalcando más adelante: «...pero nunca ha surtido generalmente tan buenos efectos como la sal de tartaro, como se ha esperimentado en esta enfermeria de San Carlos, por varias veces y en diversas ocasiones» ${ }^{10}$.

Esta observación de I.Lacaba referenciada por J.Ribes nos sirve no solamente para comprobar que se usaban estos textos para explicar el temario, sino también para comprobar que en el Colegio de San Carlos se experimentaban todas las novedades que, generalmente, nos venían de fuera. Estaban, al menos ese es mi parecer, en la cresta de la ola de los conocimientos científicos de la época.

También utilizaban para la docencia los casos prácticos vividos cotidianamente en las salas del Hospital General de Madrid, como cuando habla del aneurisma, de lo cual podemos deducir que era una docencia muy activa $\mathrm{y}$, aunque reiteremos lo ya dicho, sus pretensiones eran enseñar una medicina eminentemente práctica dentro de esta parte teórica. Volviendo al caso del aneurisma del Hospital General, podemos leer lo siguiente: «...y tambien podemos hacer la compresion sin embargo de mucha inflamacion de sangre como se ha visto en la arteria crural en la Sala de San Tadeo del Real Hospital de Madrid, cuando en esta Sala Don Rafael Costa asistió à un enfermo que pasaba la inflamacion de cuatro à cinco libras,...» $»^{11}$.

Es decir, la experiencia acumulada por la práctica diaria de la profesión y la experimentación de las más variadas técnicas terapéuticas en enfermos tanto de la Enfermería del Colegio como de las Salas del Hospital General, constituían una parte importante de la docencia que se impartía a los estudiantes del siglo XVIII, por lo menos en los centros referidos con anterioridad.

10 Ibidem, pp. 219-220.

11 Ibidem, p. 432. 


\section{JUNTAS LITERARIAS DE LOS JUEVES}

Para catalogar las Juntas Literarias de los Jueves ${ }^{12}$, hemos seguido el modelo que utilizaba el C.I.D.A. hace ya unos cuantos años, pero adaptándolo al tipo de fondos con los que nos encontramos en el real Colegio de Cirugía de San Carlos (Modelo de Ficha Catalográfica de Fondos Antiguos).

Hemos intentado también mantener al máximo la grafía utilizada por las personas que redactaban las memorias y las censuras, con lo cual el lector se encontrará con un elevado número de errores tipográficos e incluso gramaticales, hoy en día, pero que era correcto en aquellos tiempos. El problema es mayor aún en lo referente a los nombres propios de personas o lugares, pues en muchos casos es imposible saber de quien se trata, no porque no se entienda la letra, que a veces ocurre, sino porque son pacientes o personas de pueblos y localidades que desconocemos.

Nuestro modelo adaptado es el que sigue:

\section{MODELO DE FICHA CATALOGRÁFICA DE FONDOS ANTIGUOS}

1: NOMBRE DEL AUTOR

TÍTULO DE LA OBRA O LEGAJO

DESCRIPCIÓN INTERNA DE LA OBRA

2: SIGNATURA DEL DOCUMENTO

NOMBRE DE LA CIUDAD DONDE SE ENCUENTRA

12 Antes de empezar el análisis documental de este material comentaremos algunos aspectos importantes. Hemos transcrito el texto como se encuentra originariamente. Por este motivo el lector verá faltas de ortografía y otras anomalías gramaticales, pero hemos considerado oportuno mantener esta grafía para que el documento guarde toda su frescura original. Tampoco hemos realizado ningún tipo de índices (de materias, topográfico, etc.). Quien lo desee se le puede proporcionar una copia del fichero en formato Word para uso personal. Por último, como sólo pretendemos dar a conocer este material, no hemos realizado un análisis en profundidad del mismo (estudios bibliométricos, etc.), que dejamos para un trabajo posterior. 
BIBLIOTECA O LUGAR DE DEPÓSITO

FONDO O SECCIÓN

3: FECHA DE LA DOCUMENTACIÓN

4: LUGAR DE PROCEDENCIA DEL DOCUMENTO

5: SOPORTE Y TAMAÑO DEL DOCUMENTO FOLIO 4: 8:

6: PÁGINAS

7: NÚMERO DE FASCÍCULOS

8: ORGANIZACIÓN DE LA PÁGINA

NÚMERO DE COLUMNAS

NÚMERO DE FILAS O LÍNEAS

MÁRGENES

DISPOSICIÓN DE LAS NOTAS

9: TIPOLOGÍA

10: ESCRITURA DEL DOCUMENTO

MATERIAL: PLUMA, IMPRENTA, COLOR, TINTA

TIPO DE ESCRITURA

LENGUA

11: ENCUADERNACIÓN: NO SI FLEXIBLE O RÍGIDA

12: ESTADO DE CONSERVACIÓN

13: DESCRIPTORES ONOMÁSTICOS, GEOGRÁFICOS E INSTITUCIONALES

Visto ya el modelo que vamos a utilizar para describir las memorias y censuras, vamos a pasar al análisis de las mismas. 


\section{JUNTAS LITERARIAS DE LOS JUEVES}

\section{GIMBERNAT, ANTONIO DE (Censura: RODRÍGUEZ DEL PINO, DIEGO)}

Nuevo método de curar la hernia crural. Cirugía. 87-4-A-1, no 1 y 2, 9 y 16-Octubre1.788. Madrid, Papel (1/4). $\mathrm{N}^{\mathrm{o}}$ de Folios: 24. $\mathrm{N}^{\mathrm{o}}$ de fascículos: 2. Tipología completa. Descriptores: Gimbernat, Falopio, Hunter, Grangeot, Le Blanc, Sharp, Arnaud, Pot, Bertrandi. Censura: Falopio, Chopart, Dessault, Real Colegio de Cirugía de San Carlos, Hotel Dieu de París, Real Academia de Cirugía de París.

GIMBERNAT, ANTONIO DE

Apendice á el nueva methodo de operar la hernia crural extractado del Sistema de Cirugía del Señor Bell y Reflexión sobre el methodo de este sabio autor. Cirugía. 874-A-1, no 3. 16-Octubre-1.788. Madrid. Papel (1/4). No de Folios: 6. No de fascículos: 1. Tipología completa. Descriptores: Bell, Falopio.

\section{ANÓNIMO}

Summum Natura Porse observationibus confirmarum. Disertatio. Materia Médica y Quirúrgica, 87-4-A-1, no 4, 23-Octubre-1.788. Madrid. Papel (1/4) $\mathrm{N}^{\mathrm{o}}$ de Folios: 10, $\mathrm{N}^{\mathrm{o}}$ de fascículos: 1, Tipología completa.

\section{ANÓNIMO (Censura: SARAIS, RAMÓN)}

Extracto haciendo ver que la naturaleza sola es el verdadero remedio para curar las enfermedades. Materia Médica. 87-4-A-1, no 5 y 6. 30 Octubre-1.788 (Memoria); 13Noviembre-1.788 (Censura), Madrid. Papel (1/4). No de Folios: 8. $\mathrm{N}^{\mathrm{o}}$ de fascículos: 2. Tipología Completa.

\section{ANÓNIMO}

Perjuicios a los especificos. Materia Médica. 87-4-A-1, no 7 y 8. 6-Noviembre-1.788. Madrid. Papel: folio. $\mathrm{N}^{\mathrm{o}}$ de Folios: $6 . \mathrm{N}^{\mathrm{o}}$ de fascículos: 1. Tipología Completa.

ALCALÁ, JAIME (Censura: QUERALTÓ, JOSEF)

Observaciones y metodo de mutilar los miembros por medio del lazo gradualmente apretado. Cirugía. 87-4-A-1, no 9 y 10. 20-Noviembre-1.788 (Memoria); 27-Noviembre1.788 (Censura), Madrid. Papel: folio y 1/4. No de Folios: 28. $\mathrm{N}^{\mathrm{o}}$ de fascículos: 2. Tipología completa. Descriptores: Jaime Alcalá, (Cirujano colegial Valencia del Hospital Real, General y Militar), Josef Queraltó, Fray Juan Bolufez, Salvador Moros (Maestro Cirujano), Josef Parra, Mariana Cabanas, Agustín Navarro, Josef, Cull, Josef Rus, Serafina 
Paredes, Francisco Feliu, Pedro Ripoll, Josef de la Vega, Clara Pérez, Onofre Chinives, Juan Lema (Cirujano del regimiento de Algarve), Josef Ramonell, Bautista Zerezo, Herodoto, Alberto Haller, Juan Hunter, Pott; Colegio de Valencia, Sociedad Médico Matritense, Colegio de Cirugía de Barcelona, Convento de Nuestra Señora del Carmen, Convento de Jesús Extramuros de la Orden de San Francisco (Valencia).

SARAIS, RAMÓN

Censura: Supuración del seno maxilar. Cirugía. 87-4-A-1, n⿳ 12. 11-Diciembre-1.788. Madrid. Papel: (1/4). No de Folios: 6. No de fascículos: 1. Tipología completa. Descriptores: Ramón Sarais, Juan Solano, Josef Clavijo, Ignacio de Heredia.

\section{LLOBERA, NICOLÁS}

Porque conductos pasan a la vegiga desde el estómago los cuerpos liquidos y solidos deglutido. Fisiología. 87-4-A-1, no 13 y 14. 18-Diciembre-1.788. Madrid, Papel: (1/4). $\mathrm{N}^{\mathrm{o}}$ de Folios: 13. $\mathrm{N}^{\mathrm{o}}$ de fascículos: 2. Tipología completa. Descriptores: Claudino, Albino, Winslow, Sabariex.

JOVER, SALBIO (Cirujano Mayor de la Real Brigada de Caravineros) (Censura: RYBAS, MARIANO)

Observacion sobre una picadura de Tarantula curada por la música. Terapéutica, Toxicología. 87-4-A-1, no 17 y 18. 29-Enero-1.789 (Memoria) 5-Febrero-1.789 (Censura). Madrid. Papel: folio y 1/4, $\mathrm{N}^{\circ}$ de Folios: 16. $\mathrm{N}^{\mathrm{o}}$ de fascículos: 2. Tipología Completa. Descriptores: Manuel Fuentes, Josef Merchero, Mariano Rivas, Villa de Almagro.

NAVAS, JUAN (DE) (Censura: SOLANO, ANTONIO)

Dos observaciones para, persuadir que muchas veces estan los Profesores expuestos a errar en sus Juicios por falta de suficientes informes a los pacientes. Materia Deontológica. 87-4-A-1, no 19 y 20. 12-Febrero-1.789 (Memoria), 19-Febrero-1.789 (Censura). Madrid. Papel: (1/4). $N^{o}$ de Folios: 15. No de fascículos: 2. Tipología completa.

\section{BONILLA, JOSEF (Censura: QUERALTÓ, JOSEF)}

Observaciones sobre una mujer de cullo vientre salieran muchas idatides y una abertura artificial. Materia Quirúrgica. 87-4-A-1, no 21 y 22. 26-Febrero-1.789 (Memoria), 5Marzo-1,789 (Censura). Madrid. Papel: (1/4). $\mathrm{N}^{\mathrm{o}}$ de Folios: 16. $\mathrm{N}^{\mathrm{o}}$ de fascículos: 2, Notas en margen izquierdo: f-3: 1 nota; f-4: 3; f -4v. 2; f -5: 2; f-5v. : 1; f-6: 1; Tipología completa.

SARAIS, RAMÓN (Censura: NAVAS, JUAN (DE)

Observacion sobre un tumor muy duro y dolorido que ocupaba todo el pecho derecho con una eminencia sobre el resto del tumor en su parte lateral Interna algo su- 
perior en la que sentia dolores lancinantes curado por resolucion. Terapéutica Oncológica. 87-4-A-1, no 23 y 24. 12-Marzo-1.789 (Memoria), 16-Marzo-1.789 (Censura). Madrid. Papel: Folio y 1/4. No de Folios: 24. No de fascículos: 2. Tipología completa.

VILLALTA, JOAQUÍN (Censura: QUERALTÓ, JOSEF)

Disertatio Chirurgica Theorico-Practica sobre las operaciones del Trepano, con observaciones hechas en los Reales Hospitales de sangre del Bloqueo y sitio de la Plaza de Gibraltar. Materia Quirúrgica. 874-A-1, no 25 y 26. 6-Abril-1.789 (Memoria), 7-Mayo-1.789 (Censura). Madrid. Papel: $1 / 4$ y folio. $\mathrm{N}^{\mathrm{o}}$ de folios: $67 . \mathrm{N}^{\mathrm{o}}$ de fascículos: 2 , 1 legajo y un librillo encuadernado. Notas en margen izquierda: Memoria: $\mathrm{p}-9$ : $1 ; \mathrm{p}-9 \mathrm{v}$. 1 ; p-10: 4; p-10v. : 2; p-11:2; p-15v. : 2; p-16: 1; p- 17: 2; p-17v. 3; p-18: 2; p-19: 1; p-19v. -, 1; p-23: 1; p-23v. : 1; p- 24: 1; p-24v.: 2; p-25: 1-, p-25v.: 1; Censura: f-2- 8; f-3: 3; f-4: 7; 1; f-7v.-. 2; f-8v,: 1; f-9: 1. f-34: 2; f-34v.: 1. Tipología completa.

RODRÍGUEZ DEL PINO, DIEGO (Censura: NAVAS, JUAN (DE)

Observacion sobre hernias gangrenadas. Materia Quirúrgica. 87-4-A-1, no 27 y 28. 28Mayo-1.789 (Memoria), 4-Junio-1.789 (Censura). Madrid. Papel: (1/4). No de Folios: 21. $\mathrm{N}^{\mathrm{o}}$ de fascículos: 3. Tipología completa. Descriptores: Esteban Gallegas, Juan Sixto Rodríguez, H. Boerhaave, G. Van Swieten, Louis Pipelet, Diego Rodríguez del Pino, Juan de Navas, Hospital de la C/Colcheros (Sevilla), Academia de Cirugía de París, Hospital General de Córdoba, Real Colegio de Cirugía de Cádiz.

RYBAS, MARIANO (Censura: SARAIS, RAMÓN)

Dos observaciones cuio objeto es manifestar el feliz suceso con que se usa el opio para detener las hemorragias que preceden, acompañan y siguen al parto asi natural, como prematuro. Enfermedades de Mujeres, 87-4-A-1, no 29 y 30. 18-Junio-1.789 (Memoria), 25-Junio-1.789 (Censura), Madrid. Papel: (1/4). $\mathrm{N}^{\mathrm{o}}$ de Folios: 23. $\mathrm{N}^{\mathrm{o}}$ de fascículos: 2 . Tipología completa.

ANÓNIMO (Censura: RODRÍGUEZ, DIEGO)

Cinco observaciones que presenta el licenciado don Jaime de Alcalá Cirujano de Valencia que se reducen las dos primeras a heridas de vientre: la $3^{a}$ es una hidropica rebentada por el ombligo por cuio medio se curó: La cuarta es un Aneurisma espureo y la $5^{\text {a }}$ es otro Aneurisma espureo en la poplitea en un sujeta de 60. Materia Quirúrgica. 87-4-A-1, no 31 y 31 repetido. 2-Julio-1.789 (Memoria), 9-Julio-1.789 (Censura). Madrid. Papel: (1/4). $\mathrm{N}^{\mathrm{o}}$ de Folios: 97, $\mathrm{N}^{\mathrm{o}}$ de fascículos: 2. Notas en el margen izquierdo: Censura: f-3:1, Tipología completa.

MONELAU, MARCOS (Censura: GINESTÁ, AGUSTÍN)

Curacion de los estrumas indolentes o benignos situados sobre los musculos de la faringe hecha en el año de $\mathbf{1 7 8 8}$ por.... Cirujano de la Villa de Villarroya de la Sierra 
de la Comunidad de Calatayud. Cirugía, Terapéutica. 87-4-A-1, no 32 y 33, 8-Octubre1.789 (Memoria), 15-Octubre-1.789 (Censura). Madrid. Papel: Folio. $\mathrm{N}^{\mathrm{o}}$ de Folios: 6. $\mathrm{N}^{\mathrm{o}}$ de fascículos: 2. Tipología completa. Descriptores: Barbara Navarro, Celso, Hipócrates, Agustín Ginestá, Marcos Hanleon?, Calatayud, Daroca, Almunia.

\section{FERNÁNDEZ SOLANO, ANTONIO (Censura: RODRÍGUEZ DEL PINO, DIEGO)}

Reflexiones sobre los medios a perfeccionar y extender los usos del Respirador de Mudge. Materia Quirúrgica. 87-4-A-1, no 34 y 35. 22-Octubre-1.789 (Memoria), 29Octubre-1.789 (Censura). Madrid. Papel: (1/4). $\mathrm{N}^{\mathrm{o}}$ de Folios: 12, $\mathrm{N}^{\mathrm{o}}$ de fascículos: 2. Tipología completa.

\section{QUERALTÓ, JOSEF (Censura: NAVAS, JUAN (DE)}

Observacion sobre una herida penetrante de vientre con lesion del estomago lleno, acompañada de circunstancias particulares. Materia Quirúrgica. 87-4-A-1, no 36 y 37 19-Noviembre-1.789 (Memoria), 26-Noviembre-1.789 (Censura). Madrid. Papel: (1/4). $\mathrm{N}^{\mathrm{o}}$ de Folios: 98. $\mathrm{N}^{\mathrm{o}}$ de fascículos: 2, Notas a pie de página, Memoria: f-7v., 1; f-9. 1. Tipología completa.

\section{MARTURIA, ESTEBAN (Censura: SARAIS, RAMÓN)}

Observacion de una concepcion en una tuba Falopiana izquierda Dirigida al Real Colegio de Cirugia de San Carlos en Madrid, por el Licenciado Don Estevan Marturia substituto de Catedra en el Real Colegio de Cirugia de Barcelona. Enfermedades de Mujeres. 87-4-A-1, no 38 y 39. 5-Noviembre-1.789 (Memoria), 12-Noviembre-1.789 (Censura). Madrid. (1/4). No de Folios: 22. No de fascículos: 2. Tipología completa. Descriptores: Hipócrates, Rosa Canas, Miguel Carreras, Ramón Depaus, Felix Miret, Agustín Ginestá, Antonio Draper, Josseff Borrás, Falopio, Littré, Rialano, Hunter, Baudelaeque, Haller, Haen, Waserber, Petit, Van Swieten, Abulcasis, Quesnai, Sietaud, Astruc, Hospital General de Barcelona, Real Colegio de Cirugía de Barcelona, Real Academia de Cirugía de París.

\section{GIL, FRANCISCO (Censura: QUERALTÓ, JOSEF)}

Sobre el Método curativo de los Carbuncos malignos. Materia Médica. 87-4-A-1, no 40 y 41. 3-Diciembre-1.789 (Memoria), 10-Dicienbre-1.789 (Censura). Madrid. Papel. Folio. $\mathrm{N}^{\mathrm{o}}$ de Folios: 28 . $\mathrm{N}^{\mathrm{o}}$ de fascículos: 2, Notas al margen: f-4v,: 1; f-5: 1; f-6v.: 2; f-7: 1. Tipología completa.

\section{NAVAS, JUAN (DE) (Censura: FERNÁNDEZ SOLANO, ANTONIO)}

Observaciones de una perlesía producida por Lombrices. Materia Quirúrgica. 87-4A-1, no 42 y 43. 17-Diciembre-1.789 (Memoria), 7-Enero-1.789 (Censura). Madrid. Papel: (1/4). $\mathrm{N}^{\mathrm{o}}$ de Folios: 14. $\mathrm{N}^{\mathrm{o}}$ de fascículos: 2. Tipología completa. 
ARANAS, JUAN JOSEF (Censura: RYBAS, MARIANO)

Sobre una hidropesía que se tuvo por preñez. Afectos Internos. 87-4-A-1, no 44 y 45. 14-Enero-1.790 (Memoria), 21-Enero-1.790 (Censura). Madrid. Papel: (1/4). No de Folios: 10. $\mathrm{N}^{\mathrm{o}}$ de fascículos: 2. Tipología completa. Descriptores: Juan Josef Aranas, Mariano Rybas, Moros y Torrijo (Calatayud).

\section{SARAIS, RAMÓN (Censura: NAVAS, JUAN (DE)}

Observación sobre síntomas de menstruación observadas en una señora. Enfermedades de las Mujeres. 87-4-A-1, no 46 y 47. 28-Enero-1.790 (Memoria), 4-Febrero-1.790 (Censura). Madrid. Papel: (1/4), No de Folios: 24, No de fascículos: 2. Tipología completa. Descriptores: Ramón Sarais, Juan de Navas, Real Colegio de San Carlos de Madrid.

SANCHO, JOSEF (Censura: GINESTÁ, AGUSTÍN)

Observacion sobre una procidencia de la vagina presentada al Real Colegio de Cirugia de San Carlos por Don Josef Sancho, Cirujano revalidado en Zaragoza. Enfermedades de la Mujer. 87-4-A-1, no 48 y 49. Ll-Febrero-1.790 (Memoria), 18-Febrero1.790 (Censura). Madrid. Papel: 1/4 y Folio. $N^{\circ}$ de Folios: 10. $N^{\circ}$ de fascículos: 2. Tipología completa, Descriptores: Josef Sancho, Agustín Ginestá, Madrid, Zaragoza, Real Colegio de San Carlos.

\section{RODRÍGUEZ DEL PINO, DIEGO (Censura: QUERALTÓ, JUAN)}

Sobre un absceso lumbar curado felizmente. Cirugía y Terapéutica. 87-4-A-1, no 50 y 51. 25-Febrero-1.790 (Memoria), 4-Marzo-1.790 (Censura). Madrid. Papel: Folio y 1/4. $\mathrm{N}^{\mathrm{o}}$ de Folios, 19. $\mathrm{N}^{\mathrm{o}}$ de fascículos: 2. Tipología completa. Descriptores- Bell, Jordyce, Jolui? Aitrans, Diego Rodríguez del Pino, Juan Queraltó, Hospital de Santo Thomás.

\section{GINESTÁ, AGUSTÍN (Censura: RODRÍGUEZ DEL PINO, DIEGO)}

Disertacion sobre la utilidad del opio para la reduccion de algunas dislocaciones. Materia Médica, 87-4-A-1, no 52 y 53, 11-Marzo-1.790 (Memoria), 18-Marzo-1790 (Censura). Madrid. Papel: Folio y 1/4. $\mathrm{N}^{\mathrm{o}}$ de Folios: 13. $\mathrm{N}^{\mathrm{o}}$ de fascículos: 2. Descriptores: Agustín Ginestá, Diego Rodríguez del Pino, Real Colegio de San Carlos de Madrid.

\section{RIBES JOSEF (Censura: GINESTÁ, AGUSTÍN)}

Observacion sobre una gangrena en el escroto que curo en vivio venéreo. Enfermedades Venéreas. 87-4-A-1, 8-Abril-1.790 (Memoria), 15-Abril-1.790 (Censura). Madrid. Papel: Folio y 1/4. No de Folios: 17. $\mathrm{N}^{\mathrm{o}}$ de fascículos: 2. Descriptores: Josef Rybes, Agustín Gínestá, Real Colegio de San Carlos de Madrid. 
RYBAS, MARIANO (Censura: RIBES JOSEF)

Observacion sobre el uso de los emeticos en Cirugia y particularmente en la curacion de algunos tumores. Cirugía y Materia Médica. 87-4-A-1, no 56 y 57. 22-Abril1.790 (Memoria), 29-Abril-1.790 (Censura). Madrid. Papel: (1/4). No de Folios. 11. $\mathrm{N}^{\mathrm{o}} \mathrm{de}$ fascículos: 2. Descriptores: Mariano Rybas, Josef Ribes, Hipócrates.

\section{FERNÁNDEZ SOLANO, ANTONIO (Censura: RODRÍGUEZ DEL PINO, DIEGO)}

Relación sobre la observacion de Hydatides vivientes. Afectos Internos. 87-4-A-1, no 58 y 59. 6-Mayo-1.790 (Memoria), 20-Mayo-1.790 (Censura). Madrid. Papel: (1/4). Descriptores: Antonio Fernández Solano, Diego Rodríguez del Pino, Malpigio, Fontana, Laguna, Real Colegio de San Carlos de Madrid.

\section{BERNÁRDEZ, JUAN (Censura: SARAIS, RAMÓN)}

Consulta remitida por D. Juan Bernardez sobre la enfermedad de la religiosa que consistía en una hemicrania y odontología y dictamen. Afectos Internos. 87-4-A-1, no 60 y 61. 27-Mayo-1.790 (Memoria), 27-Mayo-1.790 (Censura), Madrid, Papel: Folio y 1/4, Descriptores: Juan Bernárdez, Ramón Sarais, Real Colegio de Cirugía de San Carlos de Madrid.

\section{SANCHO, JOSEF (Censura: NAVAS, JUAN (DE)}

Observacion de un enterocele de extraordinario volumen. Afectos Internos. 87-4-A-1, no 62 y 63. 10-Junio-1.790 (Memoria), 17-Junio-1.790 (Censura), Madrid. Papel: Folio y 1/4. Descriptores: Josef Sancho, Juan de Navas, Dionis, Real Colegio de San Carlos de Madrid, Zaragoza.

\section{QUERALTÓ, JOSEF (Censura: RODRÍGUEZ DEL PINO, DIEGO)}

Observacion de un ano accidental de la ingle, con retencion voluminosa de excremento y sin procidencia, otra de una fistula recto vaginal tratada por la sutura en asa para probar con que ventajas la naturaleza procura por la inflamacion adhesiva y granulaciones bien dirigida la curacion de esas enfermedades. Materia Quirúrgica. 87-4-A-1, no 64 y 65. 1-Julio-1.790 y 8-Julio-1,790. Madrid. Papel: Folio. No de Folios: 13. $\mathrm{N}^{\mathrm{o}}$ de fascículos: 2. En la Memoria: una ilustración. Descriptores: Josef Queraltó, Diego Rodríguez, Antonio de Gimbernat, Lorenzo Roland, Agustín Ginestá, Hospital de Barcelona, Real Colegio de Cirugía de San Carlos de Madrid, Real Colegio de Cirugía de Barcelona, Academia de Cirugía de París.

NAVAS, JUAN (DE) (Censura: SOLANO, ANTONIO)

Observacion sobre una locura venerea curada con el mercurio. Enfermedades Venéreas, Terapéutica, 87-4-A-1, no- 66 y 67. 19-Julio- 1.790 y 22-Julio-1.790. Madrid. Papel. 
(1/4). $N^{o}$ de Folios-. 10. No de fascículos: 2. Descriptores: Juan de Navas, Antonio Solano, Lima, Cádiz.

CASTELlAR, JOSEF (Médico y Cirujano del Real Hospital de Cumaná) (Censura: RIBES, JOSEF)

Observacion de un hombre que crío a sus pechos uno de sus hijos (Observacion del Lechero Antonio Lozano). Afectos Internos. 87-4-A-1, no 68 y 69. 7-Octubre-1.790 y 14-Octubre-1.790. Madrid. Papel: (1/4). $\mathrm{N}^{\mathrm{o}}$ de Folios: 14. $\mathrm{N}^{\mathrm{o}}$ de fascículos: 2. Descriptores: Josef Castellar, Josef Ribes, Manuel de Navarrete, Antonio Lozano, Pamplie (Burgos), Cumaná.

\section{SARAIS, RAMÓN (Censura: GINESTÁ, AGUSTÍN)}

Observaciones sobre los efectos de la cicuta en la curacion de varias enfermedades. Materia Médica. 87-4-A-1, no 70 y 71. 21-Octubre-1.790 y 4-Noviembre-1.790. Madrid. Papel: Folio. $\mathrm{N}^{\mathrm{o}}$ de Folios: 17. $\mathrm{N}^{\mathrm{o}}$ de fascículos: 2. Descriptores: Ramón Sarais, Agustín Ginestá, Rutty (Médico de Dublín), Cleghorn, Bell, Schmuker, Delafaye, Juan Sardañons, Crok, Boate (cirujano de Dublín), Fothergell, Farr (médico del Hospital General de Plinout), Nicolson, Douglas, Clerk, Stork, Colegio Médico de Londres, Hospital de Barcelona, Colegio de la Trinidad de Dublín.

\section{RODRÍGUEZ DEL PINO, DIEGO (Censura: SARAIS, RAMÓN)}

Observacion de un pulmón derecho destruido a consecuencia de una herida. Materia Quirúrgica, 87-4-A-1, no 72 y 73. 11-Noviembre-1.790 y 18-Noviembre-1.790. Madrid. Papel: (1/4). $N^{o}$ de Folios: 8. № de fascículos: 2. Descriptores: Diego Rodríguez del Pino, Ramón Sarais, Morgagni, Platero, Senac, Domingo Paseri, Albino, Haller, Juan Takio, Rittero.

\section{GINESTÁ, AGUSTÍN}

Solucion a los reparos confirmados en la censura de Don Diego Rodríguez presentó sobre el proyecto de una nueva operacion para reducir ciertas luxaciones del húmero. Enfermedades de los Huesos. 874-A-1, no 74. (sf, aproximadamente de Diciembre de 1790.) Madrid. Papel: Folio. $\mathrm{N}^{\mathrm{o}}$ de Folios: 4. $\mathrm{N}^{\mathrm{o}}$ de fascículos: 1. Descriptores: Diego Rodríguez, Agustín Ginestá, Real Colegio de Cirugía de Madrid.

\section{GINESTÁ, AGUSTÍN (Censura: RODRÍGUEZ DEL PINO, DIEGO)}

Proyecto de una nueva operacion para reducir las dislocaciones antiguas del húmero. Enfermedades de los Huesos. 87-4-A-1, no 74 y 75. 25-Noviembre-1.790 y 3Diciembre-1.790, Madrid, Papel: Folio. $N^{o}$ de Folios: 15. $\mathrm{N}^{\mathrm{o}}$ de fascículos: 2. Descriptores, Hipócrates, Agustín Ginestá, Diego Rodríguez del Pino, Madrid. 
RIBES, JOSEF (Censura: NAVAS, JUAN (DE)

De las utilidades que se sacan del alcanfor maridado con el mercurio. Materia Médica, 87-4-A-1, no 76 y 77. 9-Diciembre-1,790 y 16-Diciembre-1.790. Madrid, Papel: (1/4). $\mathrm{N}^{\mathrm{o}}$ de Folios: 17, $\mathrm{N}^{\mathrm{o}}$ de fascículos: 2. Descriptores: Josef Ribes, Juan de Navas, Plumer, Witer, Saunders, Plenk, Keiser.

\section{RYBAS, MARIANO (Censura: GINESTÁ, AGUSTÍN)}

Reflexiones sobre la importancia del conocimiento de diversas complicaciones de las enfermedades quirurgicas. Materia Quirúrgica, 87-4-A-1, no 78 y 79. 23-Diciembre1.790 y 13-Enero-1.791. Madrid. Papel: Folio y 1/4. No de Folios: 10. No de fascículos: 2. Descriptores: Mariano Rybas, Agustín Ginestá, Real Colegio de Cirugía de San Carlos.

NAVAS, JUAN (DE) (Censura: RIBES, JOSEF)

Observacion sobre los malos efectos del tortor aplicado para contener las hemorragias y sobre las ventajas de descubrir el vaso rato, y ligarlo, o quando menos acabarlo de cortar y hacer sobre el la compresion, si la herida se halla donde se pueda conseguir sin mayor riesgo. Materia Quirúrigica. 87-4-A-2, no 80 y 81. 20-Enero-1.791 y 27-Enero-1.791. Madrid. Papel: (1/4). No de Folios: 14, No de fascículos: 2. Descriptores: Juan de Nabas, Josef Ribes, Agustín Ginestá, Real Hospital General de Madrid.

\section{SARAIS, RAMÓN (Censura: NAVAS, JUAN (DE)}

Observacion cuyo objeto es probar la necesidad que los cirujanos tienen de los conocimientos médicos. Materia Médica y Quirúrgica, 874-A-2, no 82 y 83. 3-Febrero1.791 y 10-Febrero-1.791. Madrid. Papel: (1/4). $\mathrm{N}^{\mathrm{o}}$ de Folios: 14. $\mathrm{N}^{\mathrm{o}}$ de fascículos: 2, Descriptores: Ramón Sarais, Juan de Navas, Hipócrates, Antonio de Gimbernat, Londres.

\section{RODRÍGUEZ DEL PINO, DIEGO (Censura: FERNÁNDEZ SOLANO, ANTONIO)}

Observacion sobre una angina habitual curada con el extracto de cicuta. Afectos Internos. 87-4-A-2, no 84 y 85. 10-Marzo-1.791 y 17-Marzo-1.791. Madrid. Papel: (1/4). $\mathrm{N}^{\mathrm{o}}$ de Folios: 15, $\mathrm{N}^{\mathrm{o}}$ de fascículos: 2. Descriptores: Diego Rodríguez del Pino, Antonio Fernández Solano, Madrid, Sacedón.

Censura: SARAIS, RAMÓN (falta la memoria)

Dos observaciones latinas una sobre el empiema y otra sobre amaurosis. Afectos Internos. 87-4-A-2, $\mathbf{n}^{\mathbf{0}}$ 85. 17-Febreo-1.791 y 3-Marzo-1.791. Madrid. Papel: (1/4). $\mathrm{N}^{\mathrm{o}}$ de Folios, 10. $\mathrm{N}^{\mathrm{o}}$ de fascículos: 1. Descriptores: Ramón Sarais, Juan Crisóstomo, Antonio Fernández Solano, Madrid. 
VICTORIANO GÓMEZ, JOSÉ (Cirujano de los Reales Exercitos: titular del Ilmo. Señor Deán y Cavildo de la Santa Iglesia Metropolitana de Burgos: Mayor de su Hospital de Cirugia nominado de San Julian (vulgo Barrantes) y socio Profesor de la Real Sociedad Bascongada) (Censura: RODRÍGUEZ DEL PINO, DIEGO)

Disertacion Chirurgíca en que se demuestra un nueva metodo incruento, fácil, $\mathbf{y}$ seguro de curar las Fístulas del Ano. Materia Quirúrgica. 87-4-A-2, no 86 y 87. 24Marzo-1.791 y 31-Marzo-1.791. Madrid. Papel: (1/4). No de Folios: 46. No de fascículos: 3 (1 libro: Censura duplicada). Descriptores: Foubert, Gaspar Hainart, Joaquín de Salcedo, Isidoro Martínez, Josef Citerni, María Uruguru, Isidoro Sánchez Monge, Tomás Vasagoitia, Juan Martínez, Antonio Gómez de Velasco, Josef Simó, Benito Rodrigo, Celso, Pouteau, Jose Victoriano Gómez, Diego Rodríguez del Pino, Siones (Valle de Herra), Bolonia, Guipúzcoa, Palacios de la Sierra, Vega de la Serrana (León), Burgos, París, Bilbao, Davay, Hospital militar de Davay, Academia de Cirugía de París, Iglesia Metropolitana de Burgos, Hospital de San Julián (o Barrantes), Hospital de Bilbao, Monasterio de Obarenes, Monasterio de San Juan de Burgos, Iglesia de Santander.

GINESTÁ, AGUSTÍN (Censura: RYBAS, MARIANO)

Observacion de un parto preternatural, seguida de algunas consideraciones. Enfermedades de las Mujeres. 87-4-A-2, no 88 y 89. 7-Abril-1.791 y 14-Abril-1.791. Madrid. Papel: Folio y 1/4. No de Folios: 21. No de fascículos: 2. Descriptores: Agustín Ginestá, Mariano Rybas, Madrid, Tarrasa.

CASIELLA, ROMÁN (Censura: SOLANO, ANTONIO)

Observacion de una espina ventosa. Materia Quirúrgica, 87-4-A-2, no 90 y 91.28 Abríl-1.791 y 5-Mayo-1.791, Madrid, Papel: Folio y 1/4. No de Folios: 16 . No de fascículos: 2. Descriptores: Román Casiella, Antonio Solano, Madrid.

RIBES, JOSEF (Censura: NAVAS, JUAN (DE)

Varias observaciones sobre los malos efectos del catheterismo y sobre las ventajas de las cuerdas de tripa. Materia Quirúrgica. 87-4-A-2, no 92 y 93. 12-Mayo-1.791 y 19Mayo-1.791. Madrid. Papel: (1/4). $\mathrm{N}^{\mathrm{o}}$ de Folios: 23. $\mathrm{N}^{\mathrm{o}}$ de fascículos: 2. Descriptores: Josef Ribes, Juan de Navas, Madrid.

RYBAS, MARIANO (Censura: SARAIS, RAMÓN)

Las causas de la iscuria no se limitan a las vías urinarias. Afectos Internos. 87-4-A-2, no 94 y 95. 26-Mayo-1.791 y 2-Junio-1.791, Madrid, Papel: (1/4). No de Folios: 20. No de fascículos: 2. Descriptores: Mariano Rybas, Ramón Sarais, Madrid.

FERNÁNDEZ SOLANO, ANTONIO (Censura: GINESTÁ, AGUSTÍN)

Observacion de un parto de cinco fetos complicado con una mola seguida de algunas reflexiones dirigidas a ilustrarla. Obstetricia. 87-4-A-2, no 97, 16-Junio-1.791 у 30- 
Junio-1.791. Madrid. Papel: Folio y 1/4. No de Folios: 1.3. $\mathrm{N}^{\mathrm{o}}$ de fascículos: 2. Descriptores: Esperanza Cordobés, Esteban de los Santos, Miguel Ramonell, Tryphonio, Aristóteles, Abulcasis, Paulo Zakias y otros, Cádiz.

QUERALTÓ, JOSEF (Censura: RIBES, JOSEF)

Observacion sobre ciertas hemorragias que sobrevienen á las contusiones y ligaduras de las arterias. Materia Quirúrgica. 87-4-A-2, no 98 y 99. 7-Julio-1.791 y 14-Julio1.7911. Madrid. Papel: (1/4). $\mathrm{N}^{\mathrm{o}}$ de Folios. 8. $\mathrm{N}^{\mathrm{o}}$ de fascículos: 2. Descriptores: Petit, Warner, José Queraltó, Josef Ribes, Argel, Campo de Gibraltar, Hospital de sangre de San Roque.

\section{NAVAS, JUAN (DE) (Censura: FERNÁNDEZ SOLANO, ANTONIO)}

Reflexiones sobre el tratamiento de algunas heridas de los intestinos, que aconseja el señor Bell en su sistema de la Cirugia. Materia Quirúrgica. 87-4-A-2, no 100 y 101. 21 Junio-1.791 y 28-Junio-1.791. Madrid. Papel: (1/4). $\mathrm{N}^{\mathrm{o}}$ de Folios: 26. $\mathrm{N}^{\mathrm{o}}$ de fascículos: 2, Descriptores: Juan de Navas, Antonio Fernández Solano, Bell, Sharp, Guido de Gauliaco, Hunter, Madrid.

\section{SARAIS, RAMÓN (Censura: RYBAS, MARIANO)}

Observacion sobre varias enfermedades externas e Internas que padecía un mismo sujeto, curada con el $\mathbf{N}^{\mathbf{0}} 10$ de los emeticos. Afectos Internos. 87-4-A-2, no 102 y 103 . 6-Octubre-1.791 y 13-Octubre-1.791. Madrid. Papel: Folio y 1/4. No de Folios-, 15, NO de fascículos: 2. Descriptores: Ramón Sarais, Mariano Rybas, Madrid.

\section{MASCAROS, JOSEF (Censura: QUERALTÓ, JOSEF)}

Observacion de un epiplocele antiguo y permanente reducido en el termino de 6 meses. Materia Quirúrgica. 87-4-A-2, no 104 y 105. 20-Octubre-1.791 y 27-Octubre1.791. Madrid, Papel: Folio y 1/4. $\mathrm{N}^{\mathrm{o}}$ de Folios: $15 . \mathrm{N}^{\mathrm{o}}$ de fascículos: 4 (La Memoria por triplicado). Descriptores: Josef Mascaras, Josef Bonillo, Josef Queraltó, Diego Rodríguez del Pino, Real Hospital General de Madrid.

SOCIAS, GREGORIO (Profesor de Cirugía de la Villa de Tárrega en el Principado de Cataluña) (Censura: NAVAS, JUAN (DE)

Observacion de un Niño que nació con un oido imperforado y se curo por una operacion Chirurgica que executó el Licenciado Don.... Enfermedades de los Ojos, Oídos y Boca, Materia Quirúrgica. 87-4-A-2, no 106 y 107. 3-Noviembre-1.791 y 10Noviembre-1.791. Tárrega (Cataluña). Papel: 1/4. $\mathrm{N}^{\mathrm{o}}$ de Folios: 9. $\mathrm{N}^{\mathrm{o}}$ de fascículos: 2. Descriptores: Gregario Socías, Juan de Navas, Josef Port, Tárrega (Cataluña). 
GINESTÁ, AGUSTÍN (Censura: SARAIS, RAMÓN)

Observacion sobre un dolor lácteo curado con repetidos vesicatorios. Enfermedades de las Mujeres. 87-4-A-2, no 108 y 109. 17-Noviembre-1.791 y 24-Noviembre-1.791. Madrid. Papel: Folio y 1/4. No de Folios: 18. No de fascículos: 2. Descriptores: Agustín Ginestá, Ramón Sarais, Antonio Fernández Solano, Madrid.

\section{CAPRISTAN, JACOME (Censura: RODRÍGUEZ DEL PINO, DIEGO)}

Observacion sobre un abceso fecal abandonado por los profesores, y tratado sin método, remitido por el presbítero Jacome Capristano de Moya. Materia quirúrgica. 87-4-A-2, no 110 y 111. 1-Diciembre-1.791 y 15-Diciembre-1.791. Madrid, Papel: Folio. $\mathrm{N}^{\mathrm{o}}$ de Folios: 12. $\mathrm{N}^{\mathrm{o}}$ de fascículos: 2. Descriptores: Jacome Capristán, Diego Rodríguez del Pino, Madrid, Albadalejo del Duende, Cuenca, Real Colegio de San Carlos de Madrid.

\section{RIBES, JOSEF (Censura: GINESTÁ, AGUSTÍN)}

Observacion sobre varias blenorragias habituales curadas con el remedio de las Candelillas de Cuerda de Tripa. Enfermedades Venéreas, Materia Médica y Terapéutica. 87-4-A-2, no 112 y 113. 22-Diciembre-1.791 y 5-Enero-1.792. Madrid. Papel: Folio y 1/4. No de Folios- 15. No_de fascículos: 2. Descriptores: Josef Ribes, Agustín Ginestá, Schwidaner, Fabre, Perluille?, J. Raspau. R. Sarais, W. Cullen, Edimburgo.

\section{RYBAS, MARIANO (Censura: FERNÁNDEZ SOLANO, ANTONIO)}

Observacion sobre los efectos del frio aplicado al exterior. Materia Quirúrgica. 87-4A-2, no 114 y 115. 12-Enero-1.792 y 19-Enero-1.792. Madrid. Papel: (1/4). No de Folios: 17. $\mathrm{N}^{\mathrm{o}}$ de fascículos: 2. Descriptores: Mariano Rybas, Antonio Fernández Solano, Rast, Madrid.

\section{GUZMÁN Y SÁNCHEZ, EUGENIO (Censura: RIBES, JOSEF)}

Observacion sobre una operación practicada en el vientre con feliz suceso. Materia quirúrgica y Terapéutica. 87-4-A-2, no 116 y 117. 26-Enero-1.792 y 9-Febrero-1.792. Talavera de la Reina. Papel: Folio y 1/4. Descriptores: Eugenio Guzmán y Sánchez, J. Ribes, Pedro Virgili, Juan Galisteo y Xirro, Josef Román, Petit, Francisco Martínez Sobral, Francisco Villiers, Talavera de la Reina (Toledo).

\section{FERNÁNDEZ SOLANO, ANTONIO (Censura: RYBAS, MARIANO)}

Observacion sobre una clorosis láctea. Enfermedades de las Mujeres. 87-4-A-2, no 118 y 119. 16-Febrero-1.792 y 23-Febrero-1.792. Madrid. Papel: (1/4). $\mathrm{N}^{\mathrm{o}}$ de Folios: 14. $\mathrm{N}^{\mathrm{o}}$ de fascículos: 2. Descriptores: Antonio Fernández Solano, Mariano Rybas, Madrid. 
MARTÍN CARRILLO, FRANCISCO; DÍAZ, PEDRO; PÉREZ DECTONITES, JOSÉ (Censura: GINESTÁ, AGUSTÍN)

Observacion sobre un fetus como de cinco meses sacado vivo del vientre de su madre muerta 20 horas y media antes. Obstetricia, 87-4-A-2, no 120 y 122. 1-Marzo1.792 y 15-Marzo-1.792. Madrid, Papel: Folio. $\mathrm{N}^{\mathrm{o}}$ de Folios: 10. $\mathrm{N}^{\mathrm{o}}$ de fascículos: 2. Descriptores: Francisco Martín Carrillo, Pedro Díaz, José Pérez Dectonites, Agustín Ginestá, Vigo, Madrid, Granada, Regimiento de Infantería de Granada.

BERNÁRDEZ, JUAN (Censura: GINESTÁ, AGUSTÍN)

Reflexiones remitidas desde Vigo por el Médico Don Juan Bernardez en la que se alegan varios motivos para persuadir de la imposibilidad de la extraccion de un fetus vivo del vientre de una madre muerta mucha tiempo antes. Obstetricia, 87-4-A2, no 121. 8-Marzo-1.792. Vigo. Papel: 1/4. No de Folios: 16. $\mathrm{N}^{\mathrm{o}}$ de fascículos: 1. Descriptores: Juan Bernárdez, Agustín Ginestá, Vigo, Granada, Cardona.

NAVAS, JUAN (DE) (Censura: RIBES, JOSEF)

Observacion sobre una ulcera fungosa curada por el cauterio y compresion. Materia Quirúrgica y Terapéutica. 87-4-A-2, no 123 y 124. 22-Marzo-1.792 y 29-Marzo-1.792. Madrid. Papel: Folio y 1/4. $N^{o}$ de Folios: 10. No de fascículos: 2. Descriptores: Juan de Navas, Josef Ribes, Underwood, Pouteau, Hospital General de Madrid.

\section{CANELA, RAMÓN (Censura: QUERALTÓ, JOSEF)}

Observaciones sobre dos operaciones de labio leporino y otra sobre una piedra sacada por incision de la uretra en un Niño. Materia Quirúrgica. 87-4-A-2, no 125 y 126. 12-Abril-1.792. 19-.Abril-1.792, Oviedo. Papel: Folio. $\mathrm{N}^{\mathrm{o}}$ de Folios: $4 . \mathrm{N}^{\mathrm{o}}$ de fascículos: 2. Descriptores: Ramón Canela, Josef Queraltó, Oviedo.

\section{QUERALTÓ, JOSEF (Censura: RODRÍGUEZ DEL PINO, DIEGO)}

Observacion de una herida de cabeza complicada de fractura y subintracion de piezas del craneo, con dislaceracion de meninges y herida de cerebro curada felizmente. Materia Quirúrgica y Terapéutica. 87-4-A-2, no 127 y 128. 26-Abril-1.792 y 10Mayo-1.792. Madrid. Papel. (1/4). $\mathrm{N}^{\mathrm{o}}$ de Folios: 12, $\mathrm{N}^{\mathrm{o}}$ de fascículos: 3 (La censura por duplicado). Descriptores; Josef Queraltó, Diego Rodríguez del Pino, Francisco Barba, Josef Santos, Hospital Real de la Isla de Santa Catalina (Brasil).

SARAIS, RAMÓN (Censura: RYBAS, MARIANO)

Observacion de la Inflamacion erisipelatosa de los recien nacidos. Enfermedades de los Niños, Afectos Internos, Terapéutica. 87-4-A-2, no 129 y 130, 24-Mayo-1.792 y 31Mayo-1.792. Madrid. Papel: (1/4). No de Folios: 13. No de fascículos: 2. Descriptores: R. Sarais, Rybas, M. Underwood, Quesnay, Le Dran, Pringle, Bell, Haen, Hunter. 
RODRÍGUEZ DEL PINO, DIEGO (Censura: SARAIS, RAMÓN)

Observacion sobre un gran depósito con Hidatides. Materia Médica y Terapéutica. 874-A-2, no 131 y 132. 14-Junio-1.792 y 21-Junio-1.792. Madrid. Papel: (1/4). Descriptores: Diego Rodríguez del Pino, Ramón Sarais, John Hunter, Simons, Wetherín, Baker, Samuel Foant, John Callet.

GINESTÁ, AGUSTÍN (Censura: NAVAS, JUAN (DE)

Observacion de una fractura machacada. Materia Quirúrgica. 87-4-A-2, no 134. 28Junio-1.792 y 5-Julio-1.792. Madrid. Papel: Folio. No de Folios: 6. № de fascículos: 2. Descriptores: Agustín Ginestá, Juan de Navas, Bell, Londres, Barcelona, Hospital General de Barcelona.

RIBES, JOSEF (Censura: GINESTÁ, AGUSTÍN)

Observacion sobre dos Caries curadas con el Sedal. Enfermedades de los Huesos. Materia Quirúrgica. 87-4-A-2, no 135 y 136. 12-Julio-1.792 y 19-Julio-1.792. Madrid. Papel: Folio y 1/4. No de Folios: 13. No de fascículos: 2. Descriptores: Josef Ribes, Agustín Ginestá, Hunter, Josef Queraltó, Vilguer, Pott, Barcelona, Hospital General de Barcelona.

RYBAS, MARIANO (Censura: GINESTÁ, AGUSTÍN)

Observaciones sobre un punto difícil ocasionado por la resistencia en el cuello del útero. Enfermedades de Mujeres. 87-4-A-2, $\mathbf{n}^{\mathbf{0}} 137$ v 138. 4-Octubre-1.792 y 11Octubre-1.792. Madrid. Papel: Folio y 1/4. $\mathrm{N}^{\mathrm{o}}$ de Folios: $9 . \mathrm{N}^{\mathrm{o}}$ de fascículos: 2. Descriptores: Mariano Rybas, Agustín Ginestá, Simson, Uenckel, Louis, Real Colegio de Cirugía de San Carlos de Madrid.

\section{GUZMÁN Y SÁNCHEZ, EUGENIO (DE) (Censura: RIBES, JOSEF)}

Observacion sobre un polipo en la nariz extirpado con feliz suceso. Materia quirúrgica y Terapéutica. 87-4-A-2, no 139 y 140. 17-Octubre-1.792 y 25-Octubre-1.792. Talavera de la Reina. Papel. Folio y 1/4. Eugenio Guzmán y Sánchez, Josef Ribes, Josefa Alonso del Moral, Francisco Javier Díaz, Josef Palucci, Isidro López Calot, Josef Alvarado, Talavera de la Reina (Toledo).

SOLANO, ANTONIO (Censura: SARAIS, RAMÓN)

Observacion sobre un pólipo en la nariz que creció de nuevo varias veces despues de extirpado por ligadura. Materia Quirúrgica. 87-4-A-2, no 141 y 142. 8-Noviembre1,792 y 22-Noviembre-1.792. Madrid. Papel: (1/4). No de Folios: 15. No de fascículos: 2. Descriptores: Antonio Solano, Ramón Sarais, Cádiz, Real Colegio de Cirugía de San Carlos, Colegio de Cirugía de Cádiz. 


\section{MUÑOZ, PASCUAL (Censura: RODRÍGUEZ DEL PINO, DIEGO)}

Observacion echa sobre la reunión de un trazo del dedo índice que se cortó separándosela de lo restante del dedo. Materia Quirúrgica. 87-4-A-2, no 143, 143* y 144. 29-Novienbre-1.792 y 6-Diciembre-1.792. Alcira (Valencia). Papel: (1/4). No de Folios: 13. $N^{o}$ de fascículos: 3 ( 1 por duplicado). Descriptores: Pascual Muñoz, Diego Rodríguez del Pino, Gaspar Tagliccoti, Hipócrates, Demócrito, Villaverde, Saavedra, Madrid, Alcira, Colegio de Cirugía de San Carlos.

\section{FERNÁNDEZ SOLANO, ANTONIO}

Sobre la observacion de reunían de un trazo de dedo índice más acta notarial. Materia Quirúrgica. 87-4-A-2, no 144. 7-Diciembre-1.792 y 17-Diciembre-1.792. Madrid y Alcira. Papel: Folio (Acta) y 1/4. $\mathrm{N}^{\mathrm{o}}$ de Folios: 3. $\mathrm{N}^{\mathrm{o}}$ de fascículos: 1. Descriptores: Antonio Fernández Solano, Pasqual Muñoz, Alcira, Madrid, Real Colegio de Cirugía de San Carlos.

\section{QUERALTÓ, JOSEF (Censura: NAVAS, JUAN (DE)}

Observaciones y advertencias sobre la necesidad del trepano en ciertas heridas de la cabeza y a las veces de su pronta aplicación. Materia Quirúrgica. 87-4-A-2, $\mathbf{n}^{\mathbf{0}} 145$ y 146. 13-Diciembre-1.792 y 20-Diciembre-1.792. Madrid. Papel: Folio, No de Folias: 13, $\mathrm{N}^{\mathrm{o}}$ de fascículos: 2. Notas al margen: p-lv.; p-3v.; p-4v.; p-5v.; p-6v.; p-7v. Descriptores: J. de Navas, J. Queraltó, Carlos Ribas, Lanfranco, Bell, Meckren, Vido Vidio, Antonio Ferrer, Lanfranc, Paul Masiserp, París, Segovia, Gibraltar, Academia Real de Prusia.

\section{NAVAS, JUAN (DE) (Censura: FERNÁNDEZ SOLANO, ANTONIO)}

Observacion de un dolor en la cara, que suscitó convulsiones generales, procedido de una muela cariada en la mandibula inferior. 874-A-3, no 147 y 148. 3-Enero-1.793 y 10-Enero-1.793. Madrid. Papel: (1/4). $\mathrm{N}^{\mathrm{o}}$ de Folios: 10. $\mathrm{N}^{\mathrm{o}}$ de fascículos: 2. Descriptores: J. de Navas, Antonio Fernández Solano.

\section{GUZMÁN SÁNCHEZ, EUGENIO (DE) (Censura: RIBES, JOSEF)}

Observacion sobre un parto preternatural. $87-4-A-3, \mathbf{n}^{\mathbf{0}} 150$ y 151. sf. Talavera de la Reina. Papel: Folio y 1/4. $\mathrm{N}^{\mathrm{o}}$ de Folios: 10. $\mathrm{N}^{\mathrm{o}}$ de fascículos: 2. Descriptores: E. de Guzmán y Sánchez, Josef Ribes, Francisco Calderón, Jacobs, Antonio de Gimbernat, Ana García Villanueva, Miguel de Huerta, Real Colegio de Cirugía de San Carlos de Madrid, Talavera de la Reina (Toledo).

\section{RODRÍGUEZ DEL PINO, DIEGO (Censura: GINESTÁ, AGUSTÍN[CV1])}

Descriptores: Ramón Canella, Juan de Navas, Van Swieten, Dionis, Fabré, Hipócrates, Galeno, Real Colegio de Cirugía de San Carlos de Madrid. 


\section{RIBES, JOSEF (Censura: FERNÁNDEZ SOLANO, ANTONIO)}

Observacion sobre unos tumores escrofulosos curados al mismo tiempo que se corrigio una erupcion herpetica. Materia Quirúrgica y Materia Médica. 87-4-A-3, no 160 y 161. 18-Abril-1.793 y 25-Abril-1.793. Madrid. Papel: (1/4). $\mathrm{N}^{\mathrm{o}}$ de Folios: $14 . \mathrm{N}^{\mathrm{o}}$ de fascículos: 2. Descriptores: Josef Ribes, Antonio Fernández Solano, Bell.

\section{RYBAS, MARIANO (Censura: GINESTÁ, AGUSTÍN)}

Observacion porque se dan esencialmente mortales las heridas de la vejiga de la orina en su parte posterior y se propone una operación para solventarlas. Materia Quirúrgica. 87-4-A-3, no 162 y 163. 2-Mayo-1.793 y 16-Mayo-1.793. Madrid. Papel: Folio y 1/4. $\mathrm{N}^{\mathrm{o}}$ de Folios: 9. $\mathrm{N}^{\mathrm{o}}$ de fascículos: 2, Descriptores: Mariano Rybas, Agustín Ginestá, Real Colegio de Cirugía de San Carlos de Madrid.

\section{GUZMÁN Y SÁNCHEZ, EUGENIO (Censura: RYBAS, MARIANO)}

Observacion sobre un tumor en la corba que se tubo por absceso, ya sin abertura se siguio una hemorragia funesta. Materia Quirúrgica y Materia Médica. 87-4-A-3, no 164 y 165. 29-Mayo-1.793 y 6-Junio-1.793. Madrid. Papel: Folio y 1/4. No de Folios: 15 . No de fascículos: 2. Descriptores: Eugenio Guzmán y Sánchez, Mariano Rybas, Madrid.

\section{DÍAZ, FRANCISCO JAVIER (Censura: FERNÁNDEZ SOLANO, ANTONIO)}

Observacion latina sobre un parto preternatural. Obstetricia, 87-4-A-3, no 166 y 166 bis. 20-Junio-1.793. Talavera de la Reina. Papel: Folio y 1/4. No de Folios: 8. No de fascículos: 2. Descriptores: Francisco Javier Díaz, Antonio Fernández Solano, Hipócrates, Vicente Manzanas, Domingo Melchor Ximénez, Talavera de la Reina (Toledo), Ravalmorcuende.

NAVAS, JUAN (DE) (Censura: SARAIS, RAMÓN)

Observacion a una retroversion del utero a que se siguio el aborto. Materia Quirúrgica y Obstetricia. 87-4-A-3, no 167 y 168. 27-Junio-1.793 y 14-Julio-1.793. Madrid. Papel: (1/4). $\mathrm{N}^{\mathrm{o}}$ de Folios: 12, $\mathrm{N}^{\mathrm{o}}$ de fascículos: 2. Descriptores: Juan de Navas, Ramón Sarais, M. Gregoire, Walter Wall, Hunter, Linn (Cirujano de Woodbridge), Perfet, Hooper, Bird, Garthshures, Gil, Lomder, París, Inglaterra, Londres, Sociedad de Médicos de Londres, Diario de Medicina de París.

\section{SARAIS, RAMÓN (Censura: NAVAS, JUAN (DE)}

Observacion sobre una inflamacion y abceso críticos en el periné. Materia Quirúrgica. 87-4-A-3, no 169 y 170, ll-Julio-1.793 y 18-Julio-1.793. Madrid. Papel: (1/4). No de Folios: 11, $\mathrm{N}^{\mathrm{o}}$ de fascículos: 2. Descriptores: Ramón Sarais, Juan de Navas, Gulard, Colegio de San Carlos de Madrid. 


\section{GUZMÁN Y SÁNCHEZ, EUGENIO}

Observacion sobre la extirpacion de una matriz que de resultas de un parto quedo enteramente inversa y no ha podido reducirse. Materia Quirúrgica y Obstetricia. 87-4A-3, $\mathbf{n}^{\mathbf{0}}$ 171. 19-Julio-1.793. Madrid. Papel: Folio. $\mathrm{N}^{\mathrm{o}}$ de Folios: $6 . \mathrm{N}^{\mathrm{o}}$ de fascículos: 1, Descriptores: Eugenio Guzmán Sánchez. Talavera de la Reina (Toledo), Madrid.

\section{GINESTÁ, AGUSTÍN (Censura: RODRÍGUEZ DEL PINO, DIEGO)}

Observación sobre una herida hecha en la rodilla con arma de fuego. Heridas por Arma de Fuego, 87-4-A-3, no 172 y 173. 3-Octubre-1.793 y 10-Octubre-1.793, Madrid. Papel: Folio. $\mathrm{N}^{\mathrm{o}}$ de Folios: 5. $\mathrm{N}^{\mathrm{o}}$ de fascículos: 2. Descriptores: Agustín Ginestá, Diego Rodríguez del Pino, Ravatas, Le Dran, Canivell, Vesalio, Daza Chacón, La Faye, Bell, Bartalomé Catley.

\section{PÉREZ, JUAN (Censura: RIBES, JOSEF)}

Observacion de una herida penetrante a la cavidad del pecho con lesión del pulmón. Materia Quirúrgica. 87-4-A-3, no 174 y 175. 17-Octubre1.793 y 24-Octubre-1.793. Lérida. Papel: (1/4). $\mathrm{N}^{\mathrm{o}}$ de Folios: 12. $\mathrm{N}^{\mathrm{o}}$ de Fascículos: 2. Descriptores: Juan Pérez, José Ribes, Lérida, Madrid.

\section{RODRÍGUEZ DEL PINO, DIEGO (Censura: GINESTÁ, AGUSTÍN)}

Noticias del uso de las raices de magnes y begonia para la curacion de un vicio venéreo. Materia Médica y Botánica. 87-4-A-3, no 176 y 177. 3-Octubre-1.793 y 7, 14, y 21Octubre-1.793. México. Papel. Folio y 1/4. $\mathrm{N}^{\mathrm{o}}$ de Folios 22, No de Fascículos: 2. Descriptores: Diego Rodríguez del Pino, Agustín Ginestá, Nicolás Viana, Josef García Jove (Médico primero del Hospital General de San Andrés), Francisco Baldi (Cirujano mayor del Departamento del Galico del Hospital General de San Andrés), Alonso Nuñez de Aro y Peralta (Arzobispo de México), Antonio Medina, Josef Salomón, Bartolomé Piñera (ambos Profesores de Medicina de Madrid), Felipe Somoza (Profesor de Cirugía de Madrid), Juan Godos, Juan Henrico, Juan López, Juan de Sotos, Francisco Villa, Juan Rosado, Pedro Delgado, Jacinto Rodríguez, Ventura Gallego, Juana Rizo, Bárbara Santos, Catalina Argueta, Manuela Cuit, Josefa García, Paula Narsia, Tomasa Hernández, Josefa Hernández, Rita Berengue, Micaela Díaz, Ramona Martínez, María Requena, Josefa de la Jara, María Fernández, Josefa Franco, Josef de San Juan de Dios, Felipe Hernández, Manuel Duque, Antonio Peralta, Juan Nisoso, Josef Pinto, Manuel Rodríguez, Matías Rodríguez, Matías Fuertes., Blas Merino, Andrés Moreno, Josef Lorenzo, Antonio García, Ramón de Pancorbo, Francisco de la Torre, Isidro Hernández, Gaspar García, México, Pazquaro, Michoacan, Madrid, Obispado de Michoacan, Hospital General de San Juan de Dios de México, Hospitales de San Juan de Dios, General y Pasión de Madrid, Hospital General de San Andrés. 
FERNÁNDEZ, FRANCISCO JAVIER (Censura: SARAIS, RAMÓN)

Observacion de unos polvos de hasta de ciervo calcinados, para la curacion de las úlceras varicasas y apoyándolo contra observaciones. Materia Médica, 87-4-A-3, no 178 y 179. 5-Diciembre-1.793 y 12-Diciembre-1.793. Madrid. Papel: (1/4). No de Folias: 12. $\mathrm{N}^{\mathrm{o}}$ de fascículos, 2. Descriptares: Francisco Javier Fernández, Ramón Sarais, Manuela Gómez, Francisca Cuesta, Madrid.

RIBES, JOSEF (Censura: RODRÍGUEZ DEL PINO, DIEGO)

Observacion sobre una fístula en el conducto salivar, fomentada por un vicio venéreo acompañada de caries. Materia Quirúrgica. 87-4-A-3, no 180 y 181. 18-Diciembre1.793 y 2-Enero-1.793. Madrid. Papel: (1/4). $\mathrm{N}^{\mathrm{o}}$ de Folios: 10. $\mathrm{N}^{\mathrm{o}}$ de fascículos: 2 . Descriptores: Josef Ribes, Diego Rodríguez del Pino, Aquapendente, Saviazd, Leroy, Louis, Academia de Cirugía de París, Real Colegio de San Carlos, Madrid.

RYBAS, MARIANO (Censura: NAVAS, JUAN (DE)

Observacion sobre un absceso en la glandula próstata. Materia Quirúrgica. 87-4-A-3, no 182 y 183. 9-Enero-1.794 y 16-Enero-1.794. Madrid. Papel (1/4). No de Folios: 9. No de fascículos: 2. Descriptores: Mariano Rybas, Juan de Navas, Antonio de Gimbernat, Ramón Vila, Francisco García, Agustín Navarro.

\section{ALLEGRETTI, MIGUEL (Censura: FERNÁNDEZ SOLANO, ANTONIO)}

Consulta sobre un afecto de ojos endémico en Alhucemas. Enfermedades de los Ojos. 87-4-A-3, no 184 y 185. 30-Enero-1.794 y 6-Febrero-1.794. Alhucemas. Papel: (1/4). No de Folios: 10. $\mathrm{N}^{\mathrm{o}}$ de fascículos: 2. Descriptores: Miguel Allegretti, Antonio Fernández Solano, Alhucemas, Real Colegio de Cirugía de San Carlos de Madrid, Prisión de Alhucemas.

\section{FERNÁNDEZ SOLANO, ANTONIO (Censura: RYBAS, MARIANO)}

Observacion sobre cautelas que deben tener los principiantes en las declaraciones judiciales: deduciéndose la necesidad de estas precauciones de un proceso criminal en que por no observarles estuvo sentenciado a muerte un reo. 87-4-A-3, no 186 y 187. 13-Febrero-1.794 y 20-Febrero-1.794. Madrid. Papel: (1/4). $\mathrm{N}^{\mathrm{o}}$ de Folios: 7. $\mathrm{N}^{\mathrm{o}} \mathrm{de}$ fascículos: 2, Descriptores, Antonio Fernández Solano, Mariano Rybas, Granada, Madrid, Real Colegio de San Carlos de Madrid.

\section{NAVAS, JUAN (DE) (Censura: GINESTÁ, AGUSTÍN)}

Observacion de una señora que murió de convulsión en el parto. Enfermedades de las Mujeres. 87-4-A-3, no 188 y 189, 27-Febrero-1.794 y 6-Marzo-1.794. Madrid. Papel: Folio y 1/4. $\mathrm{N}^{\mathrm{o}}$ de Folios: 10, $\mathrm{N}^{\mathrm{o}}$ de fascículos: 2. Descriptores: Juan de Navas, Agustín Ginestá, Real Colegio de Cirugía de San Carlos de Madrid. 
SARAIS, RAMÓN (Censura: RODRÍGUEZ DEL PINO, DIEGO)

Observacion y varias reflexiones sobre el hidrocéfalo interno su diagnóstico y medios propuestos para su curacion. Materia Quirúrgica. 87-4-A-3, no 190 y 191. Madrid. Papel: (1/4), $\mathrm{N}^{\mathrm{o}}$ de Folios: 11. $\mathrm{N}^{\mathrm{o}}$ de fascículos: 2. Descriptores: Ramón Sarais, Diego Rodríguez del Pino, Robert Whitt, Watson, Quin, Fort, Culen, Madrid, Londres, Real Colegio de Cirugía de San Carlos, Hospital de Locos de Londres.

\section{FERNÁNDEZ, FRANCISCO JAVIER (Censura: SARAIS, RAMÓN)}

Observacion sobre los síntomas que acompañaron a las úlceras cancerosas curadas con polvos de asta de ciervo y tambien la observacion de una herida de útero grávido por la que salia un brazo del feto contenido, y a la que siguio un parto natural después de ocho días. Materia Médica y Obstetricia. 87-4-A-3, no 192 y 193. 29Marzo.794 y 3-Abril-1.794. Madrid, Papel. (1/4). $\mathrm{N}^{\mathrm{o}}$ de Folios: 15, $\mathrm{N}^{\mathrm{o}}$ de fascículos: 2. Descriptores: Francisco Javier Fernández, Ramón Sarais, Roeder, Lauveijctd, Hoffman, Faussins, Real Colegio de Cirugía de Madrid.

\section{GINESTÁ, AGUSTÍN (Censura: RIBES, JOSEF)}

Observacion sobre un absceso grande situado en el hipocondrio izquierdo. Materia Quirúrgica. 87-4-A-3, no 194 y 195. 10-Abril-1.794 y 24-Abril-1.794. Madrid. Papel: Folio y 1/4. $\mathrm{N}^{\mathrm{o}}$ de Folios: 12, $\mathrm{N}^{\mathrm{o}}$ de fascículos: 2. Descriptores: Agustín Ginestá, Josef, Ribes, Madrid.

\section{FERNÁNDEZ, FRANCISCO JAVIER (Censura: NAVAS, JUAN (DE)}

Observacion sobre un tumor en el cuello de una mujer curado con una incision. Materia Quirúrgica. 87-4-A-3, no 196 y 197. 8-Mayo-1.794 y 22-Mayo-1.794. Madrid. Papel: (1/4), No de Folios: 12. $\mathrm{N}^{\mathrm{o}}$ de fascículos: 2. Descriptores: Francisco Javier Fernández, Juan de Navas. Madrid.

\section{RIBES, JOSEF (Censura: FERNÁNDEZ SOLANO, ANTONIO)}

Observacion sobre un hidrocele doble en un hombre anciano curado radicalmente. Materia Quirúrgica. 87-4-A-3, no 198 y 199. 5-Junio-1.794 y 12-Junio-1794. Madrid. Papel: (1/4). $\mathrm{N}^{\mathrm{o}}$ de Folios: 16. $\mathrm{N}^{\mathrm{o}}$ de fascículos: 2. Descriptores: Josef Ribes, Antonio Fernández Solano, Fernando Pérez, Madrid, Toledo, Colegio Arzobispal de Toledo.

RYBAS, MARIANO (Censura: RIBES, JOSEF)

Observacion sobre un parto trabajoso de cuyas resultas rasgó el Periné de la Parturienta y con este motibo propone que en iguales circunstancias se corte oblicuamente uno de los labios para evitar que lo haga violentamente la naturaleza. Obstetricia. 
87-4-A-3, no 200 y 201. 26-Junio-1.794 y 3-Julio-1.794. Madrid, Papel: (1/4). No de Folios 9. $\mathrm{N}^{\mathrm{o}}$ de fascículos: 2. Descriptores: Mariano Rybas, Josef Ribes.

SARCOS DE MIGUEL, MANUEL; SOSCIAS, GREGORIO; CANALS, AMBROSIO (Censura: GINESTÁ, AGUSTÍN)

Observacion de una herida de Cabeza con fractura de Cráneo, en que se hicieran quatro trepanaciones con feliz suceso. Materia Quirúrgica. 87-4-A-3, no 202 y 203. 10Julio-1.794 y 17-Julio-1794. Tárrega (Cataluña). Papel: Folio y 1/4. $\mathrm{N}^{\mathrm{o}}$ de Folios: $6 . \mathrm{N}^{\mathrm{o}}$ de fascículos: 2. Descriptores: Manuel Sarcós de Miguel, Gregorio Soscias, Ambrosio Canals, Agustín Ginestá, Josef Llorens, Tárrega (Cataluña), C/ de las Picas (Tárrega), Francia, Real Colegio de Cirugía de Barcelona.

\section{VICENTE, ANTONIO (Censura: RODRÍGUEZ DEL PINO, DIEGO)}

Tres observaciones; una sobre la curacion de un aparalisis en los extremos inferiores; otra sobre una fractura de Pierna complicada con heridas exteriores y hemorragia copiosa; y otra sobre un parto dificil en que fueron necesarias los auxilios del Arte para la extraccion de dos fetos, despues de haver arrojado uno por si misma la parturienta. Afectos Internos, Algebra Quirúrgica, Obstetricia. 87-4-A-3, no 204 y 205. 24-Julio-1.794 y 31-Julio-1.794. Madrid. Papel: (1/4). No de Folios. 24. No de fascículos: 2. Descriptores: Antonio Vicente, Diego Rodríguez del Pino, Juan Francisco Polo, Hipócrates, Galeno, Celso, Vallés, Paracelso, Vega, Aecio, Vido de Vidio, Zacuto Lusitano, San Pablo, María Mathías, Rosa Abril, P. Pott, Camarillas (Teruel), Alfambra (Reino de Arag6n), Madrid, Lidon, Zaragoza, Orrios, Colegio de Cirugía de San Carlos de Madrid.

\section{FERNÁNDEZ SOLANO, ANTONIO (Censura: RIBES, JOSEF)}

Observacion sobre un parto que siendo muy largo el rafe se hizo un desgarro considerable; y habiéndose doblado hacia dentro una de las Paredes se unieron las dos mitades de ella sin embargo de la evacuacion lochial. Obstetricia. 87-4-A-3, no 206 y 207. 2-Octubre-1.794 y 9-Octubre-1.794. Madrid. Papel: (1/4), $\mathrm{N}^{\mathrm{o}}$ de Folios: $8 . \mathrm{N}^{\mathrm{o}}$ de fascículos: 2. Descriptores, Antonio Fernández Solano, Josef Ribes, Stenon, Paré, Aguapendente, París, Memorias de Cirugía de París.

\section{ALLEGRETTI, MIGUEL (Censura: GINESTÁ, AGUSTÍN)}

Observacion sobre un método especifico curativo de la hemeralopia endemica en este destino (Alhucemas) practicado repetidas veces siempre con feliz éxito. Materia Médica. Enfermedades de los Ojos, 87-4-A-3, no 208 y 209. 16-Octubre-1.794 y 23Octubre-1.794. Alhucemas. Papel: Folio y 1/4. $\mathrm{N}^{\mathrm{o}}$ de Folios: 6. $\mathrm{N}^{\mathrm{o}}$ de fascículos: 2. Descriptores: Miguel Allegretti, Agustín Ginestá, Dr. Dubé, Callisen, Alhucemas, Libro de Tobias (Biblia), Instituciones de Cirugía de Callisen, 


\section{NAVAS, JUAN (DE) (Censura: RODRÍGUEZ DEL PINO, DIEGO)}

Observacion sobre una tos habitual acompañada de incontinencia de orina en una Señora que sin embargo de no haver padecido síntoma alguno venéreo, se curó con el uso del mercurio, opio y un sedal a la nuca. Afectos Internos. Terapéutica. 87-4-A-3, no 210 y 211. 30-Octubre-1.794 y 6-Noviembre-1.794. Madrid. Papel: (1/4). No de Folios. 8. $\mathrm{N}_{-}^{\mathrm{o}}$ de fascículos: 2. Descriptores: Juan de Navas, Diego Rodríguez del Pino.

GONZÁLEZ, ANTONIO JOAQUÍN (Cirujano del Regimiento de Infantería Provincial de Ciudad Rodrigo) (Censura: SARAIS, RAMÓN)

Curacion de un tumor canceroso Nolíme Tangere hecha por D.... (Adjunta un acta notarial). Materia Quirúrgica. 87-4-A-3, no 212 y 213. 13-Noviembre-1.794 y 20Noviembre-1.794. Santander. Papel: Folio (acta) y 1/4 (Memoria y Censura). No de Folios: 16. $\mathrm{N}^{\mathrm{o}}$ de fascículos: 3. Descriptores: Antonio Joaquín González, Ramón Sarais, Jalope de Madena, Vesalio, Valverde, Francisco Villaverde, Velasco, Francisco Collantes, Francisca Pastor y Escalán, Juan Antonio Mantilla, Ramón Eguarás, Ciudad Rodrigo, Santander.

\section{SARAIS, RAMÓN (Censura: RIBES, JOSEF)}

Observacion sobre un joven acometido de un vicio venéreo y sucesivamente de una fiebre catarral, $y$ de un reumatismo cuya curacion se completo felizmente. Enfermedades Venéreas, Afectos Internos. 874-A-3, no 214 y 215. 27-Noviembre-1.794 y 4Diciembre-1.794. Madrid. Papel: (1/4). No de Folios: 13. No de fascículos: 2. Descriptores: Ramón Sarais, Josef Ribes, John Hunter, Cruikshank.

\section{CIBAT, ANTONIO (Censura: NAVAS, JUAN (DE)}

Ensayo sobre el Trismus traumatico: o sea la insignificancia de los Antiespasmodicas comunmente usados para su curacion; compuesto por el Licenciado en Cirugía Don.... Heridas por Armas de Fuego y Terapéutica, 87-4-A-3, no 216 y 217. 11Diciembre-1.794 y 18-Diciembre-1.794. Madrid. Papel: (1/4). $\mathrm{N}^{\mathrm{o}}$ de Folios: 12. $\mathrm{N}^{\mathrm{o}}$ de fascículos: 2. Descriptores: Antonio Cibat, Juan de Navas, Juan Rigau, Sydenhan, Josef Antonio Capdevila, Hunter, Ovidio, Whitt, Boerhaave, Hipócrates, Celso, Agustín Ginestá, Van Switen, Cullen, Albino, Paré, Vilguer, Haen, Galeno, Grau, Duncan, Nisbet, Bajan, La Croíx, Sawnders, Lucas, Claen, Huckio, Lind. Ceret (Condado de Rosillon),

\section{RODRÍGUEZ DEL PINO, DIEGO (Censura: FERNÁNDEZ SOLANO, ANTONIO)}

Observacion sobre un absceso sobre las costillas falsas del lado derecho, y consiguiente a una caída, el cual se curo felizmente. Materia Quirúrgica. Terapéutica. 87-4A-3, no 218 y 219, 8-Enero-1.795 y 15-Enero-1.795. Madrid, Papel: (1/4). Descriptores: 
Diego Rodríguez del Pino, Antonio Fernández Solano, Manuel Bascuñana, Sala de San Tadeo del Hospital General de Madrid.

DE GIMBERNAT, ANTONIO (Censura: NAVAS, JUAN (DE)

Observacion sobre un Aneurisma en la Arteria Crural que para dictamen de Don Antonio de Gimbernat se cura felizmente comprimiendo el vaso con un torniquete. Materia Quirúrgica. 87-4-A-3, no 220 y 221, 22-Enero-1.795 y 29-Enero-1.795, Madrid, Papel: Folio. $\mathrm{N}^{\mathrm{o}}$ de Folios, 14. $\mathrm{N}^{\mathrm{o}}$ de fascículos: 2. Descriptores: Antonio de Gimbernat, Agustín de Ginestá, Juan de Navas, Marco Aurelio Severino, Jayme Burchal, Henrique Moinichen, De Pelletan, Guatani, Cavallini, Hunter, Jorge Luis Alefelo, Beaussier, Daza, Avicena, Francisco Marqueti, Francisco González (Practicante Mayor), Ramón Sarais, Josef Queraltó, Francisco Marguetti, Francisco González, Antonio Prado (Cirujano). Hospital de San Bartolomé, Hospital General, Hospital de San Jorge de Londres. Medicina Eficacci de Marco Aurelio Severino, Observaciones e indagaciones Médicas de la Sociedad de Médicos de Londres de Jayme Burchal.

\section{RIBES, JOSEF (Censura: SARAIS, RAMÓN)}

Observacion sobre una herupcion herpetica en la cara y margen del ano que se trató con el sublimado corrosivo y cedia a uno de los baños frios y con este motivo reflexiona el autor sobre si las herpes, y otros males cutaneos suponen vicio general en los humores o son unicamente enfermedades tropicales. Materia Médica y Quirúrgica. 87-4A-3, no 222 y 223. 12-Febrero-1.795 y 19-Febrero-1.795. Madrid. Papel: (1/4). No de Folios: 12. $\mathrm{N}^{\mathrm{o}}$ de fascículos: 2. Descriptores: Josef Ribes, Ramón Sarais, Leandro Pascual, Hipócrates, Galeno, Dioscórides, Enfermería del Colegio de San Carlos de Madrid.

FERNÁNDEZ SOLANO, ANTONIO (Censura: RODRÍGUEZ DEL PINO, DIEGO)

Observacion sobre un hidrocele disipado inopinadamente en un baño de rio. Materia Médica y Quirúrgica. 87-4-A-3, no 224 y 225. 26-Febrero-1.795 y 5-Marza-1.795. Madrid Papel: (1/4). № de Folios: 9. № de fascículos: 2. Descriptores: Antonio Fernández Solano, Diego Rodríguez del Pino, Platner.

\section{SARAIS, RAMÓN (Censura: GINESTÁ, AGUSTÍN)}

Observacion de donde se deduce que existiendo en un sujeto los vicios y reumático desaparecen los sintomas de un quando se manifiestan notables los del otro. Afectos Internos, 87-4-A-3, no 226 y 227. 12-Marzo-1.795 y 26-Marzo-1.795. Madrid. Papel: (1/4). No de Folios: 12. No de fascículos: 2. Descriptores: Ramón Sarais, Agustín Ginestá, Sauvages, Cullen, Fuller, Selle, Hunter, Vogel, Hecker, Brown, Paracelso, Alpujarras (Granada), Ecija (Sevilla), Madrid. 


\section{RODRÍGUEZ DEL PINO, DIEGO (Censura: RIBES, JOSEF)}

Observacion sobre un Trismo ocasionado por una fractura del dedo pulgar y curada con el uso del opio. Materia Quirúrgica y Terapeutica. 87-4-A-3, no 228 y 229. 9-Abril1.795 y 16-Abril-1.795. Madrid. Papel: (1/4). $\mathrm{N}^{\circ}$ de Folios: 8 . $\mathrm{N}^{\mathrm{o}}$ de fascículos: 2 . Descriptores: Diego Rodríguez del Pino, Josef Ribes, Manuel Ximémez (Cochero de la Casa Real).

\section{GINESTÁ, AGUSTÍN (Censura: DE NAVAS, JUAN)}

Observacion sobre un tumor en el vientre, cuyo origen residía en un absceso lornbar. Materia Quirúrgica. 87-4-A-3, no 230, 231 y 232. 23-Abril-1.795 y 30-Abril-1.795. Madrid. Papel: Folio y 1/4. $N^{\circ}$ de Folios: 15. $N^{\circ}$ de fascículos: 3. (Memoria, Censura y Observación). Notas al margen: 1 en la Memoria y 2 en la Observación. Descriptores: Agustín Ginestá, Juan de Navas, Camper.

\section{VOLÁ, MAGÍN (Censura: FERNÁNDEZ SOLANO, ANTONIO)}

Observacion de un depósito 1ombar curado por medio de la observacion. Materia Quirúrgica. 87-4-A-3, no 233 y 234. 7-Mayo-1.795 y 21-Mayo-1.795, Barbastro (Huesca), Papel; (1/4), $\mathrm{N}^{\mathrm{o}}$ de Folios: 16. No de fascículos: 2. Descriptores: Magín Volá, Antonio Fernandez Solano, Pablo de Bezelga, Madrid, Barbastro, Real Colegio de Cirugía de San Carlos, Obispado de Barbastro.

\section{FERNÁNDEZ SOLANO, ANTONIO (Censura: SARAIS, RAMÓN)}

Disertacion sobre un Depósito Seroso en el muslo, consiguiente á un dolor ischiatico. Materia Quirúrgica. 87-4-A-3, no 235 y 236. 28-Mayo-1795 y 21-Junio-1795. Madrid. Papel: Folio. $\mathrm{N}^{\circ}$ de Folios: 14. $\mathrm{N}^{\circ}$ de fascículos : 2. Descriptores: Antonio Fernández Solano, Ramón Sarais.

\section{IBARROLA, PABLO (Censura: GINESTÁ, AGUSTÍN)}

Observacion sobre una fractura causada en el húmero por bala de fusil, y curada felizmente. Enfermedades de los Huesos. Materia Quirúrgica. 87-4-A-3, no 237 y 238. 18-Junio-1 795 y 25-Junio-1795. Mondragón. Papel: Folio y 1/4. $\mathrm{N}^{\mathrm{o}}$ de Folios: 8. $\mathrm{N}^{\mathrm{o}} \mathrm{de}$ fascículos: 2. Descriptores: Pablo Ibarrola, Agustín Ginestá, Madrid, Mondragón, Real Colegio de Cirugía de San Carlos.

\section{NAVAS, JUAN (DE) (Censura: GINESTÁ, AGUSTÍN)}

Observacion de un atsma convulsiva, que cesó con los dolores del parto, y de un síncope por dimocion sobrevenido á este. Afectos Internos. Obstetricia. 87-4-A-3, no 239 y 240. 2-Ju1io-1795 y 9-Julio-1.795. Madrid. Papel: (1/4) . $\mathrm{N}^{\circ}$ de Folios: 9. $\mathrm{N}^{\circ}$ de fascículos: 2. Descriptores: Juan de Navas, Agustín Ginestá, Sauvages. 


\section{VOLÁ, MAGÍN (Censura: RIBES, JOSEF)}

Observacion sobre una herida que recibió en campaña el Marques de San Simon. Materia Quirúrgica. 87-4-A-3, no 241 y 242, 16-Julio-1 795 y 23-Julio-1.795, Barbastro , Papel: (1/4). $\mathrm{N}^{\mathrm{o}}$ de Folios: 10. $\mathrm{N}^{\mathrm{o}}$ de fascículos: 2. Descriptores: Licenciado Magín Volá, Josef Ribes, Masdevall, Vogel, Cirujano Bizarrón, Marqués de San Simón, Campo de Anduicio (Reino de Navarra), Tudela, Miranda de Arga, Pamplona, San Juan de Pie de Puerto, Orden de San Luis, Legión Real de los Pirineos.

\section{SARAIS, RAMÓN (Censura : LACABA, IGNACIO)}

Observacíon sobre que e1 vicio especifico es reumático. Materia Médica. 87-4-A-3, no 243 y 244. 8-Octubre-1.795 y 15-Octubre-1 .795. Madrid. Papel: (1/4). No de Folios: 13. $\mathrm{N}^{\circ}$ de fascículos: 2. Descriptores: Ramón Sarais, Ignacio Lacaba.

\section{RODRÍGUEZ DEL PINO, DIEGO (Censura: NAVAS, JUAN (DE)}

Observación de un hidrocele de la túnica vaginal. Más Censura y reflexiones. Materia Quirúrgica. 87-4-A-3, no 245 y 246: 22-0ctubre-1.795 y 29-Octubre-1.795. Procedencia del documento desconocida. Papel: $(1 / 4)$. $\mathrm{N}^{\circ}$ de Folios: $13 \mathrm{~N}^{\circ}$ de fascículos: 2. Descriptores: Diego Rodríguez del Pino, Juan de Navas, Antonio de Gimbernat, Ignacio Lacaba, Ramón Sarais, Agustín Ginestá, Josef Ribes, Real Colegio de Cirugía de San Carlos de Madrid .

\section{GINESTÁ, AGUSTÍN (Censura : SARAIS, RAMÓN)}

Observacion sobre un punto en el que el feto se presentaba de nalgas. Obstetricia. 874-A-3, no 247 y 248. 5-Noviembre-1.795 y 12-Noviembre-1.795. Madrid. Papel: Folio y 1/4. $N^{\circ}$ de Folios: 13, $N^{\circ}$ de fascículos: 2. Descriptores: Agustín Ginestá, Ramón Sarais, Josef Ribes, Diego Rodríguez del Pino, Juan de Navas, Ignacio Lacaba.

\section{RIBES, JOSEF (Censura: RODRÍGUEZ DEL PINO, DIEGO)}

Observación sobre un absceso con caries en la superficie interna y externa del hueso ileon izquierdo. Materia Médica, Enfermedades de los huesos, Materia Quirúrgica. 87-4A-3, no 249 y 250. 19-Noviembre-1.795 y 26-Noviembre-1.795. Madrid. Papel: (1/4). No de Folios: 12, $\mathrm{N}^{\mathrm{o}}$ de fascículos: 3 Descriptores: Josef Ribes, Diego Rodríguez del Pino, Ignacio Lacaba, Agustín Ginestá, Ramón Sarais, Juan de Navas, Salas de Nuestra Señora de Madrid y de San Tadeo del Hospital General de Madrid.

\section{LACABA, IGNACIO (Censura: GINESTÁ, AGUSTÍN)}

Observacion sobre un punto trabajoso por descenso del útero y callosidad de su orificio, á lo qual se agregaba una retención de orina. Obstetricia. 87-4-A-3, no 251 y 252. 3-Diciembre-1.795 y 10-Diciembre-1.795. Madrid. Papel: Folio y 1/4. No de Folios: 
14. $\mathrm{N}^{\circ} \mathrm{d}$ e fascículos. 2. Notas al margen: en Censura: 2 . Descriptores: Ignacio Lacaba, Agustín Ginestá.

NAVAS, JUAN (DE) (Censura: RIBES, JOSEF)

Observacion de un parto laborioso por haber salido fuera de la vulva la cabeza del feto envuelta en el útero. Obstetricia. 87-4-A-3, no 253 y 254. 17-Diciembre-1.795 y 7Enero-1.796. Madrid. Papel: (1/4). $\mathrm{N}^{\mathrm{o}}$ de Folios: 7. $\mathrm{N}^{\mathrm{o}}$ de fascículos: 2. Descriptores: Juan de Navas, Josef Ribes, Real Colegio de Cirugía de San Carlos.

SARAIS, RAMÓN (Censura: LACABA, IGNACIO)

Observaciones sobre un eritema de 1as vísceras del vientre. Materia Quirúrgica. 87-4A-4, no 255 y 256. 14-Enero-1.796 y 21-Enero-1.796. Madrid. Papel: (1/4), $\mathrm{N}^{\circ}$ de folios: 11. $\mathrm{N}^{\circ}$ de fascículos: 2. Descriptores: Ramón Sarais, Ignacio Lacaba, Real Colegio de Cirugía de San Carlos.

RODRÍGUEZ DEL PINO, DIEGO (Censura : NAVAS, JUAN (DE)

Observacion sobre una gangrena del antebrazo a que siguio la amputacion. Materia Quirúrgica. 87-4-A-4, no 257 y 258. 28-Enero-1.796 y 4-Febrero-1.796. Madrid. Papel: (1/4). $\mathrm{N}^{\circ}$ de Folios: 8. $\mathrm{N}^{\mathrm{o}}$ de fascículos: 2. Descriptores. Diego Rodríguez del Pino, Juan de Navas, Córdoba.

\section{GINESTÁ, AGUSTÍN (Censura. SARAIS RAMÓN)}

Observación de una Disuria Reumática. Afectos Internos. 87-4-A-4, no 259 y 260. 11 Febrero-1.796 y 18-Febrero-1.796. Madrid. Papel: Folio y 1/4. $\mathrm{N}^{\circ}$ de Folios: 6. $\mathrm{N}^{\circ}$ de fascículos: 2. Descriptores: Agustín Ginestá, Ramón Sarais, Sydenbam, Boerhaave, Clenck, Sauvages, Plenck, Hermanos Murray, Perensen, Oftendinger, Balsto , Morgagni, Hunter, Hoffman, Merzgen, Swediaur, Francia.

RIBES, JOSEF (Censura: RODRÍGUEZ DEL PINO, DIEGO)

Observacion sobre un Fungus considerable en el ojo izquierdo. Enfermedades de los Ojos. 87-4-A-4, no 261 y 262. 3-Marzo-1.796 y 10-Marzo-1.796. Madrid. Papel: 1/4. № de Folios: 9. $\mathrm{N}^{\mathrm{o}}$ de fascículos: 2. Descriptores: Josef Ribes, Diego Rodríguez del Pino, Manuel Serrano, Agustín Ginestá, Sala de San Tadeo del Colegio de Cirugía de San Carlos.

\section{LACABA, IGNACIO (Censura: GINESTÁ, AGUSTÍN)}

Observacion sobre un Enteroepiplocele extrangulado, curado por las operaciones. Materia Quirúrgica. 87-4-A-4, no 263 y 264. Madrid. Papel: Folio y 1/4, No de Folios: 12. $\mathrm{N}^{\mathrm{o}}$ de fascículos: 2. Descriptores: Ignacio Lacaba, Asustín Ginestá. 
SARAIS, RAMÓN (Censura: RYBES, JOSEF)

Observacion sobre una anomalia reumática. Afectos Internos. 87-4-A-4, no 265 y 266, 7-Abril-1.796 y 14-Abril-1.796. Madrid. Papel: (1/4) , $\mathrm{N}^{\circ}$ de Folios: 7, $\mathrm{N}^{\circ}$ de fascículos:

2. Descriptores: Ramón Sarais, Josef Rybes, Real Colegio de San Carlos de Madrid.

RODRÍGUEZ DEL PINO, DIEGO (Censura: LACABA, IGNACIO)

Observacion sobre un tumor anómalo en el pecho derecho. Enfermedades de Mujeres y Materia Quirúrgica. 87-4-A-4, no 267 y 268, 21-Abril-1.796 y 28-Abril-1.796. Madrid, Papel: (1/4). $\mathrm{N}^{\mathrm{o}}$ de Folios: 8 . $\mathrm{N}^{\mathrm{o}}$ de fascículos: 2. Descriptores: Diego Rodríguez del Pino, Ignacio Lacaba.

RIBES, JOSEF (Censura: SARAIS, RAMÓN)

Testículo duro, bastante elevado y dolorido. (No hay memoria). Materia Quirúrgica y Terapéutica. 87-4-A-4. Madrid, Papel: (1/4). $\mathrm{N}^{\mathrm{o}}$ de Folios: 4. $\mathrm{N}^{\mathrm{o}}$ de fascículos: 4. Descriptores: Josef Ribes, Ramón Sarais, Francisco Cororninas.

SARAIS, RAMÓN (Censura: RODRÍGUEZ DEL PINO, DIEGO)

Observacion sobre una erisipela en una niña de 21 días, la cual se extendio desde el lado del pecho por todo el tronco y extremidades superiores e inferiores excepto el vientre que habia sido untado con aceite rosado y alcanfor. Enfermedades de los Niños. 87-4-A-4, no 270 y 271. 2-Junio-1.796 y 9-Junio-1.796 . Madrid. Papel: (1/4). N ${ }^{\circ}$ de Folios: 6. $\mathrm{N}^{\mathrm{o}}$ de fascículos: 2. Descriptores: Ramón Sarais, Diego Rodríguez del Pino, Real Colegio de Cirugía de San Carlos.

\section{LACABA, IGNACIO (Censura: RIBES, JOSEF)}

Observacion sobre un Bubonocele reducido con una taxis particular. Materia Quirúrgica. 87-4-A-4, no 272 y 273. 16-Junio-1.796 y 23-Junio-1.796. Madrid. Papel: (1/4). $\mathrm{N}^{\mathrm{o}}$ de Folios: 6. $\mathrm{N}^{\mathrm{o}}$ de fascículos: 2. Descriptores: Ignacio Lacaba, Josef Ribes, Dessault, Juan Chaez, Pipelet, París, Lecciones de Anatomía y Cirugía de Mr. Dessault en París.

RODRÍGUEZ DEL PINO, DIEGO (Censura: LACABA, IGNACIO)

Observacion de un corto discurso excitando á la Juventud á imitar á los antiguos en el Tratamiento de los flemones. Materia Quirúrgica, 87-4-A-4, no 274 y 275, 30-Junio-1.796 y 7-Julio-1.796. Madrid, Papel: (1/4). Descriptores: Diego Rodríguez del Pino, Ignacio Lacaba, Galeno, Goulard, Bell, Daza Chacón, Boerhaave, Quesnay, Haller, Astruc, Edimburgo.

LOERA, VICENTE MARÍA (DE)

Disertacion Chirurgica y observacion de una peligrosa herida en la arteria brachial, la que fue curada por mí como dire mas adelante. Materia Quirúrgica. 87-4-A-4, no 
275 bis. 9-Agosto-1 796. Andújar. Pape1: (1/4). $\mathrm{N}^{\circ}$ de Folios: 10. $\mathrm{N}^{\circ}$ de fascículos: 2 , Descriptores: Vicente María de Loera, Andújar.

NAVA, JUAN (DE) (Censura: LACABA, IGNACIO)

Observacion sobre un parto trabajoso, a causa de la oblicuidad de la matriz. Obstetricia. 87-4-A-4, no 276 y 277. 6-0ctubre-1.796 y 13-Octubre-1.796. Madrid. Papel: (1/4). No de Folios: 8. No de fascículos: 2. Descriptores : Juan de Navas, Ignacio Lacaba, Lanvesyat.

\section{GUZMÁN Y SÁNCHEZ, EUGENIO (Censura: RIBES, JOSEF)}

Observacion de una Necrosis de la tibia de la pierna izquierda. Enfermedades de los Huesos y Materia Quirúrgica, 87-4-A-4, no 278 y 279. 20-Octubre-1.796 y 27-Octubre1.796. Talavera de la Reina (Toledo), Papel: Folio y (1/4). $N^{o}$ de Folios: 9 . No de fascículos: 2. Presenta una lámina de la tibia adosada (p-4v.). Descriptores. Eugenio Guzmán y Sánchez, Josef Ribes, Antonio de Gimbernat, Hunter, Román García, Ruyschio, Laing, Ritter, Weismann, Talavera de la Reina, Calera (Toledo), Edimburgo, Real Colegio de Cirugía de San Carlos de Madrid.

\section{SARAIS, RAMÓN (Censura: GINESTÁ, AGUSTÍN)}

Observacion sobre una blenorrea externa que nunca ha podido curar sin embargo de los muchos esfuerzos que para conseguirlo se han hecho. Enfermedades Venéreas. 87-4-A-4, no 280 y 281. 10-Noviembre-1.796 y 17-Noviembre-1.796. Madrid. Papel: Folio y 1/4. $\mathrm{N}^{\mathrm{o}}$ de Folios: 13. $\mathrm{N}^{\mathrm{o}}$ de fascículos: 2. Descriptores: Ramón Sarais, Agustín Ginestá, Boerhaave, Sydenham, Vencelloni, Masson, Schwidiauer, Murray, Monteggia, Bertrandi, Penchienati, Brugnoma, Hunter.

\section{SOLÁ, MAGÍN (Censura: RODRÍGUEZ DEL PINO, DIEGO)}

Ohservacion sobre una herida de pecho que tubo varias consecuencias. $87-4-\mathrm{A}-4, \mathbf{n}^{\mathbf{0}}$ 282 y 283. 24-Noviembre-1.796 y l-Diciembre-1.796. Madrid. Papel: Folio y 1/4. No de Folios: 11. $\mathrm{N}^{\mathrm{o}}$ de fascículos: 2. Descriptores: Magín Solá, Diego Rodríguez de Pino, Pedro Soyol, Eusebio Valli, Puerto de Santa María.

\section{PELÁEZ, AGUSTÍN (Censura: SARAIS, RAMÓN)}

Observacion de una herida de Arma de Fuego acompañada de un Trismus la que havía entregado para que leyese en la Junta Don Agustín Pe1aez, censurada por Ramón Sarais. Materia Quirúrgica. 87-4-A-4, no 284 y 285. 15-Diciembre-1.796 y 22Diciembre-1.796. Madrid. Papel: (1/4). $\mathrm{N}^{\circ}$ de Folios: $15 \mathrm{~N}^{\circ}$ de fascículos: 2. Descriptores: Agustín Peláez Ramón Sarais, Francisco Cahiz, Bruno Ruig, Gran.

SOLÁ, MAGÍN (Censura: DE NAVAS, JUAN)

Observacion sobre una herida de Arma de fuego. Materia Quirúrgica. 87-4-A-4 no 286 y 287, 5-Enero-1.797 y 20-Enero-1.797. Madrid. Papel: Folio y (1/4). $\mathrm{N}^{\mathrm{o}}$ de Folios: $5 \mathrm{~N}^{\circ}$ 
de fascículos: 2. Descriptores: Magín Solá, Juan de Navas. Duque de Pierme. Campo de Arquinzú (Navarra).

LACABA, IGNACIO (Censura: COSTA, RAFAEL)

Observacíon sobre una fístu1a en el Ano curada con e1 hilo de P1omo. Materia Quirúrgica. 87-4-A-4, no 288 y 289. 26-Enero-1.797 y 9-Febrero-1.797. Madrid. Papel: (1/4). $\mathrm{N}^{\mathrm{o}}$ de Folios: 21. $\mathrm{N}^{\mathrm{o}}$ - de fascículos: 2. Descriptores: Ignacio Lacaba, Rafael Costa, Heister, Pott, Dessault, Foubert, Ramón Queraltó, Licenciado Sebastián Loche.

VILA, JOSEF (Censura: LACABA, IGNACIO)

Observacion sobre varias gangrenas. Materia Quirúrgica. 87-4-A-4, no 290 y 291, 16Febrero-1.797 y 23-Febrero-1 797. Madrid. Papel: folio y 1/4. $\mathrm{N}^{\circ}$ de Folios: $13 . \mathrm{N}^{\circ}$ de fascículos: 2. Descriptores: Josef Vila, Ignacio Lacaba.

GINESTÁ, AGUSTÍN

Censura: Observacion sobre varias úlceras venéreas que cedieron al uso tópico. Enfermedades Venéreas, 87-4-A-4, no 292 y 293. 2-Marzo-1.797 y 9-Marzo-1.797. Madrid. Papel: Folio y 1/4. $\mathrm{N}^{\circ}$ de Folios: 12. $\mathrm{N}^{\mathrm{o}}$ de fascículos: 2. Descriptores. Agustín Ginestá, Josef Ribes.

PELÁEZ, AGUSTÍN (Censura: GINESTÁ, AGUSTÍN)

Observacion sobre una herida de cabeza curada. Materia Quirúrgica. 87-4-A-4, no 294 y 295. 16-Marzo-1.797 y 23-Marzo-1.797. Madrid. Papel: Folio y 1/4. N ${ }^{\circ}$ de Folios: 7. No de fascículos: 2. Descriptores: Agustín Peláez, Agustín Ginestá, Hipócrates.

RIBES, JOSEF (Censura: RODRÍGUEZ DEL PINO, DIEGO)

Observacion en un hidrocele anóma1o. Materia QuirúrQ.lca. 87-4-A-4, no 296 y 297. 30-Marzo-1.797 y 6-Abril-1.797. Madrid. Papel: (1/4). $\mathrm{N}^{\circ}$ de Folios: 11. $\mathrm{N}^{\mathrm{o}}$ de fascículos: 2. Descriptores: Josef Rybes, Diego Rodríguez del Pino, Antonio de Gimbernat.

PELÁEZ, AGUSTÍN (Censura : RAMÓN SARAIS)

Observacion sobre la curacion de las heridas de Armas de fuego. Materia Quirúrgica. 87-4-A-4, no 298 y 299. 20-Abril-1.797 y 27-Abril-1.797. Madrid. Papel: (1/4). No de Folios: 13. $\mathrm{N}^{\mathrm{o}}$ de Fascículos: 2. Descriptores: Agustín Peláez, Ramón Sarais, Vesalio, Alfonso Ferneo, Juan de Vigo, Maggio.

FERNÁNDEZ, FRANCISCO XAVIER (Censura: NAVAS, JUAN (DE)

Observacion de un útero gangrenado remitida desde Garganta la O1la. Enfermedades de Mujeres. 87-4-A-4, no 300 y 301. 18-Mayo-1.797 y 1-Junio-1.797. Madrid. Papel: 
(1/4). No de Folios: 9. N de fascículos 2. Descriptores: Francisco Xavier Fernández, Juan de Navas, Luis Gra Tostado, Celso.

\section{RODRÍGUEZ DEL PINO, DIEGO (Censura: DE LA PEÑA, EUGENIO)}

Observacion de una parálisis de las piernas producido por la cortadura de la espina. Materia Quirúrgica. 87-4-A-4, no 302 y 303. 8-Junio-1.797 y 22-Junio-1.797. Madrid. Pape1: (1/4 ). $\mathrm{N}^{\mathrm{o}}$ de Folios: 9. $\mathrm{N}^{\circ}$ de fascículos 2. Descriptores: Diego Rodríguez del Pino, Eugenio de la Peña, Pott, Agustín Frutos, Josef Bonillo, Hospital General de Madrid.

COSTA DE QUINTANA, RAFAEL (Censura: LACABA, IGNACIO)

Observacion sobre el Cancer. Materia Quirúrgica. 87-4-A-4, no 304 y 305. 6-Julio1.797 y 13-Julio-1.797. Madrid. Papel: (1/4). $\mathrm{N}^{\circ}$ de Folios: 35. $\mathrm{N}^{\circ}$ de fascículos: 2, Descriptores: Rafae1 de Costa Quintana, Ignacio Lacaba, Yustamond, Dr. Jaenisen (Médico Ruso), Van Swieten, Vogel, Josef Torner, Agustín Ginestá, Hill.

\section{DE LA PEÑA, EUGENIO (Censura: COSTA, RAFAEL)}

Observacion sobre una paralisis de las piernas, en consequencia de la cortadura del espinazo. Materia Quirúrgica. 87-4-A-4, no 306 y 307. 20-Ju1io-1.797 y 27-Julio-1.797. Madrid, Papel: (1/4). $\mathrm{N}^{\circ}$ de Folios: 20. $\mathrm{N}^{\circ}$ de fascículos: 2. Descriptores: Eugenio de la Peña, Rafael Costa .

\section{GINESTÁ, AGUSTÍN (Censura: RIBES, JOSEF)}

Observacion sobre un tumor sanguineo en los grandes labios de una mujer de dos fetos. Enfermedades de las Mujeres. Afectos Internos. 87-4-A-4, no 308 y 309. 5-0ctubre1.797 y 13-0ctubre-1.797. Madrid. Papel: (1/4). $\mathrm{N}^{\circ}$ de Folios: 10, $\mathrm{N}^{\mathrm{o}}$ de fascículos. 2. Descriptores: Agustín Ginestá, Josef Ribes.

\section{SARAIS, RAMÓN (Censura: RODRÍGUEZ DEL PINO, DIEGO)}

Observaciones de un bubón reumático. Materia Médica. 87-4-A-4, no 310 y 311 . 190ctubre-1 797 y 26-0ctubre-1 797. Madrid. Papel: (1/4). $\mathrm{N}^{\circ}$ de Folios: 8, $\mathrm{N}^{\mathrm{o}}$ de fascículos. 2. Descriptores: Ramón Sarais, Diego Rodríguez del Pino.

RIBES, JOSEF (Censura: SARAIS, RAMÓN)

Observacion sobre una oftalmía periódica. Enfermedades de los Ojos. 87-4-A-4, no 312 y 313. 9-Noviembre-1.797 y 16-Noviembre-1.797. Madrid. Papel: (1/4). No de Folios: $9 . N^{\circ}$ de fascículos: 2. Descriptores: Josef Ribes, Ramón Sarais. 


\section{RODRÍGUEZ DEL PINO, DIEGO (Censura: NAVAS, JUAN (DE)}

Observacion sobre un Edema en la muñeca. Materia Médica. 87-4-A-4, no 314 y 315. 23-Noviembre-1.797 y 7-Diciembre-1.797. Madrid. Papel: (1/4). $\mathrm{N}^{\mathrm{o}}$ de Folios: 11. $\mathrm{N}^{\mathrm{o}} \mathrm{de}$ fascículos: 2. Descriptores: Diego Rodríguez del Pino, Juan de Navas.

\section{GINESTÁ, AGUSTÍN (Censura: DE LA PEÑA, EUGENIO)}

Observacion sobre una blenorragia reumatica. Enfermedades Venéreas. 87-4-A-4, $\mathbf{n}^{\mathbf{0}}$ 316 y 317, 14-Diciembre-1.797 y 4-Enero-1.798. Madrid. Papel: Folio y 1/4. No de Folios: 12, No de fascículos: 2. Descriptores: Agustín Ginestá, Eugenio de la Peña, Juan Murray (Disertatio de artritide ad verenda aberrante).

QUINTANA, PEDRO (Autor de la Memoria)

GONZÁLEZ, ÁLVARO (Autor de la Memoria)

GIMENO, AGUSTÍN (Leída por)

(Censura: COSTA DE QUINTANA, RAFAEL)

Observacion sobre una ulcera cancerosa situada en el carrillo. Materia Quirúrgica. 874-A-4, no 318 y 319. 11-Enero-1.798 y 18-Enero-1.798. Madrid. Papel: Folio y 1/4. $\mathrm{N}^{\circ}$ de Folios: 12. $\mathrm{N}^{\circ}$ de fascículos: 2. Descriptores: Pedro Quintana, Agustín Gimeno, Rafael Costa de Quintana, Pedro Álvaro González (Cirujano de la Fuente de Pedro Narro), Apolinar Ruiz Medina (Cirujano de Yepes), Juan Antonio Pérez (Cirujano en Baldelacete), Vich, Barcelona, Valencia, Cataluña, La Fuente de Pedro Narro, Baldelacete, Yepes.

COSTA, RAFAEL (Censura: RIBES, JOSEF)

Observacion sobre una epilepsia curada por medio del corte del nervio frontal y del uso del bitriolo blanco. Materia Médica y Materia Quirúrgica. 87-4-A-4, no 320 y 321. 25-Enero-1.798 y 1-Febrero-1.798. Madrid. Papel: (1/4). No de Folios: 10. No de fascículos: 2. Descriptores: Rafae1 Costa, Josef Ribes.

GINESTÁ, AGUSTÍN (Censura: ÁLVAREZ DE QUEBEDO, JUAN)

Observacion sobre una concepcion ventral. Enfermedades de las Mujeres. 87-4-A-4, no 322 y 323. 8-Febrero-1.798 y 15-Febrero-1.798. Madrid. Papel: Folio y 1/4. Descriptores: Agustín Ginestá, Juan Álvarez de Quebedo, Biancbi, Boudeloque, Sabatier.

GARCÍA TORRES, RAMÓN (Censura: Junta del Colegio)

Carece de título, pero trata de una escara gangrenosa situada sobre el tendón del músculo extensor del dedo police del pie izquierdo. Materia Quirúrgica. Terapéutica. 87-4-A-4. no 324 y 325. 15-Febrero-1798 y 22-Febrero-1798. Alcalá del Río Júcar. Papel: Folio y 1/4.N $\mathrm{N}^{\mathrm{o}}$ de Folios: 4 . $\mathrm{N}^{\mathrm{o}}$ de fascículos: 2. Descriptores: Ramón García Torres, Alcalá del Río Júcar. 


\section{DE LA PEÑA, EUGENIO (Censura: SARAIS, RAMÓN)}

Observacion de unas gangrenas en el Carrillo. Materia Quirúrgica. Terapéutica. 87-4A-4, no 326 y 327, 1-Marzo-1.798 y 8-Marzo-1.798. Madrid. Papel: (1/4). No de Folios: 9. $\mathrm{N}^{\circ}$ de fascículos: 2, Descriptores: Eugenio de la Peña, Ramón Sarais, María Lorente, Tomás Lorente, Río Manzanares, Pozuelo de Aravaca.

BLANCO, VICENTE RAMÓN (Censura: DE LA PEÑA, EUGENIO) (Observación: BLANCO, VICENTE RAMÓN)

Observacion sobre un edema flegmonosa de la extremidad inferior. Materia Quirúrgica. 87-4-A-4, no 328 y 329. 16-Marzo-1.798 y 22-Marzo-1.798. Madrid, Papel: (1/4). $\mathrm{N}^{\mathrm{o}}$ de Folios: 11. $\mathrm{N}^{\mathrm{o}}$ de fascículos: 2. Descriptores: Vicente Ramón Blanco, Eugenio de la Peña, Rafael Costa.

NAVAS, JUAN (DE) (Censura: COSTA, RAFAEL)

Observacion sobre los tumores varicosos en los genitales de las mujeres embarazadas. Materia Quirúrgica y Obstetricia. 87-4-A-4, no 330 y 331. 29-Marzo-1.798 y 12Abril-1.798. Madrid. Papel: (1/4). $\mathrm{N}^{\circ}$ de Folios: 12, $\mathrm{N}^{\circ}$ de fascículos: 2. Descriptores; Juan de Navas, Rafael Costa de Quintana.

\section{SARAIS, RAMÓN (Censura: NAVAS, JUAN (DE)}

Observacion sobre una gota irregu1ada. Afectos Internos. Terapéutica. 87-4-A-4, $\mathbf{n}^{\mathbf{0}} 332$ y 333. 19-Abril-1798 y 26-Abril-1798. Madrid. Papel: (1/4). $\mathrm{N}^{\circ}$ de Folios: 12 . No de fascículos: 2. Descriptores: Ramón Sarais, Juan de Navas, Londres, Atocha, Hospital de Londres.

\section{RODRÍGUEZ DEL PINO, DIEGO (Censura: RIBES, JOSEF)}

Observacion sobre una hidropesia purulenta del vientre. Materia Quirúrgica. Afectos Internos. 87-4-A-4, no 334 y 335. 10-Mayo-1.798 y 24-Mayo-1.798. Madrid. Papel: (1/4) . $\mathrm{N}^{\circ}$ de Folios: 12. $\mathrm{N}^{\circ}$ de fascículos: 2. Descriptores: Diego Rodríguez del Pino, Josef Ribes, Cocimiento de Labardana.

\section{VILA, JOSEF (Censura: DE LA PEÑA, EUGENIO)}

Observacion sobre una herida de Arma de fuego. Materia Quirúrgica. 87-4-A-4, no 336 y 337. 31-Mayo-1.798 y 14-Junio-1.798. Trujillo. Papel: (1/4). $\mathrm{N}^{\mathrm{o}}$ de Folios: $13 . \mathrm{N}^{\mathrm{o}}$ de fasciculos: 2. Descriptores: Agustín Ginestá, Josef Vila, Eugenio de la Peña, Gerona, Trujillo, Batallón Reales, Guardias Valonas, Hospital Casa Manresa (Gerona).

\section{GINESTÁ, AGUSTÍN (Censura: NAVAS, JUAN (DE)}

Relacion de las anomalías encontradas en un pretendido hermafrodita. Afectos Internos. 87-4-A-4m, no 338 y 339, 21-Junio-1.798 y 28-Junio-1.798. Madrid. Papel: (1/4). $\mathrm{N}^{\circ}$ de Folios: 7. $\mathrm{N}^{\circ}$ de fascículos: 2. Descriptores: Agustín Ginestá, Juan de Navas, Ra- 
món Sarais, Gaspar Bauhino, Marqués Casa García, Parson, Madrid, Cárcel de la Corte, Ayuntamiento de Madrid, Real Colegio de Cirugía de San Carlos.

RIBES, JOSEF (Censura: SARAIS, RAMÓN)

Observacion sobre la Necrosis de los huesos. Enfermedades de los Huesos 87-4-A-4, no 340 y 341, 9-Julio-1.798 y 12-Julio-1.798. Madrid y Talavera de la Reina (Toledo). Papel ( 1/4). $\mathrm{N}^{\mathrm{o}}$ de Folios: 12. $\mathrm{N}^{\mathrm{o}}$ de fascículos: 2. Descriptores: Josef Ribes, Ramón Sarais, Eugenio Guzmán y Sánchez (Cirujano de Talavera de la Reina), Hunter, Weidman, Cordikihank, Manuel Cano, Antonio de Gimbernat, Talavera de la Reina.

\section{RUIZ, BARTOLOMÉ (Censura: GINESTÁ, AGUSTÍN)}

Observacion de un ano preternatural. Materia Quirúrgica. 87-4-A-4, no 342 y 343. 18-0ctubre-1.798 y 25-0ctubre-1 798. Madrid. Papel: Folio. $\mathrm{N}^{\circ}$ de Folios: $7 \mathrm{~N}^{\circ}$ de fascículos: 2. Descriptores: Agustín Ginestá, Bartolomé Ruiz, Carlos Federico Kaltschmidt.

DE LA PEÑA, EUGENIO (Censura: RODRÍGUEZ DEL PINO, DIEGO)

Observacion de una Preñada junto con Anasarca por infiltración y derramamiento. Obstetricia. 87-4-A-4, no 344. 8-Noviembre- 1.798. Madrid. Papel: (1/4). No de Folios: 6. No de fascículos: 2. Descriptores: Eugenio de la Peña, Diego Rodríguez del Pino, María Uyarra.

\section{RIBES, JOSEF (Censura: COSTA, RAFAEL)}

Observacion de una necrosis en los huesos del cráneo. Materia Quirúrgica y Enfermedades de los Huesos. 87-4-A-4, no 345 y 346. 17-Enero-1.799 y 24-Enero-1.799. Madrid. Papel: (1/4). $\mathrm{N}^{\circ}$ de Folios: 16. $\mathrm{N}^{\circ}$ de fascículos: 2. Descriptores: Josef Ribes, Rafael Costa, Hospital de San Juan de Dios, Tomo V de las Memorias de la Academia de París.

COSTA, RAFAEL (Censura: RIBES, JOSEF)

Observacion sobre un hidrocele por derramamiento curado en el uso de los eméticos. Materia Quirúrgica. Terapéutica. 87-4-A-4, no 347 y 348. 31-Enero-1.799 y 7Febrero-1.799. Madrid. Papel: (1/4). $\mathrm{N}^{\circ}$ de Folios: 9. $\mathrm{N}^{\circ}$ de fascicu1os: 2. Descriptores: Rafael Costa, Josef Ribes, Juan Fernández.

OLLER, FRANCISCO (Censura: DE LA PEÑA, EUGENIO)

Observacion sobre un niño de 16 meses de edad y de un tamaño y peso extraordinario. Enfermedades de los Niños. 87-4-A-4. no 349 y 350. 28-Febrero-1.799 y 7-Marzo-1.799. Madrid. Papel: Folio y 1/4. $\mathrm{N}^{\circ}$ de Folios: 7. $\mathrm{N}^{\circ}$ de fasciculos: 2. Descriptores: Eugenio de la Peña, Francisco Oller (Cirujano de Puerto Rico), Luis Raiffer (Médico y Cirujano titular Comandante de Ingenieros), Tomás Sedeño (Coronel), Juan Josef Santo, Alfonsina García Consuela, Valencia, Loysa, Puerto Rico, Castilla, Burgos, Arma de Ingenieros. 
IRIGOYEN, PEDRO (Censura: COSTA, RAFAEL)

Observacion de una Ascitis purulenta linfatica e hidatidosa. Materia Quirúrgica. 874-A-4, no 351 y 352. 27-Junio-1.799 y 4-Julio-1.799. Madrid. Papel: (1/4), $\mathrm{N}^{\circ}$ de Folios: 20. $\mathrm{N}^{\circ}$ de fascículos: 2. Descriptores: Pedro Irigoyen, Rafael Costa, Antonio de Gimbernat, Real Colegio de Medicina y Cirugía de San Carlos.

\section{SEVERO LÓPEZ, JOSEF (Censura: RIBES, JOSEF)}

Observacion de un enfermo que arrojó de una vez por la boca cantidad considerable de pus fetido, continuo arrojandole por mucho tiempo y se curó felizmente. Materia Quirúrgica. 87-4-A-4, no 353 y 354. 11-Julio-1.799 y 18-Julio-1.799. Madrid. Papel: (1/4). $\mathrm{N}^{\mathrm{o}}$ de Folios: 21. $\mathrm{N}^{\circ}$ de fascículos: 2. Descriptores: Josef Ribes, Josef Severo López.

DE LA PEÑA, EUGENIO (Censura: BONAFÓS, MANUEL)

Observacion sobre una perforación de Yntestino ocasionada por lombrices. Afectos Internos. Materia Quirúrgica. 87-4-A-4, no 356 y 357. 17-0ctubre-1.799 y 24-Octubre1.799. Madrid. Papel: (1/4) . No de Folios: 15 . No de fascículos: 2. Descriptores: Eugenio de la Peña, Manue1 Bonafós.

\section{RODRÍGUEZ DEL PINO, DIEGO (Censura: RIBES, JOSEF)}

Observacion de una especie de hidropesía complicada con un virus venéreo, Afectos Internos. Enfermedades Venéreas. 87-4-A-4, no 358. 5-Diciembre-1 .799 y 12-Diciembre1.799. Madrid , Papel: (1/4). $\mathrm{N}^{\circ}$ de Folios: 4. $\mathrm{N}^{\circ}$ de fascículos: 2. Descriptores: Diego Rodríguez del Pino, Josef Ribes, Madrid, Cádiz, Real Colegio de Cirugía de San Carlos.

\section{COSTA, RAFAEL (Censura: DIEGO RODRÍGUEZ DEL PINO)}

Observacion de un aneurisma falso consecutivo, en la Arteria femoral, curada felizmente por medio de la compresion. Materia Quirúrgica. 87-4-A-4, $\mathrm{n}^{\circ}$ (faltan la Memoria y la Censura). 3-0ctubre-1.799 y 10-0ctubre-1.799. Madrid. Descriptores: Rafael Costa, Diego Rodríguez del Pino.

SEVERO LÓPEZ, JOSEF (Censura: RODRÍGUEZ DEL PINO, DIEGO)

Observación sobre una Enfermedad cronica, entre cuyas varias y enrredosas complicaciones, sobresalió unas y llamó más la atención una Especie de Hidropesía. Afectos Internos. 87-4-A-5, $\mathrm{n}^{\mathrm{o}}$ (faltan la Memoria y la Censura). Madrid. Descriptores: Josef Severo López, Diego Rodríguez del Pino.

COSTA, RAFAEL (Censura: SARAIS, RAMÓN)

Observación sobre una oftalmía. Enfermedades de los ojos. 87-4-A-5, no 359 y 360. 30-Enero-1.800 y 6-Febrero-1.800. Madrid. Papel: (1/4). No de Folios: 6. No de fascícu- 
los: 2. Descriptores: Rafael Costa de Quintana, Ramón Sarais, Juan Verneda, Josef Serra (discípulo de quinto año de San Carlos), Piera, Barcelona, Cataluña. Convento de Trinitarios, Calzados de la Villa de Piera.

DE LA PEÑA, EUGENIO (Censura: BONAFÓS, MANUEL)

Observacion sobre un tumor al lado del cuello. Materia Quirúrgica. 87-4-A-5, no 361 y 362, 13-Febrero-1.800 y 20-Febrero-1.800. Madrid. Papel: (1/4) . $\mathrm{N}^{\mathrm{o}}$ de Folios: 18. $\mathrm{N}^{\mathrm{o}}$ de fascículos: 2. Descriptores: Eugenio de la Peña, Manuel Bonafós, Hospital de San Juan de Dios.

ASO TRAVIESO, SEBASTIÁN (Censura: ABADES, JOSEF)

Observacion sobre unos tumores duros en un pecho. Materia Quirúrgica. Materia Médica. 87-4-A-5, no 363 y 364. 13-Marzo-1 800 y 20-Marzo-1.800, Madrid. Papel: Folio. $\mathrm{N}^{\circ}$ de Folios: 17, $\mathrm{N}^{\mathrm{o}}$ de fascículos: 2. Descriptores: Sebastián Aso Travieso, Josef Abades, Manuel de la Fuente, Antonio de Gimbernat, Rafael Costa, Josef Ribes, Sebastián Loche, Voguel, Hunter, Hillary, Hipócrates, Galeno.

SARAIS, RAMÓN (Censura: COSTA, RAFAEL)

Observacion sobre un reuma complicado. Materia Médica. 87-4-A-5, no 365 y 366. 17-Abril-1.800 y 24-Abri1-1.800. Madrid. Papel: Folio y 1/4. $\mathrm{N}^{\mathrm{o}}$ de Folios: 17. $\mathrm{N}^{\mathrm{o}}$ de fascículos: 2. Desscriptores: Ramón Sarais, Rafael Costa.

NAVARRO, NARCISO (Censura: RIBES, JOSEF)

Sobre la inchazón en la articulación de la rodilla. Enfermedades de los Huesos. 87-4A-5, no 367 y 368. 24-Abril-1.800 y 5-Junio-1.800. Madrid. Papel: (1/4). No de Folios: 5. $\mathrm{N}^{\mathrm{o}}$ de fascículos: 2. Descriptores: Narciso Navarro (Cirujano de Villamalea), Josef Ribes, Cuenca, Villamalea, Obispado de Cuenca.

TORRADO, JOSÉ (Censura: ASO TRAVIESO, SEBASTIÁN)

Ohservacion de un tifus hospitalario complicado con una biliosa. Afectos Internos. 87-4-A-5, no 369 y 370. 23-0ctubre-1. 800 y 30-Octubre-1.800, Madrid. Papel: (1/4). N ${ }^{\circ}$ de Folios: 13. $\mathrm{N}^{\mathrm{o}}$ de fascículos: 2. Descriptores: José Torrado, Sebastián Aso Travieso, Rea1 Colegio de San Carlos, Real Instituto de Medicina Clínica.

GÓMEZ, CELSO (Censura: DE LA PEÑA, EUGENIO)

Observacion de una leucorrea y almorranas. Enfermedades de las Mujeres. Materia Médica. 87-4-A-5, no 371 y 372. 6-Noviemhre-1.800 y 13-Noviembre-1.800. Madrid. Papel: (1/4) . No de Folios: 6. No de fasciculos: 2. Descriptores: Celso Gómez, Eugenio de la Peña, Marrsella de Navias (Asturias), Real Colegio de San Carlos. 


\section{SEVERO LÓPEZ, JOSEF (Censura: SERRANO, JOAQUÍN)}

Consulta sobre un joven que padecia constantemente po1uciones. Enfermedades Venéreas. 87-4-A-5, no 373 y 374. 20-Noviembre-1.800 y 27-Noviembre-1.800. Madrid. Papel: (1/4). No de Folios: 12. No de fascículos: 2. Descriptores: Josef Severo López, Joaquín Serrano, Real Colegio de San Carlos.

\section{DE LA PEÑA, EUGENIO (Censura: RIBES, JOSEF)}

Observacion sobre un cálculo, y complicacion de otros males padecidos por un muchacho de 12 años. Materia Quirúrgica. 87-4-A-5, no 375 y 376. 22-Enero-1.800 y 29Enero-1.800. Madrid. Papel: (1/4). $\mathrm{N}^{\circ}$ de Folios: 9. $\mathrm{N}^{\circ}$ de fascículos; 2. Descriptores: Eugenio de la Peña, Josef Ribes, Juan Nepomuceno Mata, Whitt. Sala de Santa Gertruldis del Hospital General de Madrid, Hospital de San Juan de Dios.

\section{GINER, FRANCISCO (Censura: ABADES, JOSÉ)}

Sobre la curacion de una gota y artritis irregular. Afectos Internos. 87-4-A-5, no 377 y 378. 5-Marzo-1.800 y 12-Marzo-1.800. Madrid. Papel: Folio y 1/4 . No de Folios: no consta. $\mathrm{N}^{\mathrm{o}}$ de fascículos: 3. Descriptores : Francisco Giner, José Abades, Manuel del Pino (Capitán de Ingenieros y Regidor perpetuo de Almería), Joaquín Serrano, Gabriel de Ayesa, Almería, Arma de Ingenieros.

\section{ALONSO DÁVILA, EUSEBIO.}

Observacion de una calentura que se padeció en Valdilecha en mas de 40 niños. Enfermedades de los Niños. 87-4-A-5, no 379 y 380. 5-Febrero-1.800 y 26-Febrero1.800. Madrid. Papel: Folio y 1/4. $\mathrm{N}^{\mathrm{o}}$ de Folios: 10. $\mathrm{N}^{\mathrm{o}}$ de fascículos: 2. Descriptores: Eusebio Alonso Dávila (Cirujano de Valdilecha), Tomás Aranguren (Médico de Peñaley de Tajuña), Casimiro Vellisca (Médico de Campo Real), Josef Severo López, Sebastián Aso Travieso, Valdilecha, Campo Rea1, Peñaley de Tajuña.

\section{ABADES, JOSEF (Censura: ASO TRAVIESO, SEBASTIÁN)}

Observacion sobre un caso venereo. Enfermedades Venéreas. 87-4-A-5, no 381 y 382. 26-Marzo-1.800 y 9-Abri1-1.800. Madrid. Papel: (1/4). № de Folios: 13. ํ de fascículos: 2. Descriptores: José Abades, Sebastián Aso Travieso, Lanfranc, Chiarensi, Portugal, Corte de Portugal.

\section{HERRAINZ, ATHANASIO (Censura: DE LA PEÑA, EUGENIO)}

Observacion de una calentura remitente nerviosa. Afectos Internos, Terapéutica. 874-A-5, no 383 y 384. 15-Abril-1.800 y 23-Abril-1.800. Ribatajada (Cuenca). Papel: Folio y $(1 / 4) . N^{\circ}$ de Folios: $8 . N^{\circ}$ de fascículos: 2. Descriptores: Athanasio Herrainz, Eugenio 
de la Peña, Julián Cornejo, Hipócrates, Platón. Portilla (Cuenca), Ribatajada (Cuenca), Solar de Cabras.

ASO TRAVIESO, SEBASTIÁN (Censura: BONAFÓS, MANUEL)

Observacion sobre dolores reumáticos por la mala administracion del sublimado corrosivo y sostenidos por las pasiones de antro. Afectos Internos. 87-4-A-5, no 385 y 386. 30-Abril-1.800 y 7-Mayo-1.800. Madrid, Papel: (1/4). $\mathrm{N}^{\circ}$ de Folios: 11 . No de fascículos: 2. Descriptores: Sebastián Aso Travieso, Manuel Bonafós, Plenck.

DESCONOCIDO (Censura: COSTA, RAFAEL)

Observacion sobre una herida de la vejiga urinaria hecha por Arma de fuego. Heridas por armas de fuego, 87-4-A-5, $\mathrm{n}^{\mathrm{o}}$ (fa1 ta la Memoria y la Censura). 21-Mayo-1.801 y 28-Mayo-1.801. Madrid. Descriptores: Rafae1 Costa.

DEL VALLE, RAMÓN (Censura: ABADES, JOSEF)

Observacion remitida de fuera sobre un cálculo de la vejiga abscesado. Materia Médica. 87-4-A-5, no 387 y 388. 1l-Junio-1.801 y 17-Junio-1.801. Oviedo. Papel: (1/4). $\mathrm{N}^{\circ}$ de Folios: 6. $\mathrm{N}^{\mathrm{o}}$ de fascículos: 2. Descriptores: Ramón del Valle, Josef Abades, Oviedo, Madrid.

\section{PALAU, PABLO (ASO TRAVIESO, SEBASTIÁN)}

Observacion sobre una idrocardia con su examen crítico. Afectos Internos. 87-4-A-5, no 389 y 390. 8-Octubre-1.801 y 15-Octubre-1.801. Madrid. Papel: (1/4) $\mathrm{N}^{\circ}$ de Folios: 13. $N^{o}$ de fascículos: 2. Descriptores: Tomas Lobato (Sargento de Granaderos voluntarios), Pedro Serrat, Galeno, Pablo Palau, Josef Queraltó, Sebastián Aso Travieso, Monro, Bell, Stork. Cádiz, Badajoz, Granaderos del Ejército.

FERNÁNDEZ, FRANCISCO JAVIER (Censura: BONAFÓS, MANUEL)

Observacion singular de dos heridas contusas en la cabeza, la una penetrante con ofensa de las meninges y salida de la sustancia de1 cerebro. Materia Quirúrgica. 87-4A-5, no 391 y 392, 22-0ctubre-1 .801 y 29-0ctubre-1.801. Casas del Monte. Papel: (1/4). $\mathrm{N}^{\circ}$ de Folios: 10. $\mathrm{N}^{\circ}$ de fascículos: 3. Descriptores: Sebastián Aso Travieso, Antonio de Gimbernat, Antonio Fernández Solano, Miguel Gutiérrez, Lorenzo Delgado, Antonio Rubio (Cirujano de Jarilla), Heister, Josef Garrido, Manuel Bonafós, Francisco Javier Fernández (Cirujano de Casas del Monte), Casas del Monte, Plasencia, Jarilla.

QUINTANA, RUFINO (Censura: COSTA, RAFAEL)

Hidatides arrojadas por la uretra. Materia Quirúrgica, 87-4-A-5, no 393 y 394. 4Noviembre-1.801 y 12-Noviembre-1.801. Madrid. Papel: Folio y 1/4, $N^{o}$ de Folios: 18, 
No de fascículos: 2. Descriptores: Rufino Quintana, Rafael Costa, Madrid, Real Colegio de San Carlos.

CARCELLO, PEDRO (Censura: RIBES, JOSEF)

Observacion del señor D. Pedro Carcelló sobre un caso reumático, con su censura. Materia Médica. 87-4-A-5, no 395 y 396. 9-Noviembre-1.801 y 26-Noviembre-1.801. Madrid. Papel: Folio y 1/4. $\mathrm{N}^{\mathrm{o}}$ de Folios: 8, $\mathrm{N}^{\mathrm{o}}$ de fascículos: 2. Descriptores: Pedro Carcelló, Josef Ribes. Madrid.

ALONSO DÁVILA, EUSEBIO (Censura: RODRÍGUEZ DEL PINO, DIEGO)

Observacion sobre la dis1ocacion de los músculos producida por otras causas. Materia Médica. 87-4-A-5, $\mathrm{n}^{\circ}$ (falta la Memoria y la Censura). Madrid. Descriptores. Eusebio A1onso Dávila, Diego Rodríguez del Pino. Madrid.

MARTOS, ANDRÉS (DE) (Censura: GÁLVEZ Y LLADAS, FERNANDO (DE)

Observacion sobre un vicio venéreo herpético y varias úlceras con caries en la cara y craneo. Enfermedades Venéreas y Materia Quirúrgica. 87-4-A-5, no 397 y 398. 7-Enero1.802 y 14-Enero-1.802. Córdoba. Papel: Folio y 1/4. $\mathrm{N}^{\mathrm{o}}$ de Folios: 10 . $\mathrm{N}^{\circ}$ de fascículos: 3 (Carta de contestación a la consulta). Descriptores: Andrés de Martos, Fernando de Gálvez y Llamas, Pedro Castelló, Matías de Beimva, (Córdoba).

\section{GALLEGO, MANUEL MARÍA (Censura: ASO TRAVIESO, SEBASTIÁN)}

Observacion sobre una hemiplegia. Afectos Internos, 87-4-A-5, $\mathbf{n}^{\mathbf{0}} 399$ y 400. 21Enero-1.802 y 28-Enero-1.802, Quesada. Papel: Folio y 1/4, $\mathrm{N}^{\circ}$ de Folios: 11, $\mathrm{N}^{\circ}$ de fascículos: 2. Descriptores: Juan López Alférez, Manuel María Gallego, Sebastián Aso Travieso, Quesada.

\section{SAN GERMÁN Y BORRELLAS, ADEODATO (DE) (Censura: BONAFÓS, MANUEL)}

Sobre acción de algunos medicamentos específicos. Farmacología. 87-4-A-5, no 401 y 402. 4-Febrero-1802 y 11-Febrero-1802. San Lucas de Barrameda. Papel: (1/4). No de Folios: 20. No de fascículos: 2. Descriptores: Manuel Bonafós, Adeodato de San German y Borrellas, Caridad del Castillo, Hoffman, Carmen Robles, Hércules, San Pablo, Sydenham, San Lucas de Barrameda.

\section{DESCONOCIDO (Censura: DE LA PEÑA, EUGENIO)}

Respuesta a la consulta leída en la Junta de 18 de Febrero de 1802 sobre unas cataratas. Materia Médica. Enfermedades de los ojos. 87-4-A-5, no 403 y 404. 18-Febrero1.802 y 25-Febrero-1 802. Madrid. Papel: (1/4). $\mathrm{N}^{\mathrm{o}}$ de Folios: 16. $\mathrm{N}^{\mathrm{o}}$ de fascículos: 2. Descriptores: Eugenio de la Peña, Madrid, Real Colegio de San Car1os. 
RIBES, JOSEF (Censura: RAFAEL COSTA y TOMÁS TORRES)

Observacion de un bubonocele curado por la operación, con varias ref1exiones. Materia Quirúrgica. 87-4-A-5, no 405 y 406. 4-Marzo-1.802 y 1l-Marzo-1.802. Madrid. Papel: (1/4). No de Folios: 12. $N^{\circ}$ de fascículos: 2. Descriptores: Josef Ribes, Rafael Costa, Tomás Torres, Madrid.

COSTA, RAFAEL (Censura: RIBES, JOSEF)

Observacion sobre una catarata reumática curada por la Farmacia. Enfermedades de los Ojos. 87-4-A-5, no 407 y 408. 18-Marzo-1.802 y 1-Abril-1.802. Madrid. Papel: (1/4). $N^{\circ}$ de folios: 7. $N^{\circ}$ de fascículos: 2. Descriptores: Josef Ribes, Rafael Costa, Vicenta Labajos, Pedro Martínez, Doña Victoria (Oculista). C/ Carretas (Madrid).

DE LA PEÑA, EUGENIO (Censura: RODRÍGUEZ DEL PINO, DIEGO)

Observacion sobre una separación preternatural de la traquea, o sea una dislocacion de esta, curada por vendage adequado, á fin de mantenerla reducida en su sitio natural. Vendajes. 87-4-A-5, no 409 y 410. 8-Abril-1.802 y 22-Abril-1.802. Madrid. Papel: (1/4). $N^{o}$ de Folios: 5. $N^{o}$ de fascículos: 1 (falta la censura). Descriptores: Eugenio de la Peña, Diego Rodríguez del Pino, Pedro Yepes, Andrés de la Cruz, Orden de San Juan de Dios.

\section{LOCHE, SEBASTIÁN (Censura: CASTELLÓ, PEDRO)}

Observacion sobre una sordera antigua procedente de una debilidad del sistema. Enfermedades de los Oídos. Terapéutica. 87-4-A-5, no 411 y 412. 29-Abril-1.802 y 6Mayo-1.802. Madrid. Papel: Folio y 1/4. $\mathrm{N}^{\circ}$ de Folios: 10. $\mathrm{N}^{\mathrm{o}}$ de fascículos: 2. Descriptores: Sebastián Loche, Pedro Caste1ló, Tissot, Dowbez, Savatier, Pelletan, Cullerier, Pinel, Porta1, Haller, Bergmann, Fourcroy, Severo López. París, Caldas y Extona (Cataluña), Hospital de Dios (Hotel Dieu, París), Hospital de La Salpètriere, Escuela de Medicina de París, Real Colegio de Cirugía Médica de San Carlos de Madrid.

BONAFÓS, MANUEL (Censura: ABADES, JOSEF)

Observacion sobre un tumor craniforme en el testiculo curado por cicuta y el mercurio dulce. Afectos Mixtos. Terapéutica. 87-4-A-5, no 413 y 414. 13-Mayo-1.802 y 20Mayo- 1.802. Madrid. Papel: (1/4). $\mathrm{N}^{\circ}$ de Folios: 13. $\mathrm{N}^{\circ}$ de fascículos. 2. Descriptores: Manuel Bonafós, Josef Abades, Hervin, Peyrillre, Storck, Ledrán. Guardias Wallonas.

\section{OLLER, FRANCISCO (Censura: DESCONOCIDO)}

Observacion sobre una extraordinaria talla y disposición de un niño de diez y seis meses que nacio en Puerto Rico. Enfermedades de los Niños. 87-4-A-5, no 415. 3-Junio1.802. Puerto Rico. Papel: Folio y 1/4. $\mathrm{N}^{\mathrm{o}}$ de Folios: 3. $\mathrm{N}^{\mathrm{o}}$ de fascículos: 2 (falta la Censura. 
Hay una Carta de Recepción). Descriptores. Francisco Oller, Pedro Custodio, Josef Abades, Luis Rayffer, Tomás Sedeno, Juan Josef Santo, Alfonsa García Carmelo. Valencia, Loyza (Puerto Rico). Real Hospital Militar de San Juan Bautista en Puerto Rico.

MURCIA, JUAN (Censura: ASO TRAVIESO, SEBASTIÁN)

Afecciones cancerosas curadas con un remedio especifico por el Cirujano Don... Materia Médica. Afectos Mixtos. 87-4-A-5, no 417 y 418. 7-Octubre-1.802 y 14-0ctubre-1.802. Madrid. Papel: Folio y 1/4. $\mathrm{N}^{\circ}$ de Folios: 10. $\mathrm{N}^{\circ}$ de fasciculos: 3 (hay una carta de recepción). Descriptores: Juan Murcia, Sebastián Aso Travieso, Isabel Martín, Josef Ribes, Josef Queraltó, Jacinto Mayzonada, Francisco Nieto y Hoz, Toribia Valladares, Francisco Azañero, Francisco Luma, María Rodríguez, Juan Manuel Agámez, Diego Rodríguez del Pino, Antón Juan, Nicolás Principe, Yllescas, Rioseco, Villalbarba (Zamora), C/ Mesón de Paredes, Belver de los Montes, Real Colegio de Salamanca, Hospital General de Madrid.

\section{RODRÍGUEZ, DOMINGO (Censura: BONAFÓS, MANUEL)}

Observacion sobre unos tumores, supresión menstrual y calentura lenta. Enfermedades de las Mujeres. Terapéutica. 87-4-A-5. no 419 y 420. 21-0ctubre-1.802 y 4Noviembre-1.802. Avila. Papel: Folio y 1/4. $\mathrm{N}^{\circ}$ de Folios: 10. $\mathrm{N}^{\mathrm{o}}$ de fasciculos: 2. Descriptores: Domingo Rodríguez, Manuel Bonafós, María del Carmen González, Hunter, Cruiksauk, Hasoagni, Fourcroy, Carufort. Iglesuela (Ávila) .

\section{TRUXILLO, RAMÓN (Censura: DE LA PEÑA, EUGENIO)}

Sobre una caries venérea y si se hereda el virus venéreo. Enfermedades Venéreas. Terapéutica. 87-4-A-5, no 421 y 422. 11-Noviembre-1.802 y 18-Noviembre-1.802. Madrid. Papel: (1/4). $\mathrm{N}^{\circ}$ de Folios: 22. $\mathrm{N}^{\circ}$ de fascículos: 2. [En la primera página de la Memoria hay, envuelto en papel y pegado a la misma, un fragmento óseo que debió ser de la enferma. Es de forma piramidal. Dimensiones: Base: $1 \mathrm{~cm}$. Altura: $2 \mathrm{~cm}$.] Descriptores: Ramón Truxillo, Eugenio de la Peña, María Lucía Ximénez, Agustín Ginestá, Lorry, Antonio Fernández Solano, Sevilla.

\section{ANÓNIMO (Censura: COSTA DE QUINTANA, RAFAEL)}

Sobre una blenorrea inveterada y retencion de orinas con quartanas. Enfermedades Venéreas. Terapéutica. 87-4-A-5, n⿳ 423 y 424. 25-Noviembre-1.802 y 2-Diciembre1.802, Madrid. Papel: Folio y 1/4. $\mathrm{N}^{\mathrm{o}}$ de Folios: 8. $\mathrm{N}^{\mathrm{o}}$ de fascículos: 2. [Referente a la Memoria es el propio enfermo quien realiza la consulta firmando como D. N.] Descriptores: Rafael Costa Quintana, Píldoras de Edimburgo.

CASTRO, LUIS ANTONIO (DE) (Censura: RIBES, JOSEF)

Sobre una amaurosis al parecer reumática que padece D.... Enfermedades de los Ojos. Terapéutica. 87-4-A-5, no 425 y 426. 9-Diciembre-1.802 y 16-Diciembre-1.802. 
Madrid. Papel: Folio y 1/4. $N^{o}$ de Folios: 5. No de fascículos: 2. Descriptores: Luis Antonio de Castro, Josef Ribes, Mondoñedo (Galicia).

VARELA, JOSEF (Censura: ASO TRAVIESO, SEBASTIÁN)

Sobre una apoplexía en una Mujer embarazada. Obstetricia. Materia Médica. 87-4-A$5, \mathbf{n}^{\circ} 427$ y 428. 13-Enero-1.803 y 27-Enero-1.803. Lugo. Papel: Folio y 1/4. No de Folios: 9. $\mathrm{N}^{\mathrm{o}}$ de fascículos: 2. Descriptores: Josef Varela, Sebastián Aso Travieso, Josefa Bello, Miguel Gutiérrez de Cabiades, San Juan de Camba y Chantada (Lugo).

\section{MURCIA, JUAN (Censura: BONAFÓS, MANUEL)}

Adición al papel presentado por el Cirujano Don Juan Murcia con el título de Afecciones cancerosas curadas con un remedio específico. Materia Médica. 87-4-A-5, $\mathbf{n}^{\mathbf{0}} \mathbf{4 2 9}$ y 430. 10-Febrero-1.803 y 10-Marzo-1.803. Madrld. Papel: Folio y 1/4. N de Folios: 17. $\mathrm{N}^{\mathrm{o}}$ de fascículos: 2 , Descriptores: Juan Murcia, Manuel Bonafós, Josef Piernas, Josef Castillejo, Josef Rivera, Gaspar García, María Bonay, Nicolasa Arias, Plácido López, Gragerio Palacios, Hipócrates, Málaga, C/ Cruz del Espíritu Santo.

\section{ESPARRAGOSA Y GALLARDO, NARCISO (Censura: DE LA PEÑA, EUGENIO)}

Memoria sobre una intervencion facil y sencilla para extraer las criaturas clavadas en el paso sin riesgo de su vida ni ofensa de la madre, y para extraer 1a cabeza que ha quedado en el útero separada del cuerpo. Obstetricia. 87-4-A-5, no 431 y 432. 17Febrero-1.803 y 17-Marzo-1.803. Guatemala. Papel: (1/4). № de Folios: 47. No de fascículos: 2. [La Memoria comienza con un pensamiento inicial de Boerhaave en latín]. Descriptores: Narciso Esparragosa y Gallardo, Eugenio de la Peña, Ignacio Beteta, Lebret, Camper, Portal, Antonio de Gimbernat, Van Switen, Heister, Pastor, Astruc, Boerhaave, Mauriceau, Thouret, Deventer, Joseph Tomás Caseros, Paré. (Hay más nombres de enfermas, médicos, y sacerdotes que las atendieron, etc..., pues refiere el autor hasta nueve observaciones diferentes). Guatemala, Amsterdam, Memorias de la Academia de Cirugía de París, Memorias de la Sociedad Real de Medicina de París, Dictionnaire de Chirurgie et Accouchements, Dictionnaire de Santé.

\section{CALVANSE GARCÍA, JAVIER (Censura: COSTA DE QUINTANA, RAFAEL)}

Sobre la extracción de una piedra de la vegiga orinaria. Materia Quirúrgica. 87-4-A5, no 433 y 434. 30-Septiembre-1 802 y 31-Marzo-1.803. Villa Carrillo (Jaén). Papel: Folio y 1/4. $\mathrm{N}^{\mathrm{o}}$ de Folios: 13. $\mathrm{N}^{\mathrm{o}}$ de fascículos: 5 [Memoria, Censura. Acta Notarial y Correspondencia]. Descriptores: Javier García Calvense, Rafael Costa Quintana, Antonio de Gimbernat, Villacarrillo (Jaén), Real Colegio de Cirugía de San Carlos de Madrid.

CASTELLÓ Y GINESTÁ, PEDRO (Censura: RYBES, JOSEF)

Observacion de una retención de orina. Terapéutica y Afectos Internos. 87-4-A-5, $\mathbf{n}^{\mathbf{0}}$ 435 y 436. 14-Abril-1.803 y 21-Abril-1.803. Madrid. Papel: Folio y 1/4. No de Folios: 9. 
$\mathrm{N}^{\circ}$ de fascículos: 2. Descriptores: Pedro Castelló, Josef Rybes. Real Colegio de Cirugía de San Car1os de Madrid.

ASO TRAVIESO, SEBASTIÁN (Censura: RODRÍGUEZ DEL PINO, DIEGO)

Observacion sobre un absceso en el periné por la presencia de un cálculo en el cuello de la vejiga. Afectos Internos. 87-4-A-5, no 437 y 438. 28-Abril-1.803 y 5-Mayo-1.803. Santa Cruz de la Zarza, Papel: (1/4). No de Folios:6. No de fascículos: 2. Descriptores: Sebastián Aso Travieso, Diego Rodríguez del Pino, Santa Cruz de la Zarza (Madrid), Real Colegio de Cirugía de San Carlos de Madrid.

\section{RODRÍGUEZ DEL PINO, DIEGO (Censura: CASTELLÓ Y GINESTÁ, PEDRO)}

Observacion de una herida penetrante de vientre con salida del Epiplon. Materia Quirúrgica. 87-4-A-5, no 439 y 440. 12-Mayo-1.803 y 26-Mayo-1.803. Madrid. Papel: Folio y 1/4, No de Folios: 5. № de fascículos: 2. Descriptores: Diego Rodríguez del Pino, Pedro Castelló Ginestá, Boerhaave, Chopart, Desault, Savatier.

\section{GINESTÁ, AGUSTÍN (Censura: ABADES, JOSEF)}

Dos observaciones sobre hemorragias reumáticas. Materia Quirúrgica y Terapéutica. 87-4-A-5, no 441 y 442. 2-Junio-1.803 y 16-Junio-1.803, Madrid. Papel: Folio y 1/4. No de Folios: 8, $\mathrm{N}^{\mathrm{o}}$ de fasciculos: 2. Descriptores: Agustín Ginestá, Ramón Sarais, Josef Abades, Madrid, Real Colegio de Cirugía de San Carlos.

\section{MARTÍNEZ, SANTOS (Censura: ASO TRAVIESO, SEBASTIÁN)}

Observacion sobre una úlcera al parecer cancriforme. Materia Médica. Afectos Mixtos. 87-4-A-5, no 443 y 444. Guadalupe. Papel: Folio y 1/4, $\mathrm{N}^{\circ}$ de Folios: 7. $\mathrm{N}^{\circ}$ de fascículos: 2. Descriptores: Santos Martínez, Sebastián Aso Travieso, Domingo Pérez, Real Monasterio y Hospitales de Santa María de Guadalupe.

\section{RIBES, JOSEF (Censura: BONAFÓS, MANUEL)}

Observacion sobre un aneurisma verdadero en la arteria crural, curado por compresión. Materia Quirúrgica. 87-4-A-5, no 445 y 446. 6-0ctvbre-1.803 y 13-Octubre1.803. Madrid. Pape1: (1/4). $\mathrm{N}^{\circ}$ de Folios: 10. $\mathrm{N}^{\circ}$ de fascículos: 2. Descriptores: Josef Ribes, Manuel Bonafós, Boerhaave, Celso, Carlos Guattani, Madrid, Real Colegio de Cirugía de San Carlos, Real Academia de Cirugía de París.

\section{SANTIAGO, JOAQUÍN (Censura: DE LA PEÑA, EUGENIO)}

Sobre una Convulsion tónica. Afectos Internos. 87-4-A-5, no 447 y 448. 20-0ctubre1.803 y $27-O c t u b r e-1.803$. Barranco de Joqueyra, Papel: folio y 1/4. $\mathrm{N}^{\circ}$ de Folios: $7 . \mathrm{N}^{\circ}$ de fascículos: 2. Descriptores: Joaquín de Santiago, Eugenio de la Peña, Barranco de Joqueyra (Granada?), Colegio de Cirugía de San Carlos de Madrid. 
GINESTÁ, AGUSTÍN (Censura: COSTA, RAFAEL)

Observación sobre una fractura de la porcion superior del calcáneo. Enfermedades de los Huesos. Terapéutica. 87-4-A-5, no 449 y 450. 3-Noviembre-1.803 y 10-Noviembre1.803, Madrid, Papel: Folio y 1/4. No de Folios: 5. No de fascículos: 2. Descriptores: Agustín Ginestá, Rafael Costa.

\section{QUINTANA, RUFINO (Censura: RIBES, JOSEF)}

Observacion acerca de una Señora que tuvo una retención de orina y á pocos días echo un animal de tres pulgadas de largo. Afectos Mixtos. 87-4-A-5, n⿳0 451 y 452. 17 Noviembre-1.803 y 24-Noviembre-1.803. Medina de Pomar. Papel: (1/4), $\mathrm{N}^{\circ}$ de Folios: 6. $\mathrm{N}^{\circ}$ de fascículos: 1. [Falta la Censura y se adjuntan dos cartas. En una de ellas se hace la descripción del parásito]. Descriptores: Rufino Quintana, Josef Ríbes, Sebastián Aso Travieso, Medina de Pomar, Convento de Santa Clara.

\section{ANDRÉS, GABRIEL}

Observacion sobre unos carbuncos al parecer malignos mas correspondencia. Afectos Internos. 87-4-A-5, $\mathbf{n}^{\mathbf{0}}$ 453. 15-Diciembre-1.803. Mavanchón. Papel: Folio y 1/4, $\mathrm{N}^{\mathrm{o}}$ de Folios: 5. $\mathrm{N}^{\circ}$ de fascículos: 2 (Memoria y Correspondencia). Descriptores: Gabriel Andrés, Diego Rodríguez del Pino, Heister, Ledran, Fernández, Costa. Mavanchón. Real Colegio de Cirugía de San Carlos de Madrid.

\section{COSTA, RAFAEL (Censura: CASTELLÓ Y GINESTÁ, PEDRO)}

Observacion sobre un Carbunco con malignidad. Afectos Mixtos. Terapéutica. 87-4-A5, n⿳ 454 y 455. 5-Enero-1.804 12-Enero-1.804. Madrid, Papel: Folio y 1/4 . No de Folios: 7. $\mathrm{N}^{\circ}$ de fasciculos: 2. Descriptores: Rafael Costa, Pedro Castelló, Manuel Rodríguez.

\section{FERNÁNDEZ ARELLANO, DIEGO (Censura: ASO TRAVIESO, SEBASTIÁN)}

Observacion sobre una herida del hombro complicada con dislocacion del húmero por la mordedura de un gato. Materia Quirúrgica, Algebra Quirúrgica. 87-4-A-5, no 456 y 457. 19-Enero-1.804 y 26-Enero-1.804. Logroño, Papel: Folio y 1/4, $\mathrm{N}^{\circ}$ de Folios: $10 . \mathrm{N}^{\circ}$ de fascículos: 3 (se adjunta la carta de respuesta por el Secretario del Colegio). Descriptores: Diego Fernández Arellano, Sebastián Aso Travieso, Hipócrates. Logroño, Amberes.

\section{DE LA PEÑA, EUGENIO (Censura: BONAFÓS, MANUEL)}

Observacion sobre un tumor enquistado en los interiores de la boca correspondiente al ángulo de la mandíbula en el lado izquierdo. Materia Quirúrgica. 87-4-A-5, no 458 y 459. 9-Febrero-1.804 y 16- Febrero-1.804. Madrid. Papel: (1/4). $\mathrm{N}^{\mathrm{o}}$ de Folios: $11 . \mathrm{N}^{\mathrm{o}} \mathrm{de}$ fascículos: 2. Descriptores: Eugenio de la Peña, Manuel Bonafós. 


\section{JOAQUÍN SANTIAGO, JOSEF (Censura: DE LA PEÑA, EUGENIO)}

Continuacion de la observacion acerca de una Convulsion tónica o Epilepsia histérica. Afectos Internos. 87-4-A-5, no 460 bis y 461 bis. 23-Febrero-1.8O4 y 2-Marzo-1.804. Capileyra del Barranco (Granada). Papel: Folio y 1/4. $\mathrm{N}^{\circ}$ de Folios: $6 . \mathrm{N}^{\circ}$ de fascicu1os: 2. Descriptores: Josef Joaquín Santiago, Eugenio de la Peña, Capileyra del Barranco.

\section{JOAQUÍN SANTIAGO, JOSEF (Censura: CASTELLÓ Y GINESTÁ, PEDRO)}

Observacion acerca de un monstruo. Obstetricia. Enfermedades de los Niños. 87-4-A5, no 460 y 461. 8-Marzo-1.804 y 15-Marzo-1.804. Yllara (Granada). Papel: Folio y 1/4. $\mathrm{N}^{\mathrm{o}}$ de Folios: 5. $\mathrm{N}^{\mathrm{o}}$ de fascículos: 2. Descriptores: Josef Joaquín Santiago, Pedro Castelló y Ginestá, Eugenio de la Peña, Josef Abades, Paré, Haller, Steglio, Barchino, Liato, Ulises, Schencheio, María Vázquez, Juan Vicente Moratalla, Juan Cifuentes, Memorias de la Academia de París, Yllora y Barranco de Pogueira (Granada).

\section{GUZMÁN Y SÁNCHEZ, EUGENIO (DE) (Censura: RIBES, JOSEF)}

Noticia histórica y método curativo de un Polipo uterino manifestado en la Villa de Talavera en Diciembre de 1803. Enfermedades de las Mujeres. 87-4-A-5, no 462 y 463, 22-Marzo-1.804 y 5-Abril-1.804. Talavera de la Reina. Papel: Folio y 1/4. $\mathrm{N}^{\circ}$ de Folios: 11. $\mathrm{N}^{\circ}$ de fascículos: 3. [Carta de recepción de la Junta Superior Gubernativa]. Descriptores: Eugenio de Guzmán y Sánchez, Josef Ribes, Antonio de Gimbernat, Ignacio Lacaba, Levret, María Orzel, Francisco Ri, Alberto García, Domingo de Miralpeis, Talavera de la Reina. Junta Superior Gubernativa de los Colegios de Cirugía.

\section{BONAFÓS, MANUEL (Censura: RODRÍGUEZ DEL PINO, DIEGO)}

Observacion sobre la Danza de San Vito. Afectos Internos. Terapéutica. 87-4-A-5, no 464 y 465. 12-Abril-1.804 y 19-Abril-1.804. Madrid. Papel: (1/4). $\mathrm{N}^{\circ}$ de Folios: $6 . \mathrm{N}^{\circ}$ de fascículos: 1. (falta la Censura). Descriptores: Manuel Bonafós, Diego Rodríguez del Pino, Tissot.

\section{GÓMEZ, CELSO (Censura: ASO TRAVIESO, SEBASTIÁN)}

Observacion sobre una herida de arma de fuego penetrante en el pecho con ofensa del pulmón. Heridas por Arma de Fuego. 87-4-A-5, no 466 y 467. 26-Abril-1.804 y 17Mayo-1.804. Rivadesella. Papel: Folio y 1/4. $\mathrm{N}^{\circ}$ de Folios: 12. $\mathrm{N}^{\circ} \mathrm{d}$ e fascículos: 4. [la Memoria está duplicada. Se adjunta un acta notarial, una carta de presentación y otra de agradecimiento] . Descriptores: Celso Gómez, Sebastián Aso Travieso, Mateo de la Texa González, Francisco Prieto González, Miguel Comas, Josef Queraltó, Richter. Valle del Pas, Berbes, Rivadesella, Asturias. Memorias de la Real Academia de París. 
DESCONOCIDO (Censura: BONAFÓS, MANUEL)

Consulta acerca de un sugeto que padece varios productos venéreos. Enfermedades Venéreas. 87-4-A-5, no 468 y 469. 24-Mayo-1.804 y 7-Junio-1.804. Madrid. Papel: (1/4). $\mathrm{N}^{\mathrm{o}}$ de Folios: 9 . $\mathrm{N}^{\mathrm{o}}$ de fascículos: 2. Descriptores: Manuel Bonafós.

ANDRÉS, GABRIEL (Censura: DE LA PEÑA, EUGENIO)

Continuación a la historia de los Carbuncos malignos. Afectos Internos. 87-4-A-5, n⿳ 470 y 471. 14-Junio-1.804 y 21-Junio-1.804. Maranchón. Papel: Folio y 1/4. No de Folios: 6. $\mathrm{N}^{\mathrm{o}}$ de fascículos: 2. Descriptores: Gabriel Andrés, Eugenio de la Peña. Maranchón, Gran Bretaña.

SAIZ RAMOS, GERÓNIMO (Censura: COSTA, RAFAEL)

Consulta de un tumor Sairroso, hecha por Don...; cuya paciente es Doña Urbana SÁez y Pedrero. Enfermedades de Mujeres, 87-4-A-5, no 472 y 473. 4-0ctubre-1.804 y 11-0ctubre-1.804. Pedromuñoz. Papel: (1/4). No de Folios: 7. N$^{\mathrm{o}}$ de fascPiculos: 3 [Carta de contestación]. Descriptores: Gerónimo Saiz Ramos, Rafael Costa, Urbana Sáez Pedrero, Pedromuñoz.

\section{MARTÍNEZ, SANTOS (Censura: RIBES, JOSEF)}

Consulta acerca de una hemicranea sostenida por un vicio reumático crónico. Afectos Internos. Materia Médica. 87-4-A-5, no 474 y 475. 18-Octubre-1.804 y 25-Octubre1.804. Guadalupe. Papel: Folio y 1/4 . No de Folios: 5. $\mathrm{N}^{\mathrm{o}}$ de fascículos: 3 [Se adjunta carta de contestación al autor]. Descriptores: Santos Martínez, Josef Ribes, Bartolomé Cortijo, Guadalupe, Real Colegio de San Carlos, Hospital de Guadalupe.

\section{DÍAZ DE GUEREÑA, PEDRO (Censura: DE LA PEÑA, EUGENIO)}

Consulta sobre una manía melancólica. Afectos Internos. 87-4-A-5, no 476 y 477. 9Noviembre-1.804 y Z2-Noviembre-1.804. Madrid. Papel: Folio y 1/4. No de Folios: 9. $\mathrm{N}^{\circ}$ de fascículos: 2. Descriptores: Pedro Díaz de Guereña, Eugenio de la Peña, Pinel, Josefa Ortiz, Samaniego, Quevedo, Cervantes.

TOVAR, JULIÁN (Censura: BONAFÓS, MANUEL)

Observacion de una herida por el hasta de un buey desde el periné hasta el hipocondrio derecho. Materia Quirúrgica. Terapéutica. 87-4-A-5, no 478 y 479. 29-Noviembre1.804 y 6-Diciembre-1.804. Madrid. Papel: Folio y 1/4. $\mathrm{N}^{\circ}$ de Folios: 14. $\mathrm{N}^{\circ}$ de fascículos: 4 [Se adjuntan cartas entre el autor y Sebastián Aso Travieso]. Descriptores: Julián Tovar, Manuel Bonafós, Sebastián Aso Travieso, Ventura Pérez, Lorenzo Carbayeda, Cayetano Nicolás, Boerhaave, Louis, Santa Clara (León), Mansilla de las Mulas (León), Valdibieco (León), Monasterio Benedictino de San Pedro de Eslonza (León). 
QUINTANA RUFINO (Censura: COSTA, RAFAEL)

Observacion sobre unas membranas arrojadas por la uretra que se creyeron hydatides. Afectos Mixtos. 87-4-A-5, no 480 y 481. 4-Diciembre-1.804 y 13-Diciembre-1.804. Medina de Pomar. Papel: Folio y 1/4. $\mathrm{N}^{\mathrm{o}}$ de Folios: 5. $\mathrm{N}^{\mathrm{o}}$ de fascículos: 2. Descriptores: Rufino Quintana, Rafael Costa, Sebastián Aso Travieso, Medina de Pomar, Río Trueba.

\section{QUINTANA RUFINO}

Ilustracion á la observacion sobre unas membranas arrojadas por la uretra, que se creyeron hydatides. Afectos Mixtos. Terapéutica. 87-4-A-5, $\mathbf{n}^{\mathbf{0}}$ 482. Medina de Pomar. Papel: Folio. $N^{\circ}$ de Folios: 5. $N^{\circ}$ de fascículos: 2 [Falta la censura]. Descriptores: Rufino Quintana, Sydenham, Medina de Pomar.

\section{ASO TRAVIESO, SEBASTIÁN (Censura: CASTELLÓ Y GINESTÁ, PEDRO)}

Observacion sobre una Caries en el dedo indice de la mano derecha, sostenida por vicio escrofuloso. Enfermedades de los Huesos. 87-4-A-6, no 483 y 484. 3-Enero-1.805 y 10-Enero-1.805. Madrid. Papel: Folio y 1/4. No de Folios: 7. $N^{\circ}$ de fascículos: 2. Descriptores: Sebastián Asó Travieso, Pedro Castelló y Ginestá, Joaquín Delgado, Arganda del Rey.

\section{LOCHE, SEBASTIÁN (Censura: ASO TRAVIESO, SEBASTIÁN)}

Observacion sobre una fiebre biliosa que se presentó con apariencia de pútrida. Afectos Internos. 87-4-A-6, $\mathbf{n}^{\mathbf{0}}$ 485. 17-Enero-1.805 y 24-Enero-1.805. Madrid. Papel: (1/4). $\mathrm{N}^{\circ}$ de Folios: 11. $N^{\circ}$ de Fascículos: 1 [Falta la Memoria]. Descriptores: Sebastián Loche, Sebastián Asó Travieso, Hipócrates, Walerio, Roederer, Yaglen, Paracelso, Tagalla, Gotinga.

\section{CAMIÑA, JUAN}

Tabla sinoptica ó abreviada de los Músculos del Hombre según la Clasificacion y Nomenclatura metodica del Profesor Chaussier, traducida al Castellano por el Licenciado Don... Anatomía. 87-4-A-6, no 486. S.f. Madrid. Papel: (1/4). N de Folios: 25. $\mathrm{N}^{\circ}$ de fascículos: 1 [Hay una carta remitiendo el ejemplar al Colegio con fecha de 25Enero-1.805]. Descriptores: Juan Camiña, Chaussier, Portal, Míson, Descartes, Leibniz, Galileo, Newton, Locke, Linneo, Rousseau, Condillac, Pinel, Dumas, Bichat, Fourcroy, Morgagni, Winslow, Lacaba, Galeno.

\section{DE LA FUENTE, MANUEL (Censura: RIBES, JOSEF)}

Consulta sobre una úlcera inveterada y sanguinolenta situada en el coxis y en el Sacro. Materia Quirúrgica. 87-4-A-6, no 487 y 488. 3-Enero-1.805 y 7-Febrero-1.805. Tafalla. Papel: (1/4). $N^{o}$ de Folios. 12. $\mathrm{N}^{\mathrm{o}}$ de fascículos. 2. Descriptores: Manuel de la Fuente, Josef Ribes, Tafalla, Madrid, Real Colegio de Cirugía de San Car1os. 
LÓPEZ, PEDRO (Censura: COSTA, RAFAEL)

Consulta sobre unos cólicos reumáticos. Afectos Internos. 87-4-A-6. no 489 y 490 . 14Febrero-1.805 y 21-Febrero-1.805. Bocigas (¿Lugo?). Papel: Folio y 1/4, $\mathrm{N}^{\mathrm{o}}$ de Folios: 13. $\mathrm{N}^{\mathrm{o}}$ de fascículos: 5 [Memoria, Censura, Consulta, Dictamen y Correspondencia]. Descriptores: Pedro López, Rafael Costa, Rafael Benavente. Bocigas, Madrid. Obispado de Lugo. Real Colegio de Cirugía de San Carlos.

DE LA FUENTE, MANUEL (Censura: DE LA PEÑA, EUGENIO)

Observacion sobre la curacion del mal Vertebra1 de Pott ó Pará1isis de los Antiguos por el Licenciado Don Manuel de la Fuente Cirujano de estuche de la ciudad de Tafalla. Enfermedades de los Huesos. 87-4-A-6, no 491 y 492. 7-Marzo-1.805 y 14Marzo-1.805. Tafalla. Papel: (1/4). No de Folios. 9. $\mathrm{N}^{\mathrm{o}}$ de fascículos: 1 [Falta la Censura]. Descriptores: Manuel de la Fuente, Eugenio de la Peña, Bernardo Sagües, Pott, Josef Ribes, Rafael Costa, Sebastián Aso Travieso, Tafalla, Sala de San Tadeo.

\section{CASTELLÓ Y GINESTÁ, PEDRO}

RODRÍGUEZ DEL PINO, DIEGO

Observacion sobre una curacion de un hidrocele por observacion a beneficio del Mercurio. Afectos Mixtos. Terapéutica. 87-4-A-6, no 493 y 494. 27-Marzo-1.805 y 28Marzo-1.805. Madrid. Papel: Folio. $\mathrm{N}^{\mathrm{o}}$ de Folios: 2. $\mathrm{N}^{\mathrm{o}}$ de fascículos: 1 [Falta la Censura]. Descriptores: Pedro Castelló y Ginestá, Diego Rodríguez del Pino, Madrid, Real Colegio de Cirugía de San Carlos.

\section{(Censura: ABADES, JOSEF.)}

Observacion sobre un tumor en la región Lumbar. Afectos Internos. 87-4-A-6, S.nº 3-0ctubre-1.805 y 10-0ctubre-1.805. Barce1ona. [Faltan Memoria y Censura]. Descriptores: Josef Abades, Sebastián Loche, Madrid, Real Colegio de Cirugía de San Carlos.

COSTA DE QUINTANA, RAFAEL

BONAFÓS, MANUEL

DE LA PEÑA, EUGENIO

RIBES, JOSEF

Censuras de las observaciones del suplemento del hospital de la Isla de Menorca. Materia Quirúrgica. 87-4-A-6, no 495, 496, 497, 498 y 499. 22-Abril-1.805 y 27-Junio1.805. Madrid. Papel: (1/4). $\mathrm{N}^{\circ}$ de Folios: 30. $\mathrm{N}^{\circ}$ de fascículos: 5. Descriptores: Rafael Costa de Quintana, Manuel Bonafós, Eugenio de la Peña, Josef Ribes, Mahón (Menorca), Madrid, Real Colegio de Cirugía de San Carlos, Hospital de la Isla. 


\title{
TREVILLA, PEDRO (DE) (Censura: CASTELLÓ Y GINESTÁ, PEDRO)
}

Observacion sobre un feto supurado extraido en fragmento por medio de la operación cesárea a 1os 14 meses de una concepcion, con remision de un fragmento con los [*]. Materia Quirúrgica. 87-4-A-6, no 500 y 501. 17-0ctubre-1.805 y 24-0ctubre-1.805. Castrourdiales. Papel: (1/4) $\mathrm{N}^{\mathrm{o}}$ de Folios: 14. $\mathrm{N}^{\circ}$ de fascículos: 3 [Se adjunta certificado de intervención complementaria]. Descriptores: Pedro de Trevilla, Pedro Castelló y Ginestá, Ramona Severino, Barcelona, Madrid, Castrourdiales, Hospital de San Carlos [* Palabra ilegible].

\section{SUCRAMPES, RAMÓN JUAN (Censura: ABADES, JOSEF)}

Relacion que hace el muy R.P. Christoval Muñoz de la Orden de San Francisco, de la curación de una Perlesía de las extremidades superiores causada por la hinchazon de la última vertebra dorsal y primera Lombar. Enfermedades de los Huesos. 87-4-A6, no 502 y 503. 31-0ctubre-1.805 y 7-Noviembre-1.805. Marchena (Málaga). Papel: Folio y 1/4. $\mathrm{N}^{\mathrm{o}}$ de Folios: 17. $\mathrm{N}^{\mathrm{o}}$ de fascículos: 2. Descriptores. C. Muñoz, Juan Ramón Sucrampes, Josef Abades, Pott, Pouteau, Bichat, Marchena (Málaga), Diario de Medicina de París, Memorias de la Sociedad de Medicina de París.

\section{AIXÓN, JUAN JOSÉ (Censura: RIBES, JOSEF)}

Descripcion de un pequeño feto que tenia sus partes genitales en el ombligo. Enfermedades de los Niños. 87-4-A-6, no 504. 14-Noviembre-1.805. Puerto Rico. Papel: Folio y 1/4. $\mathrm{N}^{\mathrm{o}}$ de Folios: 3. $\mathrm{N}^{\mathrm{o}}$ de fascículos: 2. Descriptores: Juan José Aixón, Josef Ribes, Juan de la Cuerda, Juan Alexo Arismendi, Puerto Rico, Madrid, Real Colegio de Cirugía de San Carlos, Academia de Medicina.

\author{
SAMPERE, CASIMIRO \\ CEBRIÁN, JAIME \\ ASO TRAVIESO, SEBASTIÁN
}

Observacion sobre una úlcera canceriforme en las partes genitales de una mujer. Enfermedades de Mujeres. Afectos Internos. 87-4-A-6, no 505, 506 y 507. 22Noviembre-1.805 y 28-Noviembre-1.805. Lovaa (Murcia). Papel: Folio y 1/4. № de Folios: 14. $\mathrm{N}^{\mathrm{o}}$ de fascículos: 3 [Memoria, Anexo y Censura]. Descriptores: Casimiro Sampere, Jaime Cebrián, Sebastián Aso Travieso, Lovaa (Murcia), Madrid, Real Colegio de Cirugía de San Carlos.

\section{ANÓNIMO (Censura: ABADES, JOSEF)}

Observacion sobre un tumor enquistado en la porcion lateral del cuello. Materia Quirúrgica, 87-4-A-6, no 508 y 509. 5-Diciembre-1.805 y 12-Diciembre-1.805. Madrid. Papel: Folio y1/4, $\mathrm{N}^{\circ}$ de Folios: 14. $\mathrm{N}^{\circ}$ de fascículos: 2. Descriptores: Josef Abades, Madrid. 
VENTURA GÓMEZ, JOSEF (Censura: COSTA DE QUINTANA, RAFAEL)

Observacion sobre un pedazo de lápiz tragado en la Tráquea y arrojado por la Naturaleza al cabo de 8 años. Materia Quirúrgica, 87-4-A-6, no 510 y 511. 2-Enero-1.805 y 9-Enero-1.805. Rascafría. Papel: Folio y 1/4. $\mathrm{N}^{\circ}$ de Folios: 4. $\mathrm{N}^{\circ}$ de fascículos: 2. Descriptores: Josef Ventura Gómez, Rafael Costa de Quintana, Madrid, Rascafría, Rea1 Colegio de Cirugía de San Carlos.

\section{BLANCO CASARIECO, CAYETANO (Censura: BONAFÓS, MANUEL)}

Consulta Sobre una Amaurosis remitida por Don Cayetano Blanco Casarieco. Afectos Internos. Enfermedades de los Ojos. 87-4-A-6, no 512 y 513. 16-Enero-1.805 y 30-Enero1.805, Luarca. Papel: $1 / 4$ y 1/8. $\mathrm{N}^{\circ}$ de Folios: $6 . \mathrm{N}^{\circ}$ de fascículos: 2. Descriptores: Cayetano Blanco Casarieco, Manuel Bonafós, Richter, Antonio Quintana, Madrid, Luarca.

MONTENEGRO, JULIÁN; FERNÁNDEZ Y RAMOS, PABLO (Censura: DE LA PENA, EUGENIO)

Observacion sobre un Sarampion complicado de Tabardillo y sobre un efecto convulsivo. Enfermedades de los Niños. Afectos Internos. 87-4-A-6, no 514, 515 y 516. 6Febrero-1.805 y 13-Febrero-1.805. Burgos. Papel: (1/4). $\mathrm{N}^{\circ}$ de Folios: 7. $\mathrm{N}^{\circ}$ de fascículos: 3. Descriptores: Josef Montenegro, Pablo Fernández y Ramos, Eugenio de la Peña, Quintanilla del Monte (Santo Domingo de la Calzada), Balluercanes, Estragiz,

\section{VILA, JOSEF (Censura: DE LA PEÑA, EUGENIO)}

Disertacion sobre la regeneracion de las carnes. Afectos Internos. 87-4-A-6, $\mathbf{n}^{\mathbf{0}} 517 \mathbf{y}$ 518. 20-Febrero-1.806 y 27-Febrero-1.806, Madrid. Papel: (1/4). $\mathrm{N}^{\circ}$ de Folios: $14 \mathrm{~N}^{\circ}$ de fascículos: 2. Descriptores: Leonardo de Calleja, Ignacio Lacaba, Pedro Vidart, Antonio de Gimbernat, Josef Vila, Eugenio de la Peña, Chirot, Fabre, Luis Wyntte, Madrid, Memorias de la Sociedad de Edimburgo.

\section{LLUND, RAMÓN (Censura: ASO TRAVIESO, SEBASTIÁN)}

Dos observaciones de tumores escirrosos curados por la potasa administrada interior y exteriomente. Afectos Internos. Terapéutica. 87-4-A-6, no 518 y 519, 10-Abril-1.806 y 17-Abril-1.806, Madrid. Papel: Folio y 1/4. No de Folios: 14. $\mathrm{N}^{\circ}$ de fascículos: 2. Descriptores: Ramón L1und, Sebastián Aso Travieso, Hipócrates, Hunter, Storck, Theden, Pedro Castelló, Le Fevre, Goock, Jaenich, Pouteau, Madrid, Real Colegio de Cirugía de San Carlos, Volúmenes de los Comentarios de Medicina de Edimburgo.

GALLEGO, MIGUEL

Menstruación difici1. Enfermedades de las Mujeres. 87-4-A-6, n⿳0 520, 23-Abril-1.806. Madrid. Papel: 1/8. $\mathrm{N}^{\mathrm{o}}$ de Folios: 2. $\mathrm{N}^{\mathrm{o}}$ de fascículos: 2. Descriptores: Miguel Gallego, Madrid. 
TUSLÁN, JOSEF MARÍA (Censura: JOSEF RIBES)

Observacion dirigida por Josef María Tuslan. 87-4-A-6, n⿳0 521, 27-Marzo-1.806 y 24Abril-1.806. Papel: 1/8. $\mathrm{N}^{\mathrm{o}}$ de Folios: 8. $\mathrm{N}^{\mathrm{o}}$ de fascículos: 1. [Falta la Memoria]. Descriptores: Josef María Tuslán, Josef Ribes, Madrid, Real Colegio de Zapadores.

RODRÍGUEZ, MAHUEL (Censura: LOCHE, SEBASTIÁN)

Memorias Clínicas û observaciones y reflexiones acerca de las gibosidades cariosas de las vértebras, y de las corbaduras espinales, que se dirige al cuerpo de Cirugía militar su individuo el Dr. Don ... Enfermedades de los Huesos. 87-4-A-6, n⿳ 522. 20ctubre-1.806. Mahón (Menorca ). Papel: (1/4). $\mathrm{N}^{\mathrm{o}}$ de Folios: 34. $\mathrm{N}^{\mathrm{o}}$ de fascículos: 3 [Falta la Memoria. Se adjuntan dos cartas]. Descriptores: Manuel Rodríguez, Sebastián Loche, Pott, Pouteau, Portal, Josef Queraltó, Josef Ribes, Josef Sancho, Mahón (Menorca), Inglaterra, Francia. Hospital Militar de Mahón. Hospital de San Bartolomé.

\section{GONZÁLEZ GARRIDO, AGUSTÍN (Censura: CASTELLÓ Y GINESTÁ, PEDRO)}

Consulta sobre enferma aquejada de hidropesia orienytal. Afectos Internos. 87-4-A6, no 523 y 524. 9-Octubre-1.806 y 16-Octubre-1.806. Madrid. Papel: (1/4 y 1/8). Descriptores: Agustín González Garrido, Pedro Castelló y Ginestá, María Marina Francia, Carlos Nolvé, Francisco Artiga, Madrid.

\section{GUZMÁN Y SÁNCHEZ, EUSEBIO (DE) (Censura: ASO TRAVIESO, SEBASTIÁN)}

Observación sobre un absceso urinario. Materia Quirúrgica. 87-4-A-6, no 525 y 526. 23-Octubre-1.806 y 30-Octubre-1.806, Madrid. Papel: $1 / 4$ y 1/8. $\mathrm{N}^{\mathrm{o}}$ de Folios: 24 . $\mathrm{N}^{\mathrm{o}}$ de fascículos: 2. Descriptores: Eusebio de Guzmán y Sánchez, Sebastián Aso Travieso. Talavera de la Reina, Madrid.

\section{GONZÁLEZ GARRIDO, AGUSTÍN (Censura: DE LA PEÑA, EUGENIO)}

Observacion sobre una apoplejia sanguinea . Afectos Internos. 87-4-A-6, no 527 y 528. 20-Noviembre-1.806 y 27-Noviembre-1.806. Villafranca del Bierzo. Pape1: (1/8). $\mathrm{N}^{\mathrm{o}}$ de Folios: 10. $\mathrm{N}^{\mathrm{o}}$ de fascículos: 2. Descriptores: Agustín González Garrido, Eugenio de la Peña, Diego Muñoz Forrero, Josef Amigo, Villafranca del Bierzo, Madrid.

\section{HERNÁNDEZ, AGUSTÍN}

Consulta sobre una exención del Servicio militar. Afectos Internos. 87-4-A-6, no 529. 4-Noviembre-1.806. Toro. Papel: Folio y 1/4. $\mathrm{N}^{\mathrm{o}}$ de Folios: 2 . $\mathrm{N}^{\mathrm{o}}$ de fascículos: 2 [Falta la censura. Hay una carta]. Descriptores: Agustín Hernández, Toro.

RIBES, JOSEF (Censura: GINESTÁ, AGUSTÍN)

Observacion sobre una fractura de la tibia reunida por medio de rozaduras hechas en las superficies del hueso quebrado. Enfermedades de los Huesos, 87-4-A-6, no 529 
bis. 18-Diciembre-1.806 y 8-Enero-1.807. Madrid. Papel: Folio. $\mathrm{N}^{\circ}$ de Folios: 7. $\mathrm{N}^{\mathrm{o}}$ de fascículos: 1 [Falta la Memoria]. Descriptores: Josef Ribes, Agustín Ginestá, Pott, Hunter, Esculapio, Acuña, López de León, Fabricio Hildano, Dietrich, Guteken, Fragoso, Celso, Hipócrates, Barcelona.

MARÍN, ILDEFONSO (Censura: ABADES, JOSEF)

Observacion de varias heridas en un soldado. Materia Quirúrgica. 87-4-A-6. 7Octubre-1.806 y 9-Diciembre-1.806. Madrid. $\mathrm{N}^{\circ}$ de Folios: $4 . \mathrm{N}^{\mathrm{o}}$ de fascículos: 1 [Faltan la Memoria y la Censura. Se adjuntan cartas remitidas al Colegio]. Descriptores: Ildefonso Marín, Diego Rodríguez del Pino, Josef Abades, San Ildefonso, Madrid, Regimiento de la Reina.

\section{MARTÍNEZ, JOSEF (Censura: RIBES, JOSEF)}

Observacion sobre vacuna. Afectos Internos. 87-4-A-6, no 530 y 531. 5-Enero-1.807 y 22-Enero-1.807, Madrid. $\mathrm{N}^{\circ}$ de Folios: 4. $\mathrm{N}^{\circ}$ de fascículos: 2. Descriptores: Josef Martínez, Josef Ribes, Madrid.

COSTA, RAFAEL (Censura: CASTELLÓ, PEDRO)

Observacion sobre un tumor en la parte superior del pecho izquierdo extirpado y curado por primera intención. Materia Quirúrgica. 87-4-A-6, no 532 y 533. 29-Enero1.807 y 5-Febrero-1.807. Madrid. Papel: Folio y 1/4. $\mathrm{N}^{\circ}$ de Folios: 4 . $\mathrm{N}^{\mathrm{o}}$ de fascículos: 2. Descriptores: Rafael Costa Quintana, Pedro Castelló y Ginestá, Richter, Antonio Paré, Pedro Verdupi, Valeriana Segoviano, Vicálvaro.

DE LA PEÑA, EUGENIO (Censura: LOCHE, SEBASTIÁN)

Observacion sobre una convulsion general que sobrevino a la hermana de Eugenio de la Peña de resultas de un Parto. Obstetricia. 87-4-A-6, no 534 y 535. 12-Febrero1.807 y 19-Febrero-1.807. Madrid. Papel: (1/4). No de Folios: 19. $\mathrm{N}^{\mathrm{o}}$ de fascículos: 2. Descriptores: Eugenio de la Peña, Sebastián Loche, Pedro Castelló, Rafael Costa.

BONAFÓS, MANUEL (Censura: CASTELLÓ, PEDRO)

Observacion acerca de un parto en que el feto presentaba un brazo ya amoratado y de un volumen enorme, que se terminó natura1mente. Obstetricia. 87-4-A-6, n⿳0 536 y 537. 26-Febrero-1.807 y 6-Marzo-1.807. Madrid. Papel: Folio y 1/4. $\mathrm{N}^{\circ}$ de Folios: 8. $\mathrm{N}^{\circ}$ de fascículos: 2. Descriptores: Manuel Bonafós, Pedro Castelló, Rafael Costa, Barcelona.

ANÓNIMO (Censura: ASO TRAVIESO, SEBASTIÁN)

Observacion sobre una hipocondria que padece un Religioso en Alcalá. Afectos Internos. 87-4-A-6, no 538 y 539. 12-Marzo-1.807 y 2-Abril-1.807. Alcalá de Henares. 
Papel: (1/4). No de Folios: 11. Nº de fascículos: 2. Descriptores: Sebastián Aso Travieso, Madrid, Alcalá de Henares, Real Colegio de Cirugía de San Carlos.

\section{PELÁEZ, AGUSTÍN (Censura: COSTA DE QUINTANA, RAFAEL)}

Observación sobre un Aneurisma curado por el método de Don Antonio de Gimbernat. Materia Quirúrgica. 87-4-A-6, no 540, 541 y 542. 9-Abril-1.807, 16-Abril-1.807 y 23-Abril-1.807. Madrid. Papel: (1/8). No de Folios: 34. No de fascículos: 3. Descriptores: Agustín Pelaéz, Antonio de Gimbernat, Rafael Costa de Quintana, Séneca, Fragoso, Munnicks, Alcázar, Agustín Ginestá, Juan de Nava. Madrid. Biblioteca Germánica Médico-Quirúrgica.

\section{IZQUIERDO, PONCIANO (Censura: DE LA PEÑA, EUGENIO)}

Consulta sobre un Cáncer en la nariz remitida por Don Ponciano Izquierdo desde la Villa de Novales. Materia Quirúrgica, Materia Médica. 87-4-A-6, no 543 y 544. 30Abril-1.807 y 14-Mayo-1.807, Novales. Papel: Folio y 1/4. № de Folios: 6 . No de fascículos: 3 [Se adjunta carta]. Descriptores: Ponciano Izquierdo, Eugenio de la Peña, Novales.

\section{ANÓNIMO (Censura: RIBES, JOSEF; LOCHE, SEBASTIÁN)}

Observacion sobre una paralis en las extremidades inferiores y en la lengua sobrevenida a tres niños de una misma familia a la edad de 4 años. Enfermedades de los Niños. 87-4-A-6, no 545 y 546. 21-Mayo-1.807 y 4-Junio-1.807. Villa Don Diego (Zamora). Papel: Folio y 1/4. $\mathrm{N}^{\mathrm{o}}$ de Folios: 7 . $\mathrm{N}^{\mathrm{o}}$ de fascículos: 3 [Memoria, Censura y Anexo de la Censura]. Descriptores: Josef Ribes, Sebastián Loche, Villa Don Diego (Zamora), Madrid, Real Colegio de Cirugía de San Carlos, Biblioteca Germánica .

\section{XAVIERA DE CASTILLA, MARÍA FRANCISCA (Censura: GINESTÁ, AGUSTÍN)}

Observación sobre una enfermedad crónica de Nervios que remite Doña ... desde Andalucía por padecerla su marido. Afectos Internos. 87-4-0A-6, no 547, 548 y 549 . 11Junio-1.807 y 18-Junio-1.807. Andalucía. Papel: Folio y 1/4. № de Folios: 11 . No de fascículos: 3 [Adjunta carta de contestación]. Descriptores: María Francisca Xaviera de Castilla, Agustín Ginestá, Benito de Castilla, Sebastián Loche, Diego Rodríguez del Pino, Turner, Saviard, Kaaw, Sydenbam, Hoffmann, Tissot, Cullen, Arceo, Pome, Blancard.

ASO TRAVIESO, SEBASTIÁN (Censura: DE LA PEÑA, EUGENIO; GIMBERNAT, ANTONIO (DE)

Observación acerca de una úlcera en el prepucio y balano complicadas y que presentaron diversos caracteres provenidas de un cohito sin que hubiere nada de sifilítico. Enfermedades Venéreas. 87-4-A-6, no 550. 8-0ctubre-1.807 y 15-0ctubre-1.807. Madrid. Papel: (1/8). $\mathrm{N}^{\mathrm{o}}$ de Folios: 10, $\mathrm{N}^{\mathrm{o}}$ de fascículos: 1 [Falta Censura]. Descriptores: Sebastián Aso Travieso, Eugenio de la Peña, Antonio de Gimbernat, Madrid, España, El Paular. 


\section{GIMBERNAT ANTONIO (DE)}

Descripción y diseño de un feto gemelo abortado por una mujer en Barce1ona en el año de 1.774, que regala D. Antonio de Gimbernat al Gabinete del Colegio. Enfermedades de los Niños. 87-4-A-6, n⿳0 551. 22-Octubre-1.807. Barcelona. Papel: Folio. $\mathrm{N}^{\mathrm{o}}$ de Folios: 1 [Con lámina]. № de fascículos: 1. Descriptores: Antonio de Gimbernat, Sebastián Loche. Barcelona, Madrid, Real Colegio de Cirugía de San Carlos.

\section{MIGNE RODRÍGUEZ, JUAN (Censura: CASTELLÓ Y GINESTÁ, PEDRO)}

Consulta sobre el fetor fluxo de un humor sanguinolento y pútrido que sale de las narices de un joven de 21 años de edad. Afectos Internos. 87-4-A-6, no 552 y 553. 29Octubre-1.807 y 5-Noviembre-1.807. Calzadilla. Papel: (1/8). $\mathrm{N}^{\mathrm{o}}$ de Folios: 4 . $\mathrm{N}^{\mathrm{o}}$ de fascículos: 2. Descriptores: Juan Migne Rodríguez, Pedro Castelló y Ginestá, Calzadilla, Madrid.

\section{LÓPEZ GARDOC, GREGORIO (Censura: LOCHE, SEBASTIÁN)}

Consulta sobre un derrame general de vilis que aparecio despues de un golpe recibido en el epigastrio. Afectos Internos, Terapéutica. 87-4-A-6, no 554 y 555. 12-Noviembre1.807 y 19-Noviembre-1.807, Santa Cruz de Retamar. Papel: Folio y 1/4, No de Folios: 6. $\mathrm{N}^{\mathrm{o}}$ de fascículos: 2. Descriptores: Durand, Bucquet, Gregorio López, Sebastián Loche, Dijon, Santa Cruz de Retamar, Madrid, Real Colegio de Cirugía de San Carlos.

CHAMORRO, BERNARDO; URRUERTA, FRANCISCO (Censura: ASO TRAVIESO, SEBASTIÁN)

Observación sobre un pólipo de nariz que padece una joven de 17 años. Materia Quirúrgica. 87-4-A-6, no 556 y 557. 26-Noviembre-1.807 y 3-Diciembre-1.807. Madrid. Papel: (1/8). $\mathrm{N}^{\mathrm{o}}$ de Folios: 8. $\mathrm{N}^{\mathrm{o}}$ de fascículos: 2. Descriptores: Bernardo Chamorro, Francisco Urruerta, Sebastián Aso Travieso, Madrid.

CASTELLÓ, PEDRO (Censura: COSTA, RAFAEL)

Sobre un parto complicado con una mola extraordinaria. Enfermedades de Mujeres. 87-4-A-6, no 558 y 559. 10-Diciembre-1.807 y 17-Diciembre-1.807. Madrid. Papel: Folio y 1/4. No de Folios: 11. Descriptores: Pedro Castelló, Rafael Costa, Madrid, Real Colegio de San Carlos.

GINESTÁ, AGUSTÍN (Censura: RIBES, JOSEF)

Observación sobre una obstrucción y espasmo reumáticos de un ovario confundidos con un cáncer oculto del mismo. Enfermedades de las mujeres. 87-4-A-6, no 560 y 561. 7-Enero-1.808 y 14-Enero-1.808. Madrid. Papel: $1 / 4$ y 1/8. $\mathrm{N}^{\mathrm{o}}$ de Folios: 6 . No de fascículos: 2. Descriptores: Agustín Ginestá, Josef Ribes. Madrid. 
RIBES, JOSEF (Censura: CASTELLÓ Y GINESTÁ, PEDRO; FONTANA, SANTIAGO)

Observación sobre una herida de intestino estrangulada y curada, por la operación de Josef Ribes. Materia Quirúrgica. 87-4-A-6, no 562 y 563. 21-Enero-1.808 y 28-Enero1.808. Madrid. Papel: $1 / 4$ y 1/8. $N^{\circ}$ de Folios: 10. No de fascículos: 2. Descriptores: Josef Ribes, Pedro Castelló y Ginestá, Santiago Fontana.

\section{COSTA, RAFAEL (LOCHE, SEBASTIÁN)}

Observación de un aneurisma en la arteria radial. Materia Quirúrgica. 87-4-A-6, no 564. 4-Febrero-1.808 y 1l-Febrero-1.808. Hadrid. Papel: (1/4). $\mathrm{N}^{\circ}$ de Folios: $2 . \mathrm{N}^{\mathrm{o}} \mathrm{de}$ fascículos: 1 [Falta la Censura]. Descriptores: Rafael Costa, Sebastián Loche, Madrid, Real Colegio de Cirugía de San Carlos.

\section{DE LA PEÑA, EUGENIO (Censura: ASO TRAVIESO, SEBASTIÁN)}

Observacion sobre los efectos que produjo en un sugeto la detencion del podre en un absceso por tener una pequeña abertura. Materia Quirúrgica. Materia Médica. 87-4-A6, no 565 y 566. 18-Febrero-1.808 y 3-Marzo-1.808. Madrid. Papel: (1/4). No de Folios: 14. $\mathrm{N}^{\mathrm{o}}$ de fascículos: 2. Descriptores: Eugenio de la Peña, Sebastián Asó Travieso, Francisco Bataller, Galeno, Hipócrates, Avicena, Celso, Camus, Bartholino, Bell, Savitier, Richter, Mr. James, Edimburgo, Hospital de Edimburgo.

\section{MARTORELL, BERNARDO (Censura: DE LA PEÑA, EUGENIO)}

Consulta que D. Bernardo Martorell remite desde Algeciras y que hace el profesor D. José María Tulano sobre la curacion de un pólipo situado en la parte superior de la vagina. Enfermedades de las Mujeres. 67-4-A-6, nº 567 y 568. 10-Marzo-1.808 y 17Marzo-1.808. A1geciras. Papel: $1 / 4$ y 1/8. $\mathrm{N}^{\circ}$ de Folios: 10. $\mathrm{N}^{\circ}$ de fascículos: 2. Descriptores: Bernardo Martorell, José María Tulano, Eugenio de la Peña, Algeciras, Madrid.

\section{GARCÍA, ANTONIO (Censura: COSTA, RAFAEL)}

Consulta sobre una debilidad considerable de estómago con varios syntomas que padece un sugeto de 58 años de edad. Afectos Internos y Terapéutica. 87-4-A-6, n⿳ 569 y 570. 31-Marzo-1.808 y 7-Abri1-1.808. Cé. Papel: (1/4). N de Folios: 4. No de fascículos: 2. Descriptores: Antonio García, Rafael Costa, Cé, Madrid, Real Colegio de Cirugía de San Carlos.

\section{ASO TRAVIESO, SEBASTIÁN (Censura: RIBES, JOSEF)}

Observación de una Anasarca con Ascitis é Hidrotorax curada por un plan tonico y [*] del sistema absorvente. Afectos Internos y Terapéutica. 87-4-A-6, no 571 y 572. 60ctubre-1.808 y 13-0ctubre-1.808. Madrid. Papel: (1/4). No de Folios: 11. No de fascículos: 2. Descriptores: Sebastián Aso Travieso, Josef Ribes, Antonio Soliva, [*] Palabra ilegible. 
ABADES, JOSÉ (Censura: GINESTÁ, AGUSTÍN)

Observacion de un pecho extirpado en una señora de 62 años de edad. Materia Quirúrgica y Ginecología, 87-4-A-6, no 573 y 574, 20-Octubre-1.808 y 27-0ctubre-1.808. Madrid. Papel: (1/4), $\mathrm{N}^{\circ}$ de Folios: 16. $\mathrm{N}^{\mathrm{o}}$ de fascículos: 2. Descriptores: José Abades, Agustín Ginestá, Dowman, Burrows, Bierche, Peyxilme, Kuhn, Richter, Rafaela Sabonido, Villa de Algar (Sevilla).

\section{LOCHE, SEBASTIÁN (Censura: CASTELLÓ Y GINESTÁ, PEDRO)}

Observación de una úlcera corrosiva de resultas de una erisipela supurada en la parte anterior y externa del muslo. Afectos Internos y Materia Médica. 87-4-A-6, no 575. 3Noviembre-1.808 y 10-Noviembre-1.808. Madrid. Papel: Folio. $N^{\circ}$ de Folios: 3 . No de fascículos: 1 [Falta la Memoria]. Descriptores: Sebastián Loche, Pedro Castelló, Bell.

\section{CASTELLÓ Y GINESTÁ, PEDRO (Censura. LOCHE, SEBASTIÁN)}

Observación de una herida que penetraba la vejiga y el intestino recto. Materia Quirúrgica. 87-4-A-6, no 576. 17-0ctubre-1.808 y 24-Octubre-1.808. Madrid. Papel: (1/4). N de Folios: 3. No de fascículos: 1 [Falta la Censura]. Descriptores: Pedro Castelló y Ginestá, Antonio Roig, Sebastián Loche.

\section{GINESTÁ, AGUSTÍN (Censura: CASTELLÓ Y GINESTÁ, PEDRO)}

Parto complicado con procidencia de la vagina [Contiene una aportación a 1os discípulos con motivo de la nueva inauguración de las Juntas Literarias]. Obstetricia. 87-4-A-7, $\mathbf{n}^{\mathbf{0}}$ 577, 578 y 579. 14-Abril-1.814 y 21-4-1.814. Madrid. Papel: $1 / 4$ y 1/8. $\mathrm{N}^{\mathrm{o}}$ de Folios: $10 . \mathrm{N}^{\mathrm{o}}$ de fascículos: 3. Descriptores: Agustín Ginestá, Pedro Castelló y Ginestá, Madrid.

GINESTÁ, AGUSTÍN (Censura: LOCHE, SEBASTIÁN)

Observación de una rotura completa del Tendón de Aquiles. Materia Quirúrgica. 874-A-7, no 580 y 581. 28-Abril-1.814 y 5-Mayo-1.814. Madrid. Papel: Folio y 1/4. No de Folios: 17. $\mathrm{N}^{\mathrm{o}}$ de fascículos: 2. Descriptores: Agustín Ginestá, Sebastián Loche, Petit, Ravatás, Manzo.

\section{GÓMEZ GARRIDO, AGUSTÍN (Censura: ASO TRAVIESO, SEBASTIÁN)}

Disuria por obliteracion del cuello de la vegiga. Afectos Mixtos. 87-4-A-7, $\mathbf{n}^{\mathbf{0}} 582$ y 583. 26-Mayo-1.814 y 2-Junio-1.814. Villafranca del Vierzo. Papel: (1/4) . $N^{\circ}$ de Folios: 13. $\mathrm{N}^{\circ}$ de fascículos: 2. Descriptores: Sebastián Aso Travieso, Agustín Gómez Garrido (Profesor de Medicina, Cirujano del Cuerpo de Artillería, Médico Titular de Villafranca del Vierzo), Fritze, Desauto, Monteggia, Swedicum, Penilhe, Villafranca del Vierzo. Real Colegio de Cirugía de San Carlos. 
RIBES, JOSEF (Censura: BONAFÓS, MANUEL)

Observacion sobre una Anasarca en una mujer. Afectos Internos. Terapéutica. 87-4A-7, no 584 y 585. 16-Junio-1.814 y 23-Junio-1.814. Madrid. Papel: (1/4). No de Folios: 6. $\mathrm{N}^{\mathrm{o}}$ de fascículos: 2. Descriptores: Josef Ribes, Manuel Bonafós, Sydenham.

GINESTÁ, AGUSTÍN (Censura: COSTA, RAFAEL)

Observacion acerca de un parto, en que el feto se presentaba de lado. Obstetricia. 874-A-7, no 586 y 587. 6-Octubre-1.814 y 13-Octubre-1.814. Madrid. Papel: (1/8). No de Folios: 12. $\mathrm{N}^{\mathrm{o}}$ de fascículos: 2. Descriptores: Agustín Ginestá, Rafael Costa, Azada.

VERGES, JUAN; BURGER, SALVADOR (Censura: RIBES, JOSEF)

Observación sobre la Tisis pulmonar. Afectos Internos, 87-4-A-7, no 588 y 589. 20Octubre-1.814 y 27-Octubre-1.814. Almería. Papel: $1 / 4$ y 1/8. $\mathrm{N}^{\circ}$ de Folios: 4 . $\mathrm{N}^{\circ}$ de fascículos: 2. Descriptores: Juan Verges, Salvador Burguer, Josef Ribes. Madrid, Almería.

ASO TRAVIESO, SEBASTIÁN (Censura: GINESTÁ, AGUSTÍN)

Observación sobre una herida contusa en la parte media de la frente. Materia Quirúrgica. 87-4-A-7, no 590 y 591. 3-Noviembre-1.814 y 10-Noviembre-1.814. Tomelloso. Papel: Folio y 1/4. $\mathrm{N}^{\circ}$ de Folios: 7. $\mathrm{N}^{\circ}$ de fascículos: 2. Descriptores: Sebastián Aso Travieso, Agustín Ginestá, Juan García Francisco, San Agustín. Tomelloso.

\section{GONZÁLEZ MORA, RAMÓN (Censura: CASTELLÓ Y GINESTÁ, PEDRO)}

Observacion sobre un estheotoma degenerado del peso de cinco libras. Materia Quirúrgica. 87-4-A-7, no 592 y 593. 17-Noviembre-1.814 y 24-Noviembre-1.814. Ezcaray. Papel: $1 / 4$ y 1/8. $\mathrm{N}^{\mathrm{o}}$ de Folios: 8 . $\mathrm{N}^{\mathrm{o}}$ de fascículos: 2. Descriptores: Ramón González Mora, Marco de la Fuente, Pedro Castelló y Ginestá, Raymundo Díaz, Ángel Guerrero. Madrid, Ezcaray, Malganón.

\section{LOCHE, SEBASTIÁN (Censura: ASO TRAVIESO, SEBASTIÁN)}

Bubón supurado. Enfermedades Venéreas. 87-4-A-7, no 594 y 595. 1-Diciembre-1.814 y 15-Diciembre-1.814. Madrid. Papel: (1/4). $\mathrm{N}^{\circ}$ de Folios: 13. $\mathrm{N}^{\circ}$ de fascículos: 2. Descriptores: Sebastián Loche, Sebastián Aso Travieso, Bartholino, Juan de Vigo, Josef Abades, Brera, Chiarensi, Ginglio, Rossi, Tafalla, Florencia.

\section{CASTELLÓ Y GINESTÁ, PEDRO (Censura: ANÓNIMA)}

Observacion de una Herida de la mano producida por los pedazos de un fusil que se rebentó al tiempo de dispararlo. Heridas por Armas de Fuego. 87-4-A-7, no 596 y 597, 5-Enero-1.815 y 12-Enero-1.615. Madrid. Papel: Folio y 1/4. $\mathrm{N}^{\mathrm{o}}$ de Folios: 13. $\mathrm{N}^{\mathrm{o}}$ de fasciculos: 2. Descriptores: Pedro Castelló y Ginestá, Ejercito de Guipúzcoa y Navarra. 
MARTÍNEZ, SANTOS (Censura: BONAFÓS, MANUEL)

Consulta acerca de un úlcera atonica con caries de la mandíbula superior. Afectos Externos. 97-4-A-7, no 598 y 599, 19-Enero-1.815 y 26-Enero-1.815. Madrid. Papel: Folio y 1/4. $\mathrm{N}^{\mathrm{o}}$ de Folios: 10. $\mathrm{N}^{\mathrm{o}}$ de fascículos: 2. Descriptores: Santos Martínez, Manuel Bonafós, Juan Calzado, León.

(Censura: COSTA, RAFAEL)

Flujo blanco sero-mucoso por vagina. 87-4-A-7, no 600 y 601. 9-Febrero-1.815 y 16Febrero-1.815. Madrid. Papel: Folio y 1/4. $\mathrm{N}^{\mathrm{o}}$ de Folios: $6 . \mathrm{N}^{\mathrm{o}}$ de fascículos: 2. Descriptores: Rafael Costa.

GINESTÁ, AGUSTÍN (Censura: RIBES, JOSEF)

Observacion sobre un Absceso grande en el dorso. Materia Quirúrgica. 87-4-A-7, no 602 y 603. 23-Febrero-1.815 y 2-Marzo-1.815. Madrid. Papel: Folio. $\mathrm{N}^{\circ}$ de Folios. 8. $\mathrm{N}^{\circ}$ de fascículos: 2 Descriptores: Agustín Ginestá, Josef Ribes, Antonio Maroto, Román Llord, Leganés.

RIBES, JOSEF (Censura: GINESTÁ, AGUSTÍN)

Observación de una Ascitis. Afectos Internos. 87-4-A-7, no 604 y 605. 9-Marzo-1.815 y 16-Marzo-1.815, Madrid. Papel: Folio. $\mathrm{N}^{\mathrm{o}}$ de Folios: 8. $\mathrm{N}^{\mathrm{o}}$ de fascículos: 2. Descriptores: Josef Ribes, Agustín Ginestá, Francisca Bosque.

LACO, JOSÉ ANTONIO (Censor : LOCHE, SEBASTIÁN).

Observacion sobre una tumoracion escrofu1osa en el cuel1o. Materia Quirúrgica. 874-A-7, no 606, 607 y 607 bis. 7-Abri1-1.815, 14-Abril-1.815 y 20-Abril-1.815. Talavera de la Reina. Papel: 1/8. $\mathrm{N}^{\mathrm{o}}$ de Folios: 16. $\mathrm{N}^{\mathrm{o}}$ de fascículos: 3 (se adjunta explicación complementaria sobre el mismo proceso). Descriptores: Jose Antonio Laso, Sebastián Loche, José Gómez, Madrid, Talavera de la Reina.

BONAFOS, MANUEL (Censor: ASO TRAVIESO, SEBASTIÁN)

Observacion sobre una fistula lagrimal. Materia Quirúrgica. 87-4-A-7, no 608 y 609. 27-Abril-1.815 y 8-Junio-1.815. Papel: $1 / 8$. $\mathrm{N}^{\circ}$ de folios: $22 . \mathrm{N}^{\circ}$ de fascículos: 2 . Descriptores: Manuel Bonafós, Sebastián Aso Travieso, Eulalia Rosell. Madrid.

ORTI Y CRIADO, VICENTE (Censor: BONAFÓS, MANUEL)

Observacion sobre un herpe fistuloso húmedo. Afectos Internos. 87-4-A-7, $\mathbf{n}^{\mathbf{0}} \mathbf{6 1 0} \mathbf{y} \mathbf{6 1 1}$. 14-Junio-1.815 y 22-Junio-1.815. Castro del Río. Papel: 1/8. № de Folios: 8. No de Fascículos: 2. Descriptores: Vicente Orti y Criado, Manuel Bonafós. Madrid, Castro del Rio. 


\section{ASO TRAVIESO, SEBASTIÁN (Censor: COSTA, RAFAEL)}

Observacióm sobre una contusion de la cadera. Materia Quirúrgica. 87-4-A-7, no 612 y 613. 4-Octubre-1.815 y 12-0ctubre-1.815. Madrid, Papel:1/8. $\mathrm{N}^{\mathrm{o}}$ de folios: 18 . $\mathrm{N}^{\mathrm{o}}$ de fascículos: 2. Descriptores: Sebastián Aso Travieso, Rafael Costa, Mariano Lagasca, Madrid.

PAYÁ, JUAN

GONZÁLEZ, KATHIAS

(Censor: RIBES, JOSEF)

Observacion sobre un infarto gangrenoso ulcerado en el pecho derecho. Materia Quirúrgica. 87-4-A-7, no 614 y 615, 19-Octubre-1.815 y 26-Octubre-1.815. Peziel. Papel: 1/4 y 1/8. No de Folios: 20. No de fascículos: 2. Descriptores: Juan Payá, Mathías González, Josef Ribes, Madrid, Peziel.

DE SAGASTA, PEDRO (Censura: CASTELLÓ Y GINESTÁ, PEDRO)

Observacion de un parto de trillizos, dos de ellos unidos por el torax. Obstetricia. 874-A-7, no 616 y 617. 23-Enero-1.816 y 30-Enero-1.816. Fuenterrabía. Papel: Folio. $\mathrm{N}^{\mathrm{o}} \mathrm{de}$ Folios: 7, $\mathrm{N}^{\mathrm{o}}$ de fascículos: 2. Descriptores: Pedro de Sagasta, Pedro Castelló y Ginestá, Francisca Rosa de Landábal, Francisco Istibernea, Fray José de Tolosa (Religioso Capuchino), Fuenterrabía.

\section{CASTELLÓ Y GINESTÁ, PEDRO}

Observacion sobre un cálculo urinario. Afectos Internos. 87-4-A-7, no 618. 18-Enero1.816. Navas de Avilés. Papel: $1 / 4$ y 1/8. $\mathrm{N}^{\circ}$ de Folios: $16 . \mathrm{N}^{\circ}$ de fascículos: 2 . Descriptores: Pedro Castelló y Ginestá, Josef Valdés de las Navas, Madrid, Navas de Avilés.

\section{ESPARGALLAS, INOCENCIO (Censura: TRUXILLO, RAMON)}

Cancro del pecho derecho. Materia Quirúrgica y Ginecología. 87-4-A-7, no 620. 24Enero-1.816 y 1-Febrero-1.816. «Cuebas Labrados (Aragón)». Papel: (1/4) . No de Folios: 6. $\mathrm{N}^{\mathrm{o}}$ de fascículos: 1. Descriptores: Isabel Herrero, Inocencio Espargallas (Profesor de Cirugía en Cuebas Labrados (Aragón), Ramón Truxillo, Cuebas Labrados (Aragón), Villalba.

\section{MEXÍA, LUIS MARÍA (Censura: ASO TRAVIESO, SEBASTIÁN)}

Observacion de un absceso lumbar en un niño de 9 años. Materia Quirúrgica. 87-4-A7, no 621 y 622. 1-Marzo-1.816 y 7-Marzo-1.816. Valladolid, Papel: (1/4). No de Folios: 10. $\mathrm{N}^{\mathrm{o}}$ de fascículos: 2. Descriptores: Dr. Bañarés, Luis María Mexía, Sebastián Aso Travieso, Valladolid.

FRÍAS, IGNACIO (Censura: BONAFÓS, MANUEL)

Observacion de una fístula lagrimal con herpe. Enfermedades de los Ojos. 87-4-A-7, $\mathbf{n}^{\circ} 623$ y 624. 14-Marzo-1.816 y 21-Marzo-1.816. Castilfrío (Soria). Papel: (1/4), No de 
Folios: 8. $\mathrm{N}^{\mathrm{o}}$ de fascículos: 2. Descriptores: Ignacio Frías (Cirujano titular de Castilfrío Soria-), Manuel Bonafós, Castilfrío.

VIANA ROXAS, GREGORIO (Censor: COSTA, RAFAEL)

Observación de caries del oido. Materia Quirúrgica. 87-4-A-7, no 625 y 626. 28-Marzo1.816 y 4-Abril-1.816. Soria. Papel: (1/4). No de Folios: 7, No de Fascículos: 2. Descriptores: Gregorio Viana Roxas (Cirujano de Soria), Rafael Costa, Soria.

SORIANO, RAFAEL

ASÍNS, ANTONIO

(Censor: RIBES, JOSEF)

Observacion de un flujo blanco con úlceras en la matriz. Ginecología. 87-4-A-7. No 627 y 628. 18-Abril-1.816 y 25-Abril-1.816. Murcia, Papel: Folio y 1/4. $N^{o}$ de Folios: 6 $\mathrm{N}^{\mathrm{o}}$ de Fascículos: 2. Descriptores: Antonia Hernández, Rafael Soriano y Laguna (Médico de Murcia), Antonio Asíns (Médico de Murcia), Josef Ribes, Murcia.

\section{ÁLVAREZ DE CARRACEDO, FRANCISCO (Censor: TRUXILLO, RAMÓN)}

Observacion de un reumatismo cronico histerico. Afectos Internos. 87-4-A-7. No 629 y 630. 9-Mayo-1.816 y 16-Mayo-1.816. La Solana (La Mancha). Papel: (1/4). No de Folios: 6. $\mathrm{N}^{\mathrm{o}}$ de Fascículos: 2. Descriptores: Francisco Álvarez de Carracedo (Profesor de medicina en La Solana -La Mancha-), Ramón Truxillo, La Solana (La Mancha).

\section{CEAORRORE , PATRICIO (Censor: CASTELLÓ Y GINESTÁ, PEDRO)}

Observacion de caries de la nariz por una causa sifilítica. Afectos Internos. 87-4-A-7, no 631 y 632. 13-Junio-1.816 y 20-Junio-1.816. Bilbao. Papel: Folio. $\mathrm{N}^{\mathrm{o}}$ de Folios: 8 . $\mathrm{N}^{\circ}$ de Fascículos: 2. Descriptores: Patricio Ceaorrore (Médico de Bilbao), Pedro Castelló y Ginestá, Bilbao.

POLO, TELESFORO (Censor: BONAFÓS , MANUEL)

Observación de una hernia inguinal. Materia Quirúrgica. 87-4-A-7. No 633 y 634, 24Octubre-1.816 y 31-Octubre-1.816. Madrid. Papel: (1/4). $\mathrm{N}^{\circ}$ de Folios: 27. No de Fascículos: 2. Descriptores: Telesforo Polo, (Médico de Madrid), Manuel Bonafós, Bernarda Cortijo, Palencia, Junta de Catedráticos del Real Colegio de Cirugía Médica de San Carlos.

GÓMEZ, RAFAEL (Censor: COSTA, RAFAEL)

Observacion de una hernia inguinal completa. Materia Quirúrgica. 87-4-A-7. No 635 y 636. 21-Noviembre-1.816 y 28-Noviembre- 1.816. Trujillo. Papel: Folio y (1/4). $\mathrm{N}^{\mathrm{o}}$ de Folios: 13, No de Fascículos: 2. Descriptores: Ramón Gómez (Titular de Trujillo), Rafael Costa, Joaquín Paz de Loaira, Trujillo. 
CRESPO, MATÍAS (Censor: RIBES, JOSEF)

Consulta acerca de abortos frecuentes en una señora. Obstetricia. 87-4-A-7. $\mathbf{N}^{\mathbf{0}} 637$ y 638. Ciudad Real. Papel: Folio. $\mathrm{N}^{0}$ de Folios: 5 . $\mathrm{N}^{\mathrm{o}}$ de Fascículos: 2. Descriptores: Matías Crespo, Josef Ribes.

ANÓNIMO (Censor: TRUJILLO, RAMON)

Observacion de una hemiplejia. Afectos Internos y Materia Médica. 87-4-A-7. No 639 y 640. 2-Enero-1.817 y 9-Enero-1.817. Papel: Folio. $\mathrm{N}^{\mathrm{o}}$ de Folios: 3. $\mathrm{N}^{\mathrm{o}}$ de Fascículos: 1, (Falta la Memoria). Descriptores: Ramón Trujillo.

\section{MILLÁN Y LUCAS, ISIDRO (Censor: COSTA, RAFAEL)}

Observacion sobre el mal de Pott en una embarazada a término con feto de nalgas. Afectos Internos. Obstetricia, 87-4-A-7. No 641 y 642. 20-Enero-1.817 y 27-Enero-1.817. Cogolludo de Carrascosa Sobrenares. Papel: Folio, (1/4), $\mathrm{N}^{\circ}$ de Folios: 5. $\mathrm{N}^{\circ}$ de Fascículos: 2. Descriptores: I. Millán y Lucas, Rafael Costa, María Hijosa, Benito Godeo. Cogolludo de Carrascosa Sobrenares, Parroquia de San Lorenzo.

VELEZ PARDO, JOSÉ (Censor: ASO TRAVIESO, SEBASTIÁN)

Consulta sobre una ulcera con caries en la region temporal izquierda. Afectos Mixtos. 87-4-A-7. No 643 y 644. 6-Febrero-1.817 y 13-Febrero-1.817. Papel: Folio y (1/4). $\mathrm{N}^{\circ}$ de Folios: 7. $\mathrm{N}^{\mathrm{o}}$ de Fascículos: 2. Descriptores: J. Vélez Pardo, S. Aso Travieso, $\mathrm{M}^{\mathrm{a}}$ del Carmen Argüello.

LAVADÍA, MANUEL (Censura: BONAFÓS, MANUEL)

Observacion sobre una calentura catarral (Censura). Afectos Internos. 87-4-A-7, no 645. 6-Marzo-1. 817 y 13-Marzo-1.817. San Esteban de Garméz (Burgos). Papel: (1/4). No de Folios: 5. № de Fascículos: 1. Descriptores: Manuel Lavadía, Manuel Bonafós. Madrid, San Esteban de Garméz, Real Colegio de Cirujanos de San Carlos.

ARANA, B.

Historia de dolencia y medios de remediar la afección tópica de un vicio escrofuloso (Falta la censura). Afectos Internos. 87-4-A-7. No 645 bis. 10-Marzo- 1.817. Durango. Papel: (1/4). No de Folios: 4. No de Fascículos: 2. Descriptores: B. Arana. Durango.

FRÍAS, IGNACIO (Censura: RIBES, JOSEF)

Observacion sobre un tumorcito de carácter linfático sobre la tercer falange del dedo medio. Afectos Internos. Materia Quirúrgica, 87-4-A-7. No 646 y 647, 10-Abril1.817 y 17-Abril-1.817, Castilfrio (Soria). Papel: Folio y (1/4). $\mathrm{N}^{\circ}$ de Folios: 6. $\mathrm{N}^{\mathrm{o}} \mathrm{de}$ 
Fascículos: 2. Descriptores: Ignacio Frías, Josef Ribes. Castilfrío (Soria). Madrid, Real Colegio de Cirujanos de San Carlos.

\section{BLASCO, MATEO (Censor: TRUJILLO, RAMÓN)}

Observacion de una hernia estrangulada con gangrena y formacion del ano artificial. Materia Quirúrgica. 87-4-A-7. No 648 y 649. 1-Mayo-1.817 y 8-Mayo-1.817. Ateca (Aragón). Papel: (1/4) No de Folios: 15. No de Fascículos: 2. Descriptores: Ramón Trujillo, Mateo Blasco (Cirujano de Ateca), Teresa Virnen, Vicente Frax, Ateca (Aragón).

\section{SIMEN DABALILLOS, RAFAEL (Censor: CASTELLÓ Y GINESTÁ, PEDRO)}

Consulta sobre un enfermo atacado de bemoptisis y de una copiosa supuracion en los oidos acompañada de cofosis o sordera. Enfermedades de oidos, Enfermedades venéreas. 87-4-A-7. No 650 y 651. 22-Marzo-1.817 y 29-Marzo-1.817. Durango. Papel: Folio. $\mathrm{N}^{\circ}$ de Folios: 8. $\mathrm{N}^{\circ}$ de Fascículos: 2. Rafael Simen Dabalillos, Pedro Castelló y Ginestá, Pinel, Portal, Baunné, M. Bonagas, Stoll, Durango.

\section{ROLDÁN, MANUEL (Censura: LOCHE, SEBASTIÁN)}

Relación histórica de una mujer a quien resultas de un parto trabajoso se le obliteró el orificio de la vagina, Enfermedades de mujeres. 87-4-A-7. $\mathbf{N}^{\circ} 652$ y 653 . 12-Junio1.817 y 19-Junio-1.817. Aranjuez. Papel: (1/4). $\mathrm{N}^{\mathrm{o}}$ de Folios: 24. $\mathrm{N}^{\mathrm{o}}$ de fascículos: 2. Descriptores: Manuel Roldán, Sebastián Loche, Ramón Truxillo, Dulcet. Aranjuez, Madrid. Real Colegio de Cirugía de San Carlos.

DE VARGAS, JOSÉ (Censura: BONAFÓS, MANUEL)

Observacion de un tyfo ictenoydes o fiebre amarilla. Afectos Internos y Materia Médica. 87-4-A-7, no 654 y 655. 23-0ctubre-1.817 y 30-Octubre-1.817. Sevilla. Papel: (1/4). $\mathrm{N}^{\circ}$ de Folios: 13. $\mathrm{N}^{\circ}$ de fascículos: 2. Descriptores: José de Vargas (Médico de Sevilla), Dr. Gamble, Manuel Bonafós, Manuel Gamboa, Hoffnani Kendal, Juan Ferreyra de Rosa, Diego Mena, Justo Muñoz (Catedrático del Colegio de Farmacia), Francisco García Otero (Catedrático del Colegio de Farmacia), Pedro Gatica (Boticario), Cartagena de Indias, Cádiz, Sevilla, Málaga, Colegio de Farmacia.

COSTA, RAFAEL (Censura: RIBES, JOSEF)

Observacion de un mal catarral bilioso acompañado de fiebre continua. Afectos Internos. 87-4-A-7, $\mathbf{n}^{\mathbf{0}}$ 656, 657 y 658. 20-Noviembre-1.817 y 27-Noviembre-1.817. Papel: (1/4). $\mathrm{N}^{\circ}$ de Folios: 28. $\mathrm{N}^{\circ}$ de fascículos: 3 (Se adjunta carta certificando la autenticidad de lo expuesto de Cesáreo María Sáenz). Descriptores: Rafael Costa, Josef Ribes, Cesáreo María Sáenz, Juan Manuel de Gandesegui, Josef de Mendieta, Manuel de Brodeti, Ibo Roperto, Fernando de la Serna, Bartolomé Piñero, Pedro Castelló, Eugenio Arrieta, Ramón Llord, Cádiz, Costa de Bengala, Calcuta, Fuente del Berro. 


\section{ASUARO, ÁNGEL (TRUXILLO, RAMÓN)}

Observación sobre un escirro al pecho diestro de una mujer. Afectos Internos. Enfermedades de Mujeres. 87-4-A-7, no 659 y 660. 4-Diciembre-1.817 y ll-Diciembre-1. 817. Torrecilla de Cemeros. Papel: Folio y 1/4. № de Folios: 6. $\mathrm{N}^{\mathrm{o}}$ de fascículos: 2 . Descriptores: Ángel Asuaro, Ramón Truxillo. Torrecilla de Cemeros, Madrid. Real Colegio de Cirugía de San Carlos.

\section{DE VARGAS, JOSÉ (Censura: COSTA, RAFAEL)}

Observación sobre los efectos de la quina, aplicable en toda clase de enfermedades. Afectos Internos y Terapéutica. 87-4-A-7, no 661 y 662, 10-Diciembre-1.817 y 17Diciembre-1.817. Sevilla. Papel: (1/4). $\mathrm{N}^{\circ}$ de Folios: 7. $\mathrm{N}^{\circ}$ de fascículos: 2 (falta el primer pliego de la censura). Descriptores: José de Vargas (Médico de Sevilla), Rafael Costa, Montoni Buchan, Baties, Mouno, Wihit, Juan Fondizi, Fothengill, América del Sur, Europa, Santa Fé de Bogotá, Sevilla.

\section{GONZÁLEZ, BONIFACIO (CASTELLÓ Y GINESTÁ, PEDRO)}

Observaciones acerca de la Bacuna antivirólica. Afectos Internos e Higiene. 87-4-A-7 , no 663 y 664. 8-Enero-1.818 y 15-Enero-1.818. Villa de Bamba (Valladolid). Papel: Folio. $N^{o}$ de Folios: $6 \mathrm{~N}^{\mathrm{o}}$ de fascículos: 3 (dos corresponden a la Censura). Descriptores: Bonifacio González, Pedro Castelló y Ginestá, Agustín Ginestá, Salvador Nadal, Pignillen, Villa de Bamba (Valladolid), Madrid, Guisone (Gerona), Barce1ona, Real Colegio de Cirugía de San Carlos.

GRANERO, PEDRO (Censura: BONAFÓS, MANUEL)

Observación sobre un vicio escrofuloso. Afectos Internos y Materia Médica. 87-4-A-7, no 667 y 668. 16-Febrero-1.618 y 26-Febrero-1.816. Papel: (1/4) $\mathrm{N}^{\circ}$ de Folios: $7 \mathrm{~N}^{\circ}$ de fascículos: 2. Descriptores: Pedro Granero, Manue1 Bonafós.

\section{DE LA MATA CUÉLLAR, JUAN (Censura: ASO TRAVIESO, SEBASTIÁN)}

Consulta sobre un absceso escrofu1oso en un sobaco. Materia Médica y Afectos Mixtos. 87-4-A-7, no 665 y 666. 5-Febrero-1.818 y 12-Febrero-1.818. Sepúlveda. Papel: Folio y 1/4. $\mathrm{N}^{\mathrm{o}}$ de Folios: 7. $\mathrm{N}^{\mathrm{o}}$ de fascículos: 2. Descriptores. José de la Mata Cuéllar, Sebastián Aso Travieso, Ana María Vera y Cabezón, Sepúlveda.

ASUERO, ÁNGEL (Censura: TRUXILLO, RAMÓN)

Observación de un escirro en el pecho derecho de una mujer. Afectos Internos y Enfermedades de Mujeres. 87-4-A-7, no 669 y 670. 5-Marzo-1.818 y 12-Marzo-1.818. Bentrosa de Cameros. Papel: (1/4). $\mathrm{N}^{\mathrm{o}}$ de Folios: 10. $\mathrm{N}^{\mathrm{o}}$ de fascículos: 2. Descriptores: 
Ángel Asuero, Ramón Truxillo, Bentrosa de Cameros, Madrid, Real Colegio de Cirugía de San Carlos.

MANGE, CELEDONIO (Censura: COSTA, RAFAEL)

Consulta sobre un absceso en el pecho izquierdo de una mujer. Enfermedades de Mujeres. 87-4-A-7, no 671 y 672. 23-Marzo-1.818 y 2-Abril-1.818. Daroca. Papel: Folio y 1/4. No - de Folios: 4. No de fascículos: 2. Descriptores: Celedonio Mange, Rafael Costa, Villafranca del Campo (Partido de Daroca).

ASUERO, ÁNGEL (Censura: RIBES, JOSEF)

Observacion sobre una ozaena. Afectos Internos y Materia Médica. 87-4-A-7. No 673 y 674. 9-Abril-1.815 y 16-Abril-1.618. Torrecilla (Caneros). Papel: Folio y (1/4). $\mathrm{N}^{\mathrm{o}}$ de Folios: 5. No de Fascículos: 2. Descriptores: Anastasia Rubio, Ángel Asuero (Cirujano en Torrecilla en Caneros), Mateos Monga (Cirujano de cabecera), Torrecilla (Caneros), Bentrosa (Caneros).

\section{GUTIÉRREZ, JULIÁN}

Descripcion facultativa de un feto monstruoso y del parto en que nació. Enfermedades de mujeres y de niños. 87-4-A-7. No 675. 14-Mayo-1.818. Madrid. Papel: Folio. $\mathrm{N}^{\circ}$ de Folios: $8 \mathrm{~N}^{\mathrm{o}}$ de Fascículos: 1 (Incompleto, falta censura y contiene un grabado). Descriptores: Julian Gutierrez, Madrid, Real Colegio de Cirugía de Madrid.

DE FENDIS, BRAULIO ANTONIO (Censura: CASTELLÓ Y GINESTÁ, PEDRO)

Observacion sobre la frecuenia de abortos. Enfermedades de Mujeres. 87-4-A-7. $\mathbf{N}^{\mathbf{0}}$ 676 y 677. 23-Abril-1.818 y 7-Mayo-1.818. Madrid. Papel: Folio. $N^{\circ}$ de Folios: 6. Descriptores: Siebold, Aitken, Braulio Antonio Fendis, Pedro Castelló y Ginestá. Madrid. Real Colegio de Cirugía de Madrid.

ANÓNIMO (Censor: ASO TRAVIESO, SEBASTIÁN)

Observacion sobre un histerismo. Afectos Internos y Enfermedades de Mujeres. 87-4A-7. No 678 y 679. 14-Mayo-1.818 y 28-Mayo-1.818. Papel: Folio y (1/4). № de Folios: 7. No de Fascículos: 2. Descriptores: Sebastián Aso Travieso, Ramón Truxillo.

GONZÁLEZ, BONIFACIO (Censor: BONAFÓS, MANUEL)

Consulta sobre una dislocación de mandíbula. Enfermedades Huesos. 87-4-A-7. No 680 y 681. 4-Junio-1.818 y ll-Junio-1.818. Ciguñuela (Valladolid). Papel: Folio, No de Folios: 6. No de Fascículos: 2. Descriptores: B. Gonzalez, M. Bonafós, Francisco de Lorena, Bernardino Bazaco, Sue, Boyer, Gregorio Valles, R. Costa, Acuapendente, Dr. Laguna, Thonson, Pott, Hipócrates, Fabricio, Cigüeñuela, Peñaflor y Castrodeza de ... (Valladolid), Metz. 
HILARIO GUERRERO, JOSÉ

MARTÍNEZ VUES, JUAN

ANÓNIMO

(Censor: Anónimo)

Observacion sobre embarazos de molas. Enfermedades de mujeres. 87-4- A-7. $\mathbf{N}^{\mathbf{0}}$ 682, 683, 684 y 685. 18-Junio-1.818 y 25-Junio-1818. Granada. Papel: Folio y (1/4). $\mathrm{N}^{\mathrm{o}}$ de Folios: 9. No de Fascículos: 2. Descriptores: José Hilario Guerrero (Médico de Granada), Juan Marrtinez Vues (Médico de Granada). Granada.

GARCÍA, AGUSTÍN JOSÉ

MORENO, JUAN

(Censura: Anónimo)

Consulta acerca de un afecto hipocondriaco y mala qualidad del jugo gástrico. 87-4A-7, $\mathbf{n}^{\mathbf{0}} 686$ y 687. 22-Septiembre-1.818 y 29-Septiembre-1.818. Granada. Papel: Folio y 1/4. $N^{o}$ de Folios: 15. No de fascículos: 2. Descriptores: Agustín José García, Juan Moreno, Salvador Gaspar de Reyes, Hipócrates, Raulín, Whytt, Haen, Sthall, Lorry, Granada.

\section{TRUXILLO, RAMÓN (Censura: RIBES, JOSEF)}

Observacion de un ano accidental curado radicalmente. Materia Quirúrgica. 87-4-A7, no 688 y 689. 9-Diciembre-1.818 y 12-Diciembre-1.818. Papel: (1/4), No de Folios: 19, $\mathrm{N}^{\mathrm{o}}$ de fascículos: 2. Descriptores: Ramón Truxillo, Josef Ribes, José Cabrera Juarez, Pedro Castelló y Ginestá, Manuel Bonafós, Hallen, Petit, Shanp, Scampa, Hipócrates, Real Colegio de Veterinaria de Madrid, Colegio de San Carlos de Madrid.

\section{HURTADO, MANUEL (Censura: GUTIÉRREZ, BONIFACIO)}

Noticia sobre un método nuevo de curar los anos artificiales, imaginado y puesto en práctica en el Hospital Hotel Dieu de París por el Caballero Dupuytren Catedrático de la Facultad de Medicina de París, Cirujano en Gefe del dicho Hospital, y comunicada por Don... Materia Quirúrgica. 87-4-A-7, no 690 y 691. 3-Diciembre1.818 y 10-Diciembre-1. 818 Papel: (1/4). N ${ }^{o}$ de Folios: 18. No de fascículos: 2 (Notas en f-lv, f-7, f-7v, f-8v, f-9v). Descriptores: Manuel Hurtado, Bonifacio Gutiérrez, Dupuytrent, Rhamdor, Lapeyronie, Littre, Dr. Barbier, Collombe Paulin, Hipócrates, Scarpa, Guy de Chauliac, París, Hospital Hotel Dieu de Chateaudum, Hospital de Valde Gracia, Facultad de París.

\section{ANÓNIMO (Censura: TRUXILLO, RAMÓN)}

Observacion de una tisis. Afectos Internos y Terapéutica. 87-4-A-8, no 692 y 693 . 7Noviembre-1.819 y 14-Noviembre-1.819. Papel: Folio y 1/4. № de Folios: 8. No de fascículos: 2. Descriptores: Ramón Truxillo, Hipócrates, Pedros. 


\section{RAMÓN, MIGUEL}

Observacion de un cuerpo extraño arrojado por el ano. Afectos Mixtos y Materia Médica. 87-4-A-8, no 694. 18-Enero-1819. La Vega de San Andrés de Espinareda (León). Papel: Folio y 1/4. $\mathrm{N}^{\mathrm{o}}$ de Folios: 7. $\mathrm{N}^{\mathrm{o}}$ de fascículos: 2 (Hay acta notarial). Descriptores: Miguel Ramón (Cirujano titular de la villa de la Vega de San Andrés de Espinareda), Andrés Osorio, Salvio Illa, Agustín Frutus, José María Tuxlan, Villa de la Vega de San Andrés de Espinareda (León), Villafranca.

HUGARTE, BARTOLOMÉ

CARRASCO, MANUEL

(Censura: CASTELLÓ Y GINESTÁ, PEDRO)

Consulta acerca de un tumor en el pecho derecho de un varón. Materia Quirúrgica. 87-4-A-8, no 695 y 696. 21-Enero-1819 y 28-Enero-1819. Zamora. Papel: Folio. $\mathrm{N}^{\mathrm{o}} \mathrm{de}$ Folios: 6, $\mathrm{N}^{\mathrm{o}}$ de fascículos: 2. Descriptores: Bartolomé Hugarte, Manuel Carrasco, Pedro Castelló y Ginestá, Fray Miguel Álvarez, Boerhaave, Van Schwiter, Zamora.

\section{ALBALÁ, JUAN MANUEL (Censura: ASO TRAVIESO, SEBASTIÁN)}

Consulta acerca de una hematemesis. Afectos Mixtos. 87-4-A-8, no 697 y 698, 4Febrero-1.819 y 11-Febrero-1.819. Baños (Salamanca). Papel: Folio y 1/4. № de Folios: 6. $\mathrm{N}^{\circ}$ de fascículos: 2. Descriptores: Juan Manuel Albalá, Sebastian Aso Travieso, Grashuys, Bosieri, Baños (Partido de Montemaior de Salamanca).

\section{URBINA (Censura: RIBES, JOSEF)}

Observacion de una obstrucción de higado. Afectos Internos, 87-4-A-8, n⿳ 699 y 700. 25-Febrero-1.819 y 4-Marzo-1.819. Papel: Folio y 1/4. $\mathrm{N}^{\circ}$ de Folio: 8. $\mathrm{N}^{\circ}$ de Fascículos: 3 (Memoria, Censura y Dictamen). Descriptores: Urbina, Josef Ribes, Madrid, Real Colegio de Cirugía de San Carlos.

\section{RUIZ, SEBASTIAN (Censura: GUTIÉRREZ, BONIFACIO)}

Observacion sobre un caso de gota. Afectos Internos. 87-4-A-8, no 701 y 702, 8 y 15 Abril-1819. Baeza (Jaén). Papel: Folio y 1/4, No de Folios: 12, $\mathrm{N}^{\mathrm{o}}$ de fascículos: 2 (Memoria y solicitud de Dictamen). Descriptores: Sebastián Ruiz, Bonifacio Gutierrez, Hipócrates, Areteo, Descult, Pablo Eginete, Fourcroy, Ucquelin, Wolenston, Pearson, Capdevila, Baeza, Madrid, Real Colegio de Cirugía de San Carlos.

DE SILVA, FRANCISCO (Censura: TRUXILLO, RAMON)

Observacion de una herida de arma de fuego, heridas de perro rabioso y lobo rabioso. Cirugía y Terapéutica. 87-4-A-8f no 703 y 704. 22 y 29-Abril-1819. Malpartida de la Serena. Papel: (1/4). $\mathrm{N}^{\circ}$ de Folios: 20, $\mathrm{N}^{\mathrm{o}}$ de fascículos: 3 (La censura está repetida). 
Descriptores: Francisco de Silva (Cirujano de Malpartida de la Serena), Ramón Truxillo, Carlos Carballo, Ramón Capdevila, Malpartida de la Serena, Plasencia.

ORTEGA, GERÓNIMO

RUIZ DE LUZURRIAGA, JUAN

Censura: CASTELLÓ, PEDRO

Observacion sobre una hemorragia uterina. Enfermedades de Mujeres. 87-4-A-8, $\mathbf{n}^{\mathbf{0}} 705$ y 706. 6 y 13-Mayo-1819. Papel: Folio y 1/4. $\mathrm{N}^{\circ}$ de Folios: $16 \mathrm{~N}^{\mathrm{o}}$ de Fascículos: 2. Descriptores: Gerónimo Ortega, Juan Ruiz de Luzurriaga, Pedro Castelló, Ramón Capdevila, Leuret, David, Descult, Bichat, Stvach, Hunter, Madrid, Real Colegio de Cirugía de San Carlos.

HERNÁNDEZ SALINAS, MANUEL (Censura: ASO TRAVIESO, SEBASTIÁN)

Observación de una úlcera cancerosa. Afectos Internos, Terapéutica, 87-4-A-8, no 707 y 708. 27-Mayo-1819 y 3-Junio-1819. Velez Blanco (Granada). Papel: Folio y 1/4. $\mathrm{N}^{\circ}$ de Fol ios: 6. N ${ }^{\circ}$ de Fascículos: 2. Descriptores: Manuel Hernández Salinas, Sebastián Aso Travieso, Madrid, Real Colegio de Cirugía de San Carlos.

SOLORZANO, JUSTO

RABAL, JUAN

Censura: RIBES, JOSEF.

Consulta acerca de una Anasarca con absceso del vientre. Afectos Mixtos. 87-4-A-8, $\mathbf{n}^{\mathbf{0}}$ 709 y 710. 16 y 23-Noviembre-1819. Agreda. Papel: Folio y 1/4. $\mathrm{N}^{\mathrm{o}}$ de Folios: $5 \mathrm{~N}^{\mathrm{o}}$ de fascículos: 2. Descriptores: Justo Solorzano, Josef Ribes, Juan Rabal, Josef Pérez, Agreda.

GUTIÉRREZ, BONIFACIO (Censura: RIBES, JOSEF)

Observacion sobre un cólico nervioso complicado. Afectos Internos. 87-4-A-8, no 711. 9 y16-Diciembre-1819. Papel: (1/4). N$^{\circ}$ de Folios: 6. $\mathrm{N}^{\mathrm{o}}$ de fascículos: 1 (Falta la Censura). Descriptores: Bonifacio Gutiérrez, Josef Ribes, Cosme Martín Paredes, Eugenio de la Peña, Colmenar Viejo.

DE SILVA, FRANCISCO (Censura: CAPDEVILA, RAMÓN)

Consulta acerca de una fiebre biliosa en el puerperio. Enfermedades de Mujeres. 674-A-8, no 712 y 713, Enero-1820. Malpartida de la Serena. No de Folios: 20, No de Fascículos: 3. ( Memoria, Borrador de Censura, y Censura Dictamen). Descriptores: Francisco de Silva. Ramón Capdevila, Félix Camayo, Dorve, Madrid, Malpartida de la Serena, Real Colegio de Cirugía de San Carlos.

BERTRAN, RAMÓN (Censura: GUTIÉRREZ, BONIFACIO)

Consulta acerca de una sigilación venérea con úlcera de garganta. Enfermedades Venéreas, Terapéutica. 87-4-A-8, no 714 y 715. 10 y 17-Febrero-1820. Papel: Folio y 1/4. 
$\mathrm{N}^{\circ}$ de Folios: 6. № de fascículos: 2. Descriptores: Ramón Bertrán, Bonifacio Gutierrez, Diego de la Torre, Francisco Cid, Diego Mayoral, Boerhaave, Toledo, Sala de la Preparación del Real Hospital de Santiago de los Cavalleros (Toledo).

COLL, JOSÉ SEBASTIÁN (Censura: TRUXILLO, RAMÓN)

Observacion de una hipocondría. Afectos Internos. 87-4-A-8, no 716 y 717. 23Febrero-1820 y 2-Marzo-1820. $\mathrm{N}^{\circ}$ de Folios: $8 \mathrm{~N}^{\circ}$ de Fascículos: 2, Descriptores: José Sebastián Coll, Ramón Truxillo, Madrid, Real Colegio de Cirugía de San Carlos.

PÁEZ, JOSÉ (Censura: CASTELLÓ, PEDRO)

Observacion de una paralisis en el codo izquierdo en una niña. Afectos Internos y Terapéutica. 57-4-A-8, no 718 y 719. 16 y 23-Marzo-1820. Estepa. $\mathrm{N}^{\mathrm{o}}$ de Folios: $9 . \mathrm{N}^{\mathrm{o}}$ de Fascículos: 2. Descriptores: José Páez, Pedro Castelló, Madrid, Estepa, Real Colegio de Cirugía de San Carlos.

\section{GARCÍA, FRANCISCO (Censura: ASO TRAVIESO, SEBASTIÁN)}

Descripción de una camilla de nueva invencion para alivio de las mugeres en el penoso acto del parto. Enfermedades de Mujeres. 87-4-A-8 no 720 y 7216 y 13-Abril1820. Papel: Folio y 1/4 $\mathrm{N}^{\circ}$ de Folios: 6, $\mathrm{N}^{\circ}$ de fascículos: 2. Descriptores: Francisco García, Sebastián Aso Travieso, Isabel de la Fuente, Francisco Mayo, Agustín Ginestá, Stein, Calle del Amor de Dios (Madrid).

\section{ANÓNIMO (Censura: RIBES, JOSEF)}

Observación sobre una oftalmía gonococica. Enfermedades de los Ojos. Enfermedades Venéreas. Terapéutica. 87-4-A-8, No 722 y 723. 20 y 27-Abril-1820. Papel: Folio y 1/4. $\mathrm{N}^{\mathrm{o}}$ de Folios: 6. $\mathrm{N}^{\mathrm{o}}$ de fascículos: 2. Descriptores: Josef Ribes, Anónimo, Madrid, Real Colegio de Cirugía de San Carlos.

\section{ALONSO DE ISLA, MANUEL (Censura: CAPDEVILA, RAMÓN)}

Consulta acerca de un Aneurisma de la Temporal. Afectos Mixtos. 87-4-A-8, no 724 y 725. 11 y 18-Mayo-1820. Papel: (1/4). $\mathrm{N}^{\circ}$ de Folios: 5, $\mathrm{N}^{\circ}$ de Fascículos: 2. Descriptores: Ramón Capdevila, Manuel Alonso de Isla, J. de Tiedra.

RUBÍ, JUAN (Censura: GUTIÉRREZ, BONIFACIO)

Consulta acerca de una Catarata en el ojo izquierdo de un niño. Enfermedades de los Ojos. Terapéutica. 87-4-A-8, no 726 y 727. 1 y 8-Junio-1820. Papel: (1/4). No de Folios: 11, No de Fascículos: 2. Descriptores: Juan Rubí, Bonifacio Gutiérrez, Vicenta Martínez, Hinojosa de la Orden, Puebla de Almoradiel, Quintanar de la Orden. 


\section{CHICOY, JOSÉ (Censura: TRUXILLO RAMÓN)}

Consulta acerca de un flujo hemorroidal. Afectos Internos, Terapéutica. 87-4-A-8, $\mathbf{n}^{\mathbf{0}}$ 728 y 729, 15 y 22-Junio-1820. Valencia. Papel: Folio. $\mathrm{N}^{\mathrm{o}}$ de Folios: 9. № de Fascículos: 2, Descriptores: José Chicoy, Ramón Truxillo, José Sanchiz, Sydenbam, San Felipe, Navajas, Montanejos, Valencia.

\section{DE AZA, LORENZO (Censura: CASTELLÓ Y GINESTÁ, PEDRO)}

Consu1ta acerca de una mordedura de Alacrán. 87-4-A-8, no 730 y 731. 5 y 120ctubre-1820. Fuentelisendo. Papel: Folio. $N^{o}$ de Folios: $5 \mathrm{~N}^{\mathrm{o}}$ de Fascículos: 2, Descriptores: Lorenzo de Aza, Pedro Castelló y Ginesta, Juan Sanz, Hunter, Masagni, Fuentelisendo, Aranda de Duero.

\section{DEL BARCO, ANTONIO}

SIRVENT, MARIANO

Censura: ASO TRAVIESO, SEBASTIÁN

Consulta acerca de un tumor duro en la circunferencia de la mamila del pecho derecho. Enfermedades de las Mujeres. 87-4-A-8, no 732 y 733. 19 y 26-Octubre-1820. La Roda, Papel: Folio y 1/4 No de Folios: $6 \mathrm{~N}^{\mathrm{o}}$ de Fascículos: 2. Descriptores: Antonio del Barco, Mariano Sirvent, Sebastián Aso Travieso, Josefa de Arce, La Roda.

\section{CAPDEVILA, RAMÓN (Censura: MOSÁCULA, JUAN)}

Observacion sobre nuevas preparaciones con el oro para la curacion de las enfernedades venéreas. Materia Médica, 87-4-A-8, no 734 y 735. 7 y 14-Diciembre-1820. Madrid. Papel: (1/4), No de Folios: 16. No de Fascículos: 2. Descriptores: Ramón Capdevila , Juan Mosácula, Aristóteles, Teofrasto, Juan Pagés, Mesmer, Deschamp, Tenard, Lamarc, Gabriel Falopio, Juan Colle, Chrestien, Francisco Antony, Planis Campi, Horstius, Clarey. Londres, Modena, Torgan, Tolosa, Montpellier, Parlamento de París.

\section{CASTELLÓ, JUAN}

Observación de un absceso herpetico en el cuello. Afectos Internos, Terapéutica. 87-4A-8, no 736. 8-Febrero-1821. Madrid. Papel: (1/4). No de Folios: 8. No de Fascículos: 1. Descriptores: Juan Castelló, Madrid, Real Colegio de Cirugía de San Carlos.

\section{ARÉBALO, MIGUEL (Censura: MOSÁCULA, JUAN)}

Breve y exacta relación de 1os efectos hidrópicos que han muerto y de los que se han curado en este Hospital de la Misrericordia de la ciudad de Segovia con una sucinta razón de los sintomas y metodo curatibo. Afectos Internos, Terapéutica. 87-4-A-8, no 737 y 738, 22-Febrero y 8-Marzo y 13-Abril-1821. Segovia. Papel: (1/4). $\mathrm{N}^{\circ}$ de Folios: 12. No de Fascículos: 2. Descriptores: Miguel Areva1o, Juan Mosácula, Bartolomé Mar- 
tínez de Pinillos, Isidoro Pérez de Célis, Madrid, Segovia, Valladolid. Hospital General de la Misericordia (Segovia), Hospital General de Valladolid, Facultad de Medicina (Valladolid), Real Academia Médico-Quirúrgica.

\section{MARTÍNEZ LÓPEZ, FÉLIX (Censura: GUTIÉRREZ, BONIFACIO)}

Observación sobre un caso de hematuria. Afectos internos, Terapeútica. 87-4-A-8, no 739 y 740. 22 y 29-Febrero-1.821. Valladolid. Papel: (1/4). No de Folios: 7. No de Fascículos: 2. Descriptores: Félix Martínez López, Bonifacio Gutiérrez. Madrid, Valladolid. Real Colegio de Cirujanos de Madrid.

LORENZO PÉREZ, JOSEF (Censura: TRUXILLO, RAMÓN)

Observación sobre un caso de ceguera. Enfermedades de los ojos. 87-4-A-8 $\mathbf{n}^{\mathbf{0}} \mathbf{7 4 1} \mathbf{y}$ 742. 4 y 12-Abril-1821; Salamanca. Papel: (1/4) $\mathrm{N}^{\mathrm{o}}$ de Folios: 7. $\mathrm{N}^{\mathrm{o}}$ de Fascículos: 2. Descriptores: Josef Lorenzo Pérez, Ramón Truxillo, Salamanca, Ciudad Rodrigo, Madrid, Real Colegio de Cirugía de San Carlos.

\section{MILLÁN, FACUNDO (Censura: RIBES, JOSEF)}

Consulta acerca de un cuerpo extraño y 13 cálculos arrojados por la uretra. Afectos Mixtos. 87-4-A-8, $\mathbf{n}^{\mathbf{0}} 743$ y 744. 7 y 14-Junio-1821. Papel: (1/4) $\mathrm{N}^{\circ}$ de Folios: 6. $\mathrm{N}^{\mathrm{o}}$ de Fascículos: 2. Descriptores: Facundo Millán, Josef Ribes, Francisco Bravo, Cendejas de Medio, Guadalajara.

\section{CISNEROS (Censura: ASO TRAVIESO, SEBASTIÁN)}

Observacion de una fiebre nerviosa. Afectos Internos. Terapéutica. 87-4-A-8, no 745 y 746. 17 y 24-Junio-1821. Papel: (1/4). No de Folios: 7. No de Fascículos: 2. Descriptores: Cisneros, Sebastián Aso Travieso, Ávila, Madrid, Catedral de Ávila, Real Colegio de Cirujanos de San Carlos de Madrid.

\section{ANÓNIMO (Censura: SÁNCHEZ, JUAN FRANCISCO)}

Observacion acerca de un parto con hemorrragia. Obstetricia. 87-4-A-8. No 747. 27Noviembre-1821. Papel: (1/4). $\mathrm{N}^{\mathrm{o}}$ de Folios: 6. $\mathrm{N}^{\mathrm{o}}$ de Fascículos: 1 (falta la Memoria). Descriptores: Juan Francisco Sánchez, Juan Castelló.

DE VIEDMA, GERÓNIMO MARÍA (Censura: MOSÁCULA, JUAN)

Observacion de un caso de Anafrodisia. Afectos Internos. No 748 y 749. 6 y 13Diciembre-1821. Papel: (1/4). No de Folios: 18. No de Fascículos: 2. Descriptores: Gerónimo María de Viedma, Juan Mosácula, Madrid, Colegio de Cirugía de San Carlos. 


\section{DE PAZ, ISIDRO}

Observacion sobre hidropesia de la matriz. Enfermedades de las Mujeres. 87-4-A-8, $\mathbf{n}^{\mathbf{0}}$ 750. 22-Febrero-1821. Papel: (1/8). No de Fascículos: 1 (falta la Censura). Descriptores: Isidro de Paz, Ceclavin.

\section{JULBE, DOMINGO}

Consulta sobre una Disentería. Afectos Internos, Materia Médica. 87-4-A-8, no 751. Papel: Folio. N No de Fascículos: 1 (falta la Censura). Descriptores: Domingo Julbe, Sydenham.

\section{QUINTANA, RUFINO}

Observacion sobre cálcu1os urinarios. Afectos Internos. 87-4-A-8, no 752. Medina de Pomar, 16-Diciembre-1821. Papel: (1/4). No de Fascículos: 1. Descriptores: Rufino Quintana, Medina de Pomar, Madrid, Colegio de Cirugía de San Carlos.

\section{PEDRO, INFANTE}

Observacion de una tisis. Afectos Internos. 87-4-A-8, no 753. 12-1821. Becerril del Campo, $\mathrm{N}^{\mathrm{o}}$ de Folios: 8. $\mathrm{N}^{\mathrm{o}}$ de Fascículos: 1 (Falta Censura, se adjunta Carta). Descriptores: Pedro Infante, Becerril del Campo.

\section{ELIZALDE}

LLOTGE, MIGUEL

Observacion sobre un carcinoma en la lengua. Afectos Internos 87-4-A-8, no 754. 13 y 21-Diciembre-1822. Bayona. Papel: Folio. $N^{o}$ de Fascículos: 2 (Ho hay Censura, hay unas reflexiones). Descriptores: Elizalde, Miguel Llotge, Bayona, San Sebastián, Madrid. Colegio de Cirugía de San Carlos.

\section{MOSÁCULA , JUAN}

Observación de una sarna complicada con una ulcera. Afectos Mixtos. 87-4-A-8, no 755. 24-0ctubre-1822. Papel: (1/8). $\mathrm{N}^{\mathrm{o}}$ de Folios: $8 . \mathrm{N}^{\mathrm{o}}$ de Fascículos: 1 (falta Censura). Descriptores: Juan Mosácula, Madrid.

\section{GALBÁN, BENITO (Censura: GUTIÉRREZ, BONIFACIO)}

Relacion de un herido que fue asistido en la Sala clínica de cirugia del ex. Col. de San Carlos y entro à ella el dia 2 de Mayo de 1808. Heridas por Arma de Fuego. Terapéutica. 87-4-A-8, no 756 y 757, 13 y 2O-Noviembre-1822. Papel: (1/4). No de Folios: 7. $\mathrm{N}^{\mathrm{o}}$ de Fascículos: 2. Descriptores: Benito Galbán, Bonifacio Gutiérrez, Sebastián Blanco, Josef Ribes, Francisco Garnelo, Sala de San Judas Tadeo. 


\section{DE LA CRUZ MILLÁN, ANTONIO}

Observacion sobre un parto laborioso por Antonio de la Cruz Millán. Enfermedades de las Mujeres. 87-4-A-8- no 758. 11-Septiembre-1822. Papel: Folio. $\mathrm{N}^{\mathrm{o}}$ de Folios: 4. $\mathrm{N}^{\mathrm{o}}$ de Fascículos: 1 (falta la Censura). Descriptores: Antonio de la Cruz Millán, Madrid, Vela.

\section{ESPINOSA LEÓN, JUAN}

Historia de un embarazo extrauterino ocurrido en Castromontes de Campos. Recogidos los echos y formada la historia por Don ... Obstetricia. 87-4-A-8 n 759. 28Julio-1822. Villagrabina. Papel: (1/4). $\mathrm{N}^{\mathrm{o}}$ de Folios: 6. $\mathrm{N}^{\mathrm{o}}$ de Fascículos: 1 (falta Censura). Está dedicada a las Cátedras del Colegio. Descriptores: Juan Espinosa León, Feliciana Adalia, Manuel Martín Blanco, Lorenzo Gordoncillo, Alfonso del Barrio, Florencio Casado, Villagrabina, Torrelobatón (Valladolid), Universidad de Salamanca.

\section{MENÉNDEZ, JOSÉ}

Consulta acerca de una herida por metralla en las manos. Heridas por Armas de Fuego. 87-4-A-8 no 760 6-Diciembre-1823. La Coruña. Papel: Folio. $\mathrm{N}^{\circ}$ de Folios: 3. $\mathrm{N}^{\mathrm{o}}$ de Fascículos: 1 (falta la Censura). Descriptores: José Menéndez, Ángel Ruíz, Antonio Pacheco, La Coruña, Arroyo Molinos (Extremadura). Hospital de Sangre.

\section{ACADEMIA DE MEDICINA DE MURCIA}

Consulta de la Academia de Medicina de Murcia acerca de las Facultades intelectua1 es de un sexagenario por motivos médico legales. Medicina Legal. 87-4-A-8, no 761. 1822. Murcia. Papel: Folio. $\mathrm{N}^{\mathrm{o}}$ de Folios: 6. $\mathrm{N}^{\mathrm{o}}$ de Fascículos: 1 (falta la Censura. Hay citas en Latín). Descriptores: Antonio Jordá, Van Schwiten, Dr. Gall, Cullen, Pablo Zachías, Baglivi, Malpigio, Fodere, Inocencio XII, Manuel Alarcón, Academia de Medicina de Murcia, Elementos de Medicina de Cullen, Medicina Forense de Pablo Zachías.

\section{ANÓNIMO (Censura: CASTELLÓ, PEDRO)}

Observacion sobre un tumor de la lengua. Enfermedades de la Boca, 87-4-A-8, no 762. 20-Febrero-1823. Papel. Folio. $\mathrm{N}^{\mathrm{o}}$ de Folios: 2. $\mathrm{N}^{\mathrm{o}}$ de Fascículos: 1 (falta Memoria). Descriptores: Pedro Castelló, Glizalde, Madrid.

\section{DE LA FUENTE, VICENTE}

Observacion sobre un catarro pulmonar. Afectos Internos. 87-4-A-8 $\mathbf{n}^{\mathbf{0}} \mathbf{7 6 3}, 20$ Enero-1823. Getafe. Papel: Folio. $N^{o}$ de Folios: 4. $N^{0}$ de Fascículos: 1 (falta Censura), Descriptores: Vicente de la Fuente, Getafe, Madrid. 
MORRANDO Y RODRÍGUEZ, MANUEL (Censura: SORIANO, VICENTE)

Observacion sobre una hemiplegia. $87-4-A-8, n^{\circ} 764$ y 764 bis. 11-Marzo-1823. Palencia. Papel: (1/8). $\mathrm{N}^{\mathrm{o}}$ de Folios: 8 . $\mathrm{N}^{\mathrm{o}}$ de Fascículos: 2. Descriptores. Manuel Morrando y Rodríguez, Vicente Soriano, Palencia, Madrid .

\section{SÁNCHEZ, JUAN FRANCISCO (Censura: ASO TRAVIESO, SEBASTIÁN)}

Observacion sobre un hidrocele. Afectos Mixtos. 87-4-A-8, no 765 y 765 bis. 10Febrero y 4-Marzo-1824. Papel: (1/4). $\mathrm{N}^{\mathrm{o}}$ de Folios: 11. $\mathrm{N}^{\mathrm{o}}$ de Fascículos: 2 (Hay un aforismo de Hipócrates en Latín). Descriptores: Juan Francisco Sánchez, Sebastián Aso Travieso, Francisco López, Bonifacio Gutiérrez, Hipócrates, Lorry, Josef Ribes, Sala de San Judas Tadeo.

\section{RAMOS ARANE, BENITO}

Observacion sobre Huesos de feto arrojados por el ano. Enfermedades de las Mujeres. 87-4-A-8, no 766 y 767. 3-Febrero-1824. Cuenca. Papel: (1/8). $\mathrm{N}^{\mathrm{o}}$ de Folios: 8. $\mathrm{N}^{\mathrm{o}} \mathrm{de}$ Fascículos: 3 (adjunta lámina a lápiz con las figuras óseas). Descriptores: Benito Ramos Arane, Cuenca, San Lorenzo de la Parrilla.

\section{AGUADO , ESTEBAN}

Consulta acerca de un derrame en el craneo. Afectos Internos. 87-4-A-8, no 768. 17Noviembre-1824. Arabayona de Moxica. Papel: Folio. $N^{\circ}$ de Folios: 2. No de Fascículos: 1. (Falta la Censura). Descriptores: Esteban Aguado, Arabayona de Moxica.

\section{INZA, FRANCISCO}

Observacion sobre una angina ulcerosa. Cirugía. 87-4-A-8, No 769 16-Noviembre1825. Papel: Folio. $N^{o}$ de Folios: 2. $N^{\circ}$ de Fascículos: 1 (falta la Censura). Descriptores: Francisco Inza, Madrid.

\section{RIBES, JOSEF (Censura: ASO TRAVIESO, SEBASTIÁN)}

Observacion sobre un caso de retencion de Orina. Afectos Internos. Terapéutica. 87-4A-8, $\mathbf{n}^{\mathbf{0}} 770$ y 771. 6 y 13-Octubre-1825. Papel: (1/4). No de Folios: 10. No de Fascículos: 2. Descriptores: Josef Ribes, Sebastián Aso Travieso, Manuel Bonafós, Arrieta, Hipócrates, Colegio de Cirugía de San Carlos.

\section{ANÓNIMO (Censura: SÁNCHEZ, JUAN FRANCISCO)}

Observacion sobre un tumor de parto. Enfermedades de las Mujeres. 87-4-A-8, $\mathbf{n}^{\mathbf{0}} 772$ y 773. 19-Octubre-1825 y 2-Noviembre-1825. Papel: (1/8). $\mathrm{N}^{\mathrm{o}}$ de Folios: 20 . $\mathrm{N}^{\mathrm{o}}$ de Fascículos: 2 (falta el final de la Memoria). Descriptores: Juan Francisco Sánchez, Madrid. 


\section{ASO TRAVIESO, SEBASTIÁN}

Observación sobre una caries a los dos maxilares desprendidos y cerrada a beneficio del ... corrosivo. Enfermedades de la Boca. 87-4-A-8, no 774. 24-Noviembre-1825. Papel: (1/8). $\mathrm{N}^{\mathrm{o}}$ de Folios: 6. $\mathrm{N}^{\mathrm{o}}$ de Fascículos: 1 (falta Censura). Descriptores: Sebastián Aso Travieso, Madrid.

GUTIÉRREZ, BONIFACIO (Censura: GUTIÉRREZ, BONIFACIO)

Observacion y censura de un caso de encefalitis. Afectos Internos. 87-4-A-8, $\mathbf{n}^{\mathbf{0}} \mathbf{7 7 5} \mathbf{y}$ 776. 15 y 22-Diciembre-1825. Papel: (1/4). $N^{\circ}$ de Folios: 8. No de Fascículos: 2. Descriptores: Bonifacio Gutiérrez, Francisco Montero de Sales, José Ramos Hofman, Real Casa de Campo.

\section{CALVO, LORENZO}

Observacion sobre un tumor artrosico. Enfermedades de los Huesos. 87-4-A-8, no 777. 22-0ctubre-1826. Santander. Pape1: (1/8). $\mathrm{N}^{\mathrm{o}}$ de Folios: 30. $\mathrm{N}^{\mathrm{o}}$ de Fascículos: 1 (falta Censura). Descriptores: Lorenzo Calvo, Santander, Madrid, Batallón de Regimiento de Lima.

\section{SÁNCHEZ, JUAN FRANCISCO}

Observacion sobre un parto laborioso. Enfermedades de las Mujeres . 87-4-A-6 , no 778. 12-Octubre-1826. Papel: (1/8). $\mathrm{N}^{\mathrm{o}}$ de Folios: 12. $\mathrm{N}^{\mathrm{o}}$ de Fascículos: 1 (falta Censura). Descriptores: Juan Francisco Sánchez, Madrid.

\section{MIRANDA, PEDRO}

Observación de un sarcocele. Cirugía y Terapéutica. 87-4-A-8. No 779. 4-Mayo-1.826. Aranda de Duero. Papel: (1/4). No de Folios: 1. No de Fascículos: 1. Descriptores: Pedro Miranda (Médio de Aranda de Duero), Aranda de Duero.

\section{ANÓNIMO}

Observación de una hemiplegia. Afectos Internos y Terapéutica. 87-4-A-8, no 780. 30Enero-1.826. Papel: folio. $\mathrm{N}^{\mathrm{o}}$ de Folios: 2. $\mathrm{N}^{\mathrm{o}}$ de Fascículos: 1 (Falta la Censura). Descriptores: Antonio Gárate, Manuel Rodríguez (Médico titular de Haro), Juan Santamaría (Médico titular de San Vicente), Cipriano Carcano (Médico titular de Miranda de Ebro), Francisco Lachsant, Ramón Uzpurino, Valladolid, Haro, San Vicente, Miranda de Ebro.

\section{ARGUMOSA, DIEGO (Censura: GUTIÉRREZ, BONIFACIO)}

Observacion de un asma crónica. Afectos Internos. 87-4-A-8, no 781 y 782, 8 y 15-Junio1826, Papel: (1/4). No de Folios: 14. No de Fascículos: 2. Descriptores: Bonifacio Gutiérrez, Diego de Argumosa, Alcántara, (Extremadura), Valencia de Alcántara (Badajoz). 
AVILÉS, JOSEF (Censura: RIBES, JOSEF)

Observacion de una hidropesía de la matriz. Enfermedades de las Mujeres. 87-4-A-8, $\mathbf{n}^{\circ} 783$ y 784. 25-Mayo-1826 y 1-Junio-1826. Papel: Folio y 1/4. $\mathrm{N}^{\mathrm{o}}$ de Folios: 5 . $\mathrm{N}^{\mathrm{o}} \mathrm{de}$ Fascículos: 2. Descriptores: Josef Avilés (Médico de Fonrubia), Josef Ribes. Fonrubia.

DÍEZ DE CELADA, MIGUEL (Censura: Mosacula, Juan)

Observacion de una enteritis. Afectos Internos. 87-4-A-8, no 785 y 786. 13 y 20-Abril-1826. Alamedilla del Berrocal (Ávila). Papel: (1/4). No de Folios: 13. № de Fasciculos: 2. Descriptores: Miguel Díez de Celada (cura párroco de Alamedilla. del Berrocal), Juan Mosácula.

\section{CARRASCO, MANUEL (Censura: ASO TRAVIESO, SEBASTIÁN)}

Observacion de una tisis escrofulosa con tubercu1osis. Afectos Internos. 87-4-A-8, $\mathbf{n}^{\mathbf{0}}$ 787 y 788. 30-Marzo-1826 y 6-Abril-1826. Papel: Folio y 1/4. $\mathrm{N}^{\mathrm{o}}$ de Folios: 12 . $\mathrm{N}^{\mathrm{o}} \mathrm{de}$ Fascículos: 2. Descriptores: Manuel Carrasco, Sebastián Aso Travieso, Josef, Riobo, Hipócrates, Galeno, Galicia.

\section{ANONIMO (Censura: SÁNCHEZ, JUAN FRANCISCO)}

Observacion de una Amaurosis incompleta. Afectos Internos. 87-4-A-8, $\mathbf{n}^{\circ} 789$ y 790. 9 y 16-Marzo-1826. La Coruña. Papel: Folio y 1/4. No de Folios: 6. No de Fascículos: 2. Descriptores: Juan Francisco Sánchez, La Coruña, Francia.

DE PUGA, FERNANDO (Censura: GUTIÉRREZ, BONIFACIO)

Observacion sobre una paralisis de la extremidad inferior izquierda, Afectos Internos. Terapéutica. 87-4-A-8 no 791y 792. 23-Febrero y 2-Marzo-1826. Orense. Papel: Folio y 1/4. No de Folios: 5. No de Fascículos: 2. Descriptores: Fernando de Puga, Bonifacio Gutiérrez, Orense, Madrid, Real Colegio de Cirugía de San Carlos.

CAPDEVILA, RAMÓN (Censura: MOSÁCULA, JUAN)

Observacion de una erisipela flictenosa en la cara. Afectos Internos, 87-4-A-8, $\mathbf{N}^{\mathbf{0}} \mathbf{7 9 3}$ y 794, 4 y 1l-Enero-1826, Papel: (1/4), $\mathrm{N}^{\mathrm{o}}$ de Folios: 25, $\mathrm{N}^{\mathrm{o}}$ de Fascículos: 2. Descriptores: Ramón Capdevila, Juan Mosácula, Madrid, Real Colegio de Cirugía de San Carlos.

DE SALAS Y SANTISTEBAN, FRANCISCO (Censura: CAPDEVILA, RAMÓN)

Observacion de una fístula vesico vagina1. Cirugía, 87-4-A-8, no 795 y 796, 3 y 10-Enero1827, Cazorla, Papel: (1/4), No de Folios: 5, No de Fascículos: 2, Descriptores: Francisco de Salas y Santisteban (facultativo de Cirugía de Cazorla), Ramón Capdevila. Cazorla.

CASADO, ANDRÉS (Censura: GUTIÉRREZ, BONIFACIO)

Observacion de un esfínter cisto intestinal. Afectos Internos, Terapéutica, 87-4-A-8, no 797 y 798, 18 y 25-Enero-1827, Reinosa, Papel: (1/4), No de Folios: 7, No de Fascículos: 
3 (dibujos sueltos), Descriptores: Andrés Casado, Bonifacio Gutiérrez, Madrid, Reinosa, Real Colegio de Cirugía de San Carlos.

ESARGUI, JOSÉ (Censura; ASO TRAVIESO, SEBASTIÁN)

Observación de un tumor en el sobaco derecho. Cirugía y Terapéutica, 87-4-A-8, no 799 y 800, Ávila, Papel: Folio, $\mathrm{N}^{\mathrm{o}}$ de Folios; 3, $\mathrm{N}^{\mathrm{o}}$ de Fascículos: 2, Descriptores; José Esargui (Profesor de Cirugía de Ávila), Sebastián Aso Travieso, Pott, Ávila.

ORTEGA, N. (Censura: RIBES, JOSEF)

Observación de un caso de asma y gota. Afectos Internos, 87-4-A-8, no 801 y 802, 15 y 22-Febrero-1.827, Papel: Folio (1/4), No de Folios: 7, $\mathrm{N}^{\circ}$ de Fascículos: 2 (Falta la censura). Descriptores: N. Ortega, Josef Ribes, Badajoz, Madrid, Real Colegio de Cirugía de San Carlos.

\section{MÉNDEZ, HIPÓLITO (Censura: SÁNCHEZ, JUAN FRANCISCO)}

Observación de un herpes hemorroidal. Afectos Mixtos, 87-4-A-81 no 803 y 804, 3 y 10-Marzo-1.827, Sevilla. Papel: Folio(1/4), № de Folios: 6, № de Fascícu1os: 2, Descriptores: Hipólito Méndez (comerciante de Sevilla), Dr. Bañares, Juan Francisco Sánchez, Sevilla.

GÓMEZ CIFUENTES, ANTONIO (Censura: MOSÁCULA, JUAN)

Observacion sobre un caso de histerismo. Afectos Mixtos. 87-4-A-8, no 805 y 806, 15 y 22-Marzo-1.827, Gijón. Papel: (1/4), No de Folios: 9, No de Fascículos: 2, Descriptores: Antonio Gómez Cifuentes, Juan Mosácula, Gijón, Madrid, Real Colegio de Cirugía de San Carlos.

GALLEGO, ANDRÉS

CARVALLO, SANTOS

HERVÁS, JOSÉ

MARTÍNEZ DE GATICA, JOSÉ

Observacion de un caso de cistitis. Afectos Internos. 87-4-A-8 n⿳ 807, 15-Abril-1827, Valladolid, Papel: Folio, $\mathrm{N}^{\mathrm{o}}$ de Folios: 4, $\mathrm{N}^{\mathrm{o}}$ de Fascículos: 1 (falta la Censura). Descriptores: Andrés Gallego, José Hervás, Santos Carvallo, José Martínez de Gatica, Valladolid, Madrid, Real Colegio de Cirugía de San Carlos.

\section{LAFARGE, JOAQUÍN (Censura: GUTIÉRREZ, BONIFACIO)}

Observación de una úlcera cancerosa de la boca. Cirugía, 87-4-A-8, no 808 y 809, 10 y 17-Mayo-1.827, Papel: Folio, (1/4), No de Folios: 8. No de Fascículos: 2, Descriptores: Joaquín Lafarge (Pedro de Cartagena), Bonifacio Gutiérrez, Cartagena, 
DE LEÑA, SANTIAGO (Censura: RIBES, JOSEF)

Observación sobre un escrofuloso. Afectos internos, 87-4-A-8, No 810 y 811, 30-Mayo1.827, Santiago de Laria. Papel: (1/4), № de Folios: 10, No de Fascículos: 2. Descriptores: Santiago de Leña, Josef Ribes, Madrid, Santiago de Laria.

\section{ZUBELZA, JOSÉ MARÍA (Censura: SÁNCHEZ, JUAN)}

Observación sobre una afección verrugosa. Afectos internos. 87-4-A-8. No 812 y 813. 21-Junio-1.827 y 28-Junio-1.827. Vigo. Papel: Folio. No de Folios: 12. No de Fascículos:

2. Descriptores: José María Zubelza, Juan Sánchez, Madrid, Vigo, Tormes.

\section{LÁZARO, MANUEL MARÍA}

Observación sobre una glándula thiroides. $\mathbf{N}^{\circ} 814$ y 815.5 y 12-Junio-1.827. Soto. Afectos Internos. 87-4-A-8. Papel: (1/4). $N^{\circ}$ de Folios: 12. No de Fascículos: 2 (Falta la censura y se adjunta una carta complementaria). Descriptores: Manuel María Lázaro, Madrid, Soto.

\section{MOSÁCULA, JUAN (Censura: ASO TRAVIESO, SEBASTIÁN)}

Observación sobre una sordera. Afectos Internos, 87-4-A-8, No 816 y 817, 4 y 11 Otubre-1.827, Papel: (1/8), $\mathrm{N}^{\mathrm{o}}$ de Folios: 24. $\mathrm{N}^{\mathrm{o}}$ de Fascíulos: 2, Descriptores: Juan Mosácula, Sebastián Aso Travieso, Madrid.

\section{CARREÑO, JOSÉ (Censura: GUTIÉRREZ, BONIFACIO)}

Observación de polipos en la faringe. Cirugía, 87-4-A-8, № 818 y 819, 29-Noviembre1.827 y 6-Diciembre- 1.827, Peraleda de la Mata (Toledo), Papel: Folio (1/4), No de Folios: $13 \mathrm{~N}^{\circ}$ de Fascículos: 2. Descriptores: Bonifacio Gutiérrez, José Carreño (Cirujano de Peraleda de la Mata), Juan José Cepeda, José Bonillo (Profesor de Cirugía de Madrid), Francisco Viller (Profesor de Cirugía de Madrid), Genaro Fernández (segundo ayudante de cirugía del Ejército), Bell, Richerand, Ribes, Castelló, Hurtado de Mendoza, Arenas de San Pedro (Ávila), Peraleda de la Mata (Toledo), Madrid.

\section{SÁNCHEZ, JUAN FRANCISCO (Censura: CAPDEVILA, RAMÓN)}

Observacion de una dislocacion de la rotula. Cirugía, 87-4-A-8. $\mathbf{N}^{\circ} 820$ y 821, 13 y 19-Diciernbre-1.827. Papel: (1/4), $\mathrm{N}^{\mathrm{o}}$ de Folios: 11. $\mathrm{N}^{\mathrm{o}}$ de Fascículos: 2, Descriptores: Francisco Fernández (Capitán retirado), Diego Rodríguez del Pino, Francisco Sánchez, Francisco Alarcos, Leonardo Galli, Juan Francisco Sanchez, María Josefa de Borbón (Infanta de España), Petit, Louis, Heiszen, Bassnl, Ravaton, Bell, Aitken, Ramón Capdevila, Warnen, Flajan, Bucking, Dejoult, Boyer, Richerand. 


\section{SÁNCHEZ, MANUEL MARÍA}

Observacion de una herida en la cabeza. Cirugía, 87-4-A-8, N 822. 21-Marzo-1.827. Papel: Folio, $\mathrm{N}^{\mathrm{o}}$ de Folios: 1, $\mathrm{N}^{\mathrm{o}}$ de Fascículos, 1 (Falta la censura). Descriptores: Manuel María Sánchez(Cirujano titular de Montemayor), Montemayor (Salamanca).

ASO TRAVIESO, SEBASTIÁN (Censura: MOSÁCULA, JUAN)

Observacion de un parto trabajoso. Obstetricia. 87-4-A-8. $\mathbf{N}^{\circ} 823$ y 824, 10 y $17-$ Enero-1.828, Papel: (1/4), $\mathrm{N}^{\mathrm{o}}$ de Folios: 16. $\mathrm{N}^{\mathrm{o}}$ de Fascículos: 2, Descriptores: Sebastián Aso Travieso, Juan Mosácula, Juan Castelló.

\section{HERNÁNDEZ MOREJÓN, ANTONIO (Censura: SÁNCHEZ, JUAN)}

Observacion de una neuropatia interna con mudez. Afectos Internos, 87-4-A-8, $\mathbf{N}^{\circ} \mathbf{8 2 5}$ y 826. 24 y 31-Enero-1.828. Papel: (1/4), $\mathrm{N}^{\mathrm{o}}$ de Folios: 11, $\mathrm{N}^{\mathrm{o}}$ de Fascículos: 2. Descriptores: Antonio Hernández Morejón, Juan Sánchez, Hipócrates, Galeno, Haller, Meckel.

\section{GUTIÉRREZ, BONIFACIO (Censura: ASO TRAVIESO, SEBASTIÁN)}

Observacion de la curación de una infiltracion urinosa causada por la retencion de orina. Afectos Internos y Cirugía, 87-4-A-8, No 827 y 828, 14 y 21-Febrero-1.828, Papel: Folio (1/4). $\mathrm{N}^{\mathrm{o}}$ de Folios: 16. $\mathrm{N}^{\mathrm{o}}$ de Fascículos: 2, Descriptores: Bonifacio Gutiérrez, Sebastián Aso Travieso.

\section{CAPDEVILA, RAMÓN (Censura: HERNÁNDEZ MOREJÓN, ANTONIO)}

Observacion de un caso de hematemesis, Afetos Internos y Terapéutica. 87-4-A-8. $\mathbf{N}^{\mathbf{0}}$ 829 y 830. 28-Febrero-1.828. Papel: (1/4). No de Folios: 15. № de Fascículos: 2, Descriptores: Ramón Capdevila, Antonio Hernández Morejón, Madrid, Real Colegio de Cirugía de San Carlos.

\section{MOSÁCULA, JUAN (Censura: GUTIÉRREZ, BONIFACIO)}

Observacion de una preñez complicada, Obstetricia, 87-4-A-8, № 831 y 832, 13 y 20Marzo-1.828. Papel: (1/4), $\mathrm{N}^{\mathrm{o}}$ de Folios: 15, No de Fascículos: 2, Descriptores: Juan Mosácula, Bonifacio Gutiérrez.

\section{SÁNCHEZ, JUAN (Censura: CAPDEVILA, RAMÓN)}

Observacion sobre una pústula maligna, Afectos Mixtos. Terapéutica. 87-4-A-8. No 833 y 834. 27-Marzo y 10-Abril-1.828, Papel: (1/4), No de Folios: 13, № de Fascículos: 2. Descriptores: Juan Sánchez, Ramón Capdevila, Pedro González de Godoy, Fabricio del Agua Pendente, Chausier, Belot, Boerhaave, Madrid, París, Real Colegio de Cirugía de San Carlos. 


\section{ASO TRAVIESO, SEBASTIÁN (Censura: SÁNCHEZ, JUAN)}

Observacion sobre una dis1ocacion del Codo. Enfermedades de los Huesos. 87-4-A-8, No 835 y 836, 24-Abril y 8-Mayo-1.828, Papel: (1/4). No de Folios: 11, No de Fascículos: 2, Descriptores: Sebastián Aso Travieso, Juan Sánchez, Madrid, Murcia. Hospital Militar de Murcia, Real Colegio de Cirugía de San Carlos.

\section{LAPLANA, PEDRO}

Observacion de una ascitis, Afectos Internos. 87-4-A-8. $\mathbf{N}^{\circ}$ 837. Papel: (1/4), $\mathrm{N}^{\circ}$ de Folios: 2. No de Fascículos: 1 (Falta la censura). Descriptores: Pedro Laplana.

\section{ORTEGA, VICENTE (Censura: MOSÁCULA, JUAN)}

Observacion de un calculo por cuerpos extraños, Afectos Internos y Cirugía, 87-4-A8, No 838, 9 y 12-Junio-1.828, Aranda de Duero. Papel: (1/4), $\mathrm{N}^{\mathrm{o}}$ de Folios: 8, $\mathrm{N}^{\mathrm{o}}$ de Fascículos: 1, Descriptores: Ortega (Profesor de cirugía de Aranda de Duero), Sebastián Aso Travieso, Antonio Vicente Camarero, Aranda de Duero.

\section{ASO TRAVIESO, SEBASTIÁN}

Censura sobre una observacion de la expulsion de cuerpos extraños por la córnea. Enfermedades de los Ojos, 87-4-A-8, No 839, 26-Junio-1.828. Papel: (1/4), No de Folios: 5, No de Fascículos: 1 (Falta la memoria). Descriptores: Sebastián Aso Travieso, Madrid, Real Colegio de Cirugía de San Carlos.

\section{GONZÁLEZ, MAXIMINO}

Observacion sobre una mujer con sucesivos partos defectuosos y abortos, Obstetricia y Enfermedades de las Mujeres. 87-4-A-8, $\mathbf{N}^{\circ} \mathbf{8 4 0}$, 30-Mayo-1.828, Papel: (1/4), $\mathrm{N}^{\mathrm{o}}$ de Folios: 9, No de Fascículos: 1 (Falta la censura). Descriptores: Maximino Gonzalez, Madrid, Real Colegio de Cirugía de San Carlos.

\section{MARTÍNEZ, JOAQUÍN (Censura: CAPDEVILA, RAMÓN)}

Observacion de un ano contranatura, Afectos Internos y Terapéutica, 87-4-A-8. $\mathbf{N}^{\circ}$ 841 y 842. 30-0ctubre y 6-Noviembre-1.828, Dombelles, Papel: Folio, (1/4) N de Folios: 10, $\mathrm{N}^{\mathrm{o}}$ de Fascículos: 3, Descriptores: Joaquín Martínez, Ramón Capdevila, Dombelles, Madrid, Real Colegio de Cirugía de San Carlos.

\section{SAINZ DE SEGURA, ANTONIO (Censura: CASTELLÓ, JUAN)}

Observacion de una metrorragia puerperal con implantación de la placenta, Obstetricia y Cirugía, 87-4-A-8, $\mathbf{N}^{\mathbf{0}} \mathbf{8 4 3}$ y 844, 20 y 27-Noviembre-1.828, Durango. Papel: Folio (1/4), $\mathrm{N}^{\mathrm{o}}$ de Folios: 10, $\mathrm{N}^{\mathrm{o}}$ de Fascículos: 2, Descriptores: Antonio Sainz de Segura 
(Cirujano, médico titular de Durango), Juan Castelló, María Nicolasa de Aldecoa, Morejón, Gutiérrez, Capdevila, Sánchez, Durango.

CÉSPEDES, JOSÉ (Censura: SÁNCHEZ, JUAN)

Observacion sobre un caso de carbunco. Afectos Internos, 87-4-A-8, no 845 y 846. 4 y 11-Diciembre-1.828, Granátula. Papel: Folio y 1/4. $\mathrm{N}^{\mathrm{o}}$ de Folios: 6, $\mathrm{N}^{\mathrm{o}}$ de Fascículos: 2, Descriptores: José Céspedes, Juan Sánchez, Hipócrates, Celso, Pinell, Chausier, Boyer, Granatula, Madrid, Real Colegio de Cirugía de San Carlos.

TORNECILLA, VALENTÍN

EDO, ANTONIO

(Censura: ASO TEAVIESO, SEBASTIÁN)

Observacion de un absceso de la margen del ano. Afectos Internos y Terapéutica, 874-A-8, no 847 y 848, 8 y 15-Enero-1.828, Valencia, Papel: Folio y 1/4. No de Folios: 8. $\mathrm{N}^{\mathrm{o}}$ de Fascículos: 2. Descriptores: Valentín Tornecilla, Antonio Edo, Sebastián Aso Travieso, Valencia, Madrid, Real Colegio de Cirugía de San Carlos.

LÓPEZ, PASQUAL (Censura: HERNÁNDEZ MOREJÓN, ANTONIO)

Observacion de un ataque de gota en el dedo pulgar del pie derecho, Afectos Internos, 87-4-A-8, no 849 y 850, 20 y 29-Enero-1.829, Medinaceli. Papel; Folio y 1/4, Descriptores: Pasqual López, Antonio Hernández Morejón, Hofman, Heister, Allen, Boerhave, Hipócrates, Ponce (Catedratico de Valladolid y Médico de Felipe III), Sydenham, Saillant, Rugenier, Viett, Pasqualati, Nissot, Fuller, Medinaceli, Castilla, Valladolid.

MOSÁCULA, JUAN (Censura: CAPDEVILA, RAMÓN)

Observacion de un parto dificil, Obstetricia, 87-4-A-8, № 851 Y 852, 4 y 12-Febrero1829, Papel: (1/4), $\mathrm{N}^{\mathrm{o}}$ de Folios: 12 , No de Fascículos: 2 , Descriptores: Juan Mosácula, Ramón Capdevila, Madrid, Real Colegio de Cirugía de San Carlos.

BARREDO, RAMÓN

ALCÁZAR, FRANCISCO

(Censura: GUTIÉRREZ, BONIFACIO)

Observacion sobre un caso de hidropesia, Afectos Internos, Terapéutica, 87-4-A-8, no 853 y 854, 19 y 26-Febrero, Pastrana, Papel: Folio y 1/4, No de Folios: 6. No de Fascículos: 2. Descriptores: Ramón Barredo, Francisco Alcázar, Bonifacio Gutiérrez. Pastrana, Madrid, Real Colegio de Cirugía de San Carlos.

MOSÁCULA, JUAN

Censura sobre una observacion de fístula uretral. Cirugía. 87-4-A-8, $\mathbf{N}^{\mathbf{0}} \mathbf{8 5 5}, 2$-Abril1.829. Papel: (1/4). $\mathrm{N}^{\mathrm{o}}$ de Folios: 7. $\mathrm{N}^{\mathrm{o}}$ de Fascículos: 1 (Falta la memoria). Descriptores: Juan Castelló, Juan Mosácula. Real Colegio de Cirugía de San Carlos, Madrid. 


\section{FERNÁNDEZ, CIRILO (Censura: SÁNCHEZ, JUAN)}

Observacion de un caso de Manía amorosa. Afectos Internos, 87-4-A-8, no 856 y 857, 16 y 23-Abril-1.829, Carpio, Papel: Folio y 1/4. $\mathrm{N}^{\mathrm{o}}$ de Folios: 6, $\mathrm{N}^{\mathrm{o}}$ de Fascículos: 2. Descriptores: Cirilo Fernández, Juan Sánchez, Ovidio, Carpio, Madrid, Real Colegio de Cirugía de San Carlos.

\section{CAPDEVILA, RAMÓN (Censura: ASO TRAVIESO, SEBASTIÁN)}

Observacion de quemaduras tratadas por los cloruros de calcio. Afectos Internos. Terapéutica, 87-4-A-8, no 858 y 859. 30-Abril-1.829 y 7-Mayo-1.829, Papel: (1/4), No de Folios: 14. No de Fascículos: 2 . Descriptores: Ramón Capdevila, Sebastián Aso Travieso.

\section{GUTIÉRREZ, BONIFACIO (Censura: HERNÁNDEZ MOREJÓN, ANTONIO)}

Observacion de una hernia estrangulada. Cirugía., 87-4-A-8, no 860 y 861, 21 y 28Mayo-1.829. Papel: (1/4), $\mathrm{N}^{\mathrm{o}}$ de Folios: 9. $\mathrm{N}^{\mathrm{o}}$ de Fascículos: 2, Descriptores: Bonifacio Gutiérrez, Antonio Hernández Morejón, Petit, Monro, Astley, Comper, Pedro Castelló, Bertrandi, Mikaelis, Albulasis de Córdoba, Pot, Leblanc, Richter, Escarpa, Antonio Gimbernat.

\section{SÁNCHEZ, VICENTE (Censura: GUTIÉRREZ, BONIFACIO)}

Observacion de una ulcera carcinomatosa del labio inferior, Cirugía, 87-4-A-8, no 862 y 863. 16 y 25-Junio-1829, Papel: (1/4), $\mathrm{N}^{\mathrm{o}}$ de Folios: 6, $\mathrm{N}^{\mathrm{o}}$ de Fascículos: 2. Descriptores: Vicente Sánchez, Bonifacio Gutiérrez, Fray Juan Camacho (religioso franciscano), Sebastián Aso, Castelló, Capdevila, Mosácula, Argumosa, Callejo, Brador, Pozo Blanco (Córdoba).

\section{TORDESILLAS, FRANCISCO (Censura: MOSÁCULA, JUAN)}

Observacion de un hidrocele doble, Cirugía. 87-4-A-8, no 864 y 865.15 y 22-Octubre1829, Papel: Folio y 1/4, $\mathrm{N}^{\mathrm{o}}$ de Folios: 8. $\mathrm{N}^{\mathrm{o}}$ de Fascículos: 2, Descriptores: Francisco Tordesillas, Juan Mosácula, Castelló, Madrid, Valladolid.

\section{CARRASCO, JUAN FRANCISCO (Censura: SÁNCHEZ, JUAN FRANCISCO)}

Observacion de una afeccion vertinosa con epilepsia y amarosis. Afectos Internos, 874-A-8, no 866 y 867. 29-0ctubre-1829 y 5-Noviembre-1829, Toboso, Papel: (1/4), No de Folios: 6, No de Fascículos: 2. Descriptores: Juan Francisco Carrasco (profesor de Cirugía de Toboso, Juan Francisco Sánchez, Fuller, Masdeval, Toboso.

FERNANDEZ Y OCHOA, RAMÓN

CORREA

DIRECTOR DE LOS BAÑOS DE CALDAS (OVIEDO) 
Censura: DE ARGUMOSA, DIEGO

Observacion de una disfasia, 87-4-A-8, no 868 y 869, 10 y 19-Noviembre-1829. Gijón, Papel: (1/4). No de Folios: 19, No de Fascículos: 3. Descriptores: Ignacio Martínez Valdés, Correa (Médico jubilado del Cabildo de Oviedo), Ramón Fernández y Ochoa, Diego de Argumosa, Gijón, Oviedo, Baños de Caldas.

DE LA HUERTA, MANUEL (Censura: OBRADOR, BARTOLOMÉ)

Observacion de una inversión de la matriz, Cirugía, 87-4-A-8, no 870 y 871 . 26Noviembre y 3-Diciembre-1829, Papel: (1/4). $\mathrm{N}^{\mathrm{o}}$ de Folios: 7. $\mathrm{N}^{\mathrm{o}}$ de Fascículos: 2, Descriptores: Manuel de la Huerta, Bartolomé Obrador.

\section{ARDANAZ, PEDRO}

Observacion de paralisis de los extremos inferiores, Afectos Internos. 87-4-A-8, $\mathbf{n}^{\mathbf{0}}$ 872, 1829, Lorella, Papel; (1/4), $\mathrm{N}^{\mathrm{o}}$ de Folios: 2, $\mathrm{N}^{\mathrm{o}}$ de Fascículos: 1 (falta la Censura), Descriptores: Pedro Ardanaz, Lorella.

\section{BALLO, ANTONIO}

Observacion de una hemorragia anterior al parto con dolor suprapubiano, Obstetricia, Enfermedades de las Mujeres, 87-4-A-8, $\mathbf{n}^{\mathbf{0}}$ 874, 1829. Alcalá de Henares, Papel; (1/4), $N^{o}$ de Folios: 3, $N^{o}$ de Fascículos: 1 (falta la Censura), Descriptores: Antonio Ballo, Alcalá de Henares.

GUIRAO, BLAS

Observacion de una fístula recto vaginal, Cirugía, 87-4-A-8, no 875, 1829, Calzada de Calatrava, Papel: (1/4), No de Folios: 2. No de Fascículos: 1 (falta la Censura). Descriptores: Calzada de Calatrava, Blas Guirao, Sebastián Aso Travieso, Dr. Daura.

\section{TERRÓN Y MOLÉS, VICENTE}

Historia de un escirro del cerebro. Cirugía y Terapéutica. 87-4-A-8, n⿳ 876. Agosto1829, Chapinería (Madrid) . Papel: (1/4). $\mathrm{N}^{\mathrm{o}}$ de Folios: 16. $\mathrm{N}^{\mathrm{o}}$ de Fascículos: 2 (hay original y copia de la Memoria, pero falta la censura), Descriptores: Francisco Melón, Vicente Terrón y Molés, Chapineria (Madrid).

\section{BALLO, ANTONIO (Censura: ASO TRAVIESO, SEBASTIÁN)}

Observacion sobre un embarazo, Obstetricia. 87-4-A-9, no 877 y 878. 7-Enero-1830 y 14-Enero-1830. Papel: 1/4 y 1/8, $\mathrm{N}^{\mathrm{o}}$ de Folios: 10, No de Fascículos: 2. Descriptores: Antonio Ballo, Sebastián Aso Travieso, Madrid, Vigo. 
FERNÁNDEZ, MARIANO (Censura: GUTIÉRREZ, BONIFACIO)

Observacion sobre unos tumores hemorroidales, Afectos Internos. 87-4-A-9, $\mathbf{n}^{\mathbf{0}} 879 \mathbf{y}$ 880. 21-Enero-1830 y 28-Enero-1830. Papel: (1/8). No de Folios: 14, No de Fascículos: 2. Descriptores: Mariano Fernández, Bonifacio Gutiérrez, Madrid, Vigo.

Censura: MORALENA, JUAN

Observacion sobre una herida cortante en la region epigastrica del lado izquierdo, Cirugía. 87-4-A-9, no 881 y 882, 18-Febrero-1830 y 25-Febrero-1830. Papel: (1/8), No de Folios: 8. $\mathrm{N}^{\mathrm{o}}$ de Fascículos: 2 (falta la Memoria), Descriptores: Juan Moranela, Madrid.

Censura: SÁNCHEZ, JUAN

Observacion sobre una fiebre sintomatica inflamatoria. Afectos Internos, 87-4-A-9, no 883, ll-Marzo-1830, Papel: (1/8), $\mathrm{N}^{\mathrm{o}}$ de Folios: 8. $\mathrm{N}^{\mathrm{o}}$ de Fascículos: 1 (falta Memoria), Descriptores: Juan Sánchez, Madrid.

OBRADOR, BARTOLOMÉ

Observacion sobre una epilepsia. Afectos Internos, 87-4-A-9, n⿳ 884, 14-Abril-1830, $\mathrm{N}^{\mathrm{o}}$ de Folios; 8. $\mathrm{N}^{\mathrm{o}}$ de Fascículos: 1 (falta Censura), Descriptores: Bartolomé Obrador, Madrid.

GALLEGO, CÁNDIDO (Censura: OBRADOR, BARTOLOMÉ)

Observacion de una basta superficie quemada por Cándido Ga1lego, Cirugía, 87-4A-9, no 886 y 887. 6-Mayo-1830 y 13-Mayo-1830, Papel: (1/8), No de Folios: 12 , $\mathrm{N}^{\mathrm{o}}$ de Fascículos: 2, Descriptores: Cándido Gallego, Bartolomé Obrador, Madrid, Vigo.

SÁNCHEZ, ROMUALDO (Censura: ASO TRAVIESO, SEBASTIÁN)

Observacion sobre un derrame de sangre en el vientre por Romualdo Sánchez . Afectos Internos. 87-4-A-9, no 887 y 888. 27-Mayo-1830 y 3-Junio-1830, Becerril, Papel: (1/8), $\mathrm{N}^{\mathrm{o}}$ de FolioS: 22. $\mathrm{N}^{\mathrm{o}}$ de Fascículos: 2, Descriptores: Romualdo Sánchez, Sebastián Aso Travieso, Madrid, Becerril.

ARGUMOSA, DIEGO (Censura: GUTIÉRREZ, BONIFACIO)

Indicacion del arte de curar por Diego de Argumosa, 87-4-A-9, no 889 y 890, 7Octubre-1830 y 21-Octubre-1830, Castraseriz, Papel: (1/8). $\mathrm{N}^{\mathrm{o}}$ de Folios: $24, \mathrm{~N}^{\mathrm{o}}$ de Fascículos: 2, Descriptores: Diego Argumosa, Bonifacio Gutiérrez, Madrid, Castraseriz.

SÁNCHEZ, JUAN FRANCISCO (Censura: CAPDEVILA, RAMÓN)

Observacion sobre un derrame con osteitis y gangrena de una mandíbula, Cirugía, 87-4-A-9, no 891 y 892. 5-Noviembre-1830 y 11-Noviembre-1830. Vigo. Papel: (1/8), No 
de Folios: 16, No de Fascículos: 2. Descriptores: Juan Francisco Sánchez, Ramón Capdevila, Madrid, Vigo, Carballino.

\section{SAEZ, SEBASTIÁN}

Observacion sobre un catarro pulmonar crónico, Afectos Internos. 87-4-A-9, no 893, 16-Noviembre-1830, Papel: Folio, No de Folios: 4, No de Fascículos: 1 (falta la Censura), Descriptores: Sebastián Saez, Madrid.

MARTÍNEZ, PEDRO (Censura: CASTELLÓ, JUAN)

Observacion de un cálculo. Afectos Internos. 87-4-A-9, no 894 y 895, 18-Noviembre1830 y 25-Noviembre-1830, Miño, Papel: (1/8), No de Folios: 16, No de Fascículos: 2, Descriptores: Pedro Martínez, Juan Castelló, Madrid, Miño.

ESPINOSA, BERNARDO (Censura: MOSÁCULA, JUAN)

Observacion sobre una imperforacion del canal vaginal. Enfermedades de las Mujeres. 87-4-A-9, no 896 y 897. 2-Diciembre-1830 y 9-Diciembre-1830. Navas del Marqués, Papel: (1/8). N ${ }^{o}$ de Folios: 36, No de Fascículos: 2, Descriptores: Bernardo Espinosa, Juan Mosácula, Madrid, Navas del Marqués.

\section{GONZÁLEZ RIAZA, SEBASTIÁN (Censura: SÁNCHEZ, JUAN FRANCISCO)}

Ventajas del Cloruro de Cal en la gangrena, Terapéurica. 87-4-A-9, no 898 y 899. 16Diciembre-1830 y 23-Diciembre-1830. Papel: (1/8). No de Folios: 14, No de Fascículos: 2. Descriptores: Sebastián González Riaza, Juan Francisco Sánchez, Madrid, La Cabrera.

CAPDEVILA, RAMÓN (Censura: DE ARGUMOSA, DIEGO)

Observacion de una saburra gastro-intestinal complicada con una pleuro-perineumonia. Afectos Internos. Terapéutica, 87-4-A-9, no 900 y 901, 8 y 22-Noviembre-1832, Papel: (1/4), $\mathrm{N}^{\mathrm{o}}$ de Folios: 11, $\mathrm{N}^{\mathrm{o}}$ de Fascículos: 2. Descriptores: Diego de Argumosa, Ramón Capdevila, Pinel, Sauvages, Cullen, Stoll, Lerna.

DE ARGUMOSA, DIEGO (Censura: CALLEJO, CÁNDIDO)

Invención del Syringotomo, Cirugía, 87-4-A-9, no 902 y 903, 29-Noviembre-1832 y 6Diciembre-1832, Papel: Folio y 1/4, No de Folios: 17, No de Fascículos: 2, Descriptores: Diego de Argumosa, Cándido Callejo.

MARTÍNEZ, SILVERIO (Censura: OBRADOR, BARTOLOMÉ)

Observacion de una amaurosis. 87-4-A-9, no 904 y 905.13 y 20-Diciembre-1832, Aranda de Jarque o del Conde, Papel: Folio, $\mathrm{N}^{\mathrm{o}}$ de Folios: 7, $\mathrm{N}^{\mathrm{o}}$ de Fascículos: 2, Des- 
criptores: Silverio Martínez (Cirujano de Catalayud), Bartolomé Obrador, Andrés Calabria, Mariano Calabria (padre del paciente), Juan Castelló y Jaquell, Aranda de Jarque (o del Conde), Calatayud, Junta Escolástica del Colegio de Medicina y Cirugía de San Carlos.

\section{SALMILLO, GASPAR (Censura: HYSERN, JOAQUÍN)}

Observacion de una otitis y caries, 87-4-A-9, Cirugía y Terapéutica, 87-4-A-9, no 906 y 906 bis, 3 y 7-Enero-1833, Becerril de Campus, Papel: Folio y 1/4, No de Folios: 15, No de Fascículos: 2, Descriptores: Gaspar Salmillo (Cirujano de Becerril del Campo), Joaquín Hysern, Pablo de Medina, Manuel Infantes (Cirujano de Becerril de Campus), Juan Tiburcio García (Médico de Becerril), Lecat, Desault, Valsalva, Becerril de Campos, Villa Herreros (Partido de Carrión de los Condes).

\section{PARCET, JAIME (Censura: CASTELLÓ Y TAGELL, JUAN)}

Observacion de un cálculo en la uretra, Cirugía y Terapéutica, 87-4-A-9, no 907 y 908, 24 y 31-Enero-1833, Papel: Folio y 1/4. No de Folios: 11, No de Fascículos: 2, Descriptores: Jaime Parcet (Cirujano del Hospital Militar y Civil de Tarragona), Juan Castelló y Tagell, Manuel Bendres, Tarragona, Hospital Militar y Civil.

\section{ALVERTOS, ANTONIA (Censura: GUTIÉRREZ, BONIFACIO)}

Observacion de una metrorragia sospechosa, Ginecología y Obstetricia, 87-4-A-9, no 909 y 910, 7 y 14-Febrero-1833, Riaza (Segovia), Papel: Folio y 1/4. $N^{o}$ de Folios: 8, No de Fascículos: 2, Descriptores: Antonia Alvertos, Manuel Pener Mozo, Bonifacio Gutiérrez, Riaza (Segovia).

\section{GUTIÉRREZ, BONIFACIO (Censura: OBRADOR, BARTOLOMÉ)}

Observacion de una pleuroneumonía, Afectos Internos, 87-4-A-9, no 911 y 912, 18 y 25-Abril-1833, Papel: (1/4), No de Folios: 17, No de Fascículos: 2, Descriptores: Bonifacio Gutiérrez, Bartolomé Obrador, Manuel Ávila.

\section{ROYO, FRANCISCO (Censura: SÁNCHEZ, JUAN FRANCISCO)}

Observacion sobre una herida e hidrofobia. 87-4-A-9, no 913 y 914, 7-Marzo-1833 y 14-Marzo-1833. Zaragoza, Papel: (1/8), $\mathrm{N}^{\mathrm{o}}$ de Folios: 16, No de Fascículos: 2, Descriptores: Francisco Royo, Juan Francisco Sánchez, Magendie, Chausier, Madrid, Zaragoza. Hospital Militar de Zaragoza.

\section{GARCÍA BUSTILLOS, BONIFACIO (Censura: HYSERN, JOAQUÍN)}

Observacion sobre el cornezuelo del centeno, Terapéutica, 87-4-A-9, no 915 y 916, 16Mayo-1833 y 23-Mayo-1833, Olmedo, Papel: (1/8). $\mathrm{N}^{\mathrm{o}}$ de Folios: 20. No de Fascículos: 2. Descriptores: Bonifacio García Bustillos, Joaquín Hysern. Olmedo, Madrid. 
TRUJILLO, RAMÓN (Censura: CAPDEVILA, RAMÓN)

Observacion sobre una fractura del húmero con herida, Enfermedades de los Huesos. 87-4-A-9, no 917 y 918. 14-Noviembre-1833 y 21-Noviembre-1833. Papel: (1/8). No de Folios: 13, No de Fascículos: 2. Descriptores: Ramón Trujllo, Ramón Capdevila, Madrid.

DE SILVA, FRANCISCO (Censura: CASTELLÓ Y FAJEL, JUAN)

Observacion sobre una herida penetrante en el pecho. Cirugía , 87-4-A-9, no 919 y 920, 10 y 17-Octubre-1833. Papel: (1/4 y1/8). No de Folios: 22. N $^{\circ}$ de Fascículos: 2, Descriptores: Francisco de Silva, Juan Castelló y Fajel, Madrid.

Censura: GUTIÉRREZ, BONIFACIO

Observacion sobre una calentura meningo gastrica, Afectos Internos. 87-4-A-9, 7Noviembre-1833, $\mathbf{n}^{\circ}$ 921, Papel: (1/8). № de Folios: 8. No de Fascículos: 2. Descriptores: Bonifacio Gutiérrez, Madrid.

FAJEL, JUAN (Censura: TRUJILLO, RAMÓN)

Observacion sobre una (...) y delirio nervioso, Afectos Internos. 87-4-A-9, no 922, 4Diciembre-1833, Papel: (1/8), $\mathrm{N}^{\mathrm{o}}$ de Folios: 8, $\mathrm{N}^{\mathrm{o}}$ de Fascículos: 1 (falta la Memoria). Descriptores: Juan Fajel, Ramón Trujillo, Toribio Riesco, Madrid.

HYSERN, JOAQUÍN (Censura: SÁNCHEZ, JUAN FRANCISCO)

Observacion sobre litotricia, Cirugía. 87-4-A-9. No 923, 16-Enero-1834, Papel: (1/8), $\mathrm{N}^{\mathrm{o}}$ de Folios: 8, $\mathrm{N}^{\mathrm{o}}$ de Fascículos: 1 (falta la Memoria), Descriptores: Joaquín Hysern, Juan Francisco Sánchez, Madrid.

OBRADOR, BARTOLOMÉ (Censura: ARGUMOSA, DIEGO Y FERNÁNDEZ DE MORA, ANASTASIA)

Observacion sobre una epilepsia curada por el acido picrico o hidrocianuro medicinal, 87-4-A-9, no 924 y 925, 30-Enero-1834 y 6-Febrero-1834. Papel: (1/8), $\mathrm{N}^{\mathrm{o}}$ de Folios: 20, $\mathrm{N}^{\mathrm{o}}$ de Fascículos: 2. Descriptores: Bartolomé Obrador, Diego Argumosa, Anastasia Fernandez de Mora, Madrid.

\section{BARBERO MARTÍN, VALENTÍN (Censura: CALLEJO, CÁNDIDO)}

Observacion sobre un catarro febril, Afectos Internos. 87-4-A-9, no 926 y 927, 13Febrero-1834 y 20-Febrero-1834, Papel: (1/4 y 1/8), Sepúlveda, $\mathrm{N}^{\circ}$ de Folios: 22 , No de Fascículos: 2, Descriptores: Valentín Barbero Martín, Cándido Callejo, Sepúlveda, Madrid. 


\section{MONTORO, MARIÁN (Censura: OBRADOR, BARTOLOMÉ)}

Observacion sobre una afeccion hemorroidal, Cirugía. 87-4-A-9, no 928 y 929. 27 Febrero-1834 y 6-Marzo-1834, Papel: (1/4 y 1/8), $\mathrm{N}^{\mathrm{o}}$ de Folios: 16, $\mathrm{N}^{\mathrm{o}}$ de Fascículos: 2, Descriptores: Marián Montoro, Bartolomé Obrador, Madrid.

CALLEJO, CÁNDIDO (Censura: HYSERN, JOAQUÍN)

Observacion sobre una traqueobronquitis, Afectos Internos, 87-4-A-9, no 930 y 931, 13-Marzo-1834 y 20-Marzo-1834, Papel: (1/8), $\mathrm{N}^{\mathrm{o}}$ de Folios: 18, $\mathrm{N}^{\mathrm{o}}$ de Fascículos: 2, Descriptores: Cándido Callejo, Joaquín Hysern, Madrid.

\section{DE ARGUMOSA, DIEGO (Censura: CASTELLÓ Y TAGELL, JUAN)}

Observacion de una rhinoplastia, Cirugía. 87-4-A-9, no 932 y 933, 3 y 10-Abri1-1834, Papel: (1/4), No de Folios: 15, No de Fascículos: 2, Descriptores: Diego de Argumosa, Juan Castelló y Tagell, Velpeau, Astley, Cooper, Pricke, Juncken, Lallemand.

QUINTANA, RUFINO (Censura: TRUJILLO, RAMÓN)

Observacion sobre una hematuria, Afectos Internos y Terapéutica, 87-4-A-9, no 934 y 935, 17 y 24-Abril-1834, Medina de Pomar. Papel: (1/4), $\mathrm{N}^{\circ}$ de Folios: 6, $\mathrm{N}^{\mathrm{o}}$ de Fascículos: 2, Descriptores: Rufino Quintana (facultativo de Medina de Pomar), Ramón Trujillo, Medina de Pomar.

\section{SÁNCHEZ, JUAN FRANCISCO (Censura: GUTIÉRREZ, BONIFACIO)}

Extirpación de un tumor de más de 15 libras de peso, situado en la parte posterior y derecha del pecho, Cirugía, 87-4-A-9, no 936 y 937, 22-Mayo-1834 y 5-Junio-1834, Papel: (1/4), No de Folios: 7, N$^{\mathrm{o}}$ de Fascículos: 2. Descriptores: Nicolas Cid, Juan Francisco Sánchez, Bonifacio Gutiérrez, Ribes, Azaola.

\section{MERINO GONZÁLEZ NAÑÓN, FRANCISCO}

GONZÁLEZ, JUAN

Censura: POR EL CATEDRÁTICO BIBLIOTECARIO

Observacion sobre una enagenacion mental. Enfermedades Mentales y Terapéutica, 87-4-A-9, no 938 y 939. 19 y 26-Junio-1834. Santa María de Beade, Papel: Folio y 1/4. $\mathrm{N}^{\mathrm{o}}$ de Folios: 14, $\mathrm{N}^{\mathrm{o}}$ de Fascículos: 2. Descriptores: Francisco Merino González Nañón, Juan González y el Catedrático Bibliotecario, Peroja (Orense), Santa María de Beade.

\section{CAPDEVILA, RAMÓN (Censura: SÁNCHEZ, JUAN FRANCISCO)}

Observacion de una hernia umbilical. 87-4-A-9. no 940 y 941. 30-Octubre-1834 y 6Noviembre-1834, Papel: (1/4), $\mathrm{N}^{\mathrm{o}}$ de Folios: 12, $\mathrm{N}^{\mathrm{o}}$ de Fascículos: 2, Descriptores: Ramón Capdevila, Juan Francisco Sánchez, Boerhave, 
GUTIÉRREZ, BONIFACIO (Censura: DE ARGUMOSA, DIEGO)

Observacion de un hydrocele por derrame. Cirugía y Terapéutica, 87-4-A-9, no 942 y 943. 13 y 20-Noviembre-1834. Papel: (1/4). $\mathrm{N}^{\mathrm{o}}$ de Folios: 14. $\mathrm{N}^{\mathrm{o}}$ de Fascículos: 2, Descriptores: Bonifacio Gutiérrez, Diego de Argumosa.

\section{SEBASTIÁ, PEDRO (Censura: CALLEJO, CÁNDIDO)}

Observacion de un berpes retropulso a las vías digestivas. Enfermedades Venéreas, Enfermedades de la piel y Terapéutica», 87-4-A-9, n 944 y 945, 27-Noviembre-1834 y 4Diciembre-1834, Alicante, Papel: Folio y 1/4, No de Folios: 10. $\mathrm{N}^{\circ}$ de Fascículos: 2. Descriptores; Pedro Sebastiá (Médico Cirujano de Alicante), Nicolás Blanch, Cándido Callejo, Alicante.

\section{SÁNCHEZ, JUAN (Censura: OBRADOR, BARTOLOMÉ)}

Observacion de una amputacion del antebrazo. Cirugía y Terapéutica. 87-4-A-9, $\mathbf{n}^{\circ}$ 946 y 947, 11 y 18-Diciembre-1834. Papel: (1/4). No de Folios: 17. No de Fascículos: 2, Descriptores: Juan Sánchez, Bartolomé Obrador, Nicolás Baubo, Dupuytren.

DE ARGUMOSA, DIEGO (Censura: HYSERN, JOAQUÍN)

Observacion de un tumor escirroso de la parotida, Cirugía, 87-4-A-9, no 948 y 949, 8 y 15-Enero-1835, Papel: (1/4), No de Folios: 22 No de Fascículos: 2, Descriptores: Diego de Argumosa, Joaquín Hysern, Juan Bonzar.

SEBASTIÁ Y BLANCH, PEDRO (Censura: GUTIÉRREZ, BONIFACIO)

(...) Cirugía, 87-4-A-8, no 950 y 951. 19 y 26-Febrero-1835. Alicante. Papel: (1/4), No de Folios: 6. $\mathrm{N}^{\mathrm{o}}$ de Fascículos: 2, Descriptores: Pedro Sebastiá y Blanch (Médico Cirujano de Alicante), Bonifacio Gutiérrez, Alicante.

OBRADOR, BARTOLOMÉ (Censura: TRUJILLO, RAMÓN)

Observacion de una gastro-hepato-duodenitis con cálculos biliasicos. Afectos Internos y Terapéutica. 87-4-A-9, no 952 y 953, 5 y 12-Febrero-1835. Papel: (1/4). $\mathrm{N}^{\mathrm{o}}$ de Folios: $12 \mathrm{~N}^{\mathrm{o}}$ de Fascículos: 2, Descriptores: Bartolomé Obrador, Ramón Trujillo, Antonio Hernández Morejón (Catedratico de Clínica Interna de San Carlos), Madrid, Valladolid, Hospital General de Madrid.

HYSERN, JOAQUÍN (Censura: CAPDEVILA, RAMÓN)

Observacion de una herida de arma de fuego en el antebrazo, Cirugía y Terapéutica, 87-4-A-9, no 954 y 955, 5 y 12-Marzo-1835, Papel: (1/4), No de Folios: 32, No de Fascículos: 2, Descriptores: Joaquín Hysern, Ramón Capdevila, Luis de Palafox (Teniente Coronel graduado y Teniente de la Guardia Real de Provinciales), José Ribes, Pedro María Rubio, Vicente Asuero, Bonifacio Gutiérrez, Guardia Real del Ejército. 


\section{CASTELLÓ Y TAGELL (Ceusura: SÁNCHEZ, JUAN FRANCISCO)}

Observacion de fracturas de las dos piernas con heridas, Cirugía, 87-4-A-9, $\mathbf{n}^{\mathbf{0}} 956$ y 957. 26-Marzo-1835 y 2-Abril-1835, Papel: (1/4), № de Folios: 11, № de Fascículos: 2 , Descriptores : Juan Castelló y Tagell, Juan Francisco Sánchez, Mariano Martín, Juan de Vigo, Rabatón, Villaverde.

\section{TRUJILLO, RAMÓN (Censura: DE ARGUMOSA, DIEGO)}

Memoria acerca de Miguel Serveto y Francisco de la Reyna acerca de la prioridad del descubrimiento de la circulacion. Medicina, 87-4-A-9, $\mathbf{n}^{\circ} 958$ y 959. 30-Abril-1835 y 7-Mayo-1835. Papel: (1/4), No de Folios: 17. No de Fascículos: 2, Descriptores: Ramón Trujillo, Diego de Argumosa, Albeytan, Freijó, Miguel Serveto, Pablo Scarpi (fraile Servita), Calvino, Harveo, Francisco de la Reyna (veterinario), Realdo Colombo, Andrés Cesalpino (médico italiano), Hipócrates, Galeno, Celso, Julio Cesar Arancio (anatómico de Bolonia), Levasern, Bolonia, Madrid, España, Burgos, Aragón, Venecia, Roma, Zaragoza, Orden de los Benedictinos.

\section{GUTIÉRREZ, BONIFACIO (Censura: CALLEJO, CÁNDIDO)}

Observacion de una apoplejía, Afectos Internos, 87-4-A-9, no 960 y 961.14 y 21Mayo-1835. Papel: (1/4). $N^{o}$ de Folios: 11, No de Fascículos: 2, Descriptores: Bonifacio Gutiérrez, Cándido Callejo, Pedro Conde (verdulero), Monlin, Calleman, Bochoux, Madrid.

\section{ALCÁNTARA ARENAL, PEDRO (Censura: OBRADOR, BARTOLOMÉ)}

Observacion de una blenorragia uretral, Enfermedades Venéreas y Terapéutica. 87-4A-9, no 962 y 963, 4 y 1-Junio-1835, Valencia de Don Juan, Papel: (1/4), No de Folios: 13. $\mathrm{N}^{\mathrm{o}}$ de Fascículos: 2. Descriptores: Pedro Alcántara Arenal (Cirujano titular de Valencia de Don Juan), Bartolomé Obrador, Gosalves, Valencia de Don Juan.

\section{DÍAZ, JUAN (Censura: HYSERN, JOAQUÍN)}

Relacion de mis padecimientos, 87-4-A-9, no 964 y 965. 8-Octubre-1835y 15-Octubre1835. Lerma. Papel: (1/8), $N^{o}$ de Folios: 20. No de Fascículos: 2, Descriptores: Juan Díaz, Joaquín Hysern, Lerma, Madrid.

\section{SÁNCHEZ, JUAN FRANCISCO (Censura: CASTELLÓ, JUAN)}

Observacion sobre aneurisma de la arteria poplitea. Cirugía. 87-4-A-9, no 966 y 967, 22-Octubre-1835 y 29-Octubre-1825. Papel: (1/8). No de Folios: 24, No de Fascículos: 2, Descriptores: Juan Francisco Sánchez, Juan Castelló, Madrid. 
Censura: TRUJILLO, RAMÓN

Nuevo método de amputar un colgajo. Cirugía, 87-4-A-9, no 968. 12-Noviemhre-1835. Papel: (1/8). No de Folios: 16. No de Fascículos: 2. Descriptores: Ramón Trujillo, Madrid.

CALLEJO, CÁNDIDO (Censura: GUTIÉRREZ, BONIFACIO)

Observacion sobre una pleuresia. Afectos Internos. 87-4-A-9. No 969 y 970 . 26Noviembre-1835 y 3-Diciembre-1835. Papel: (1/8), No de Folios: 24. No de Fascículos: 2. Descriptores: Cándido Callejo, Bonifacio Gutiérrez, Madrid.

OBRADOR, BARTOLOMÉ (Censura: SÁNCHEZ, JUAN FRANCISCO)

Observacion sobre un parto laborioso manual con ventro peritonitis curada, Tocología. 87-4-A-9 no 971 y 972, 7-Enero-1836 y 21-Enero-1836. Papel: (1/8). No de Folios: 16, $\mathrm{N}^{\mathrm{o}}$ de Fascículos: 2. Descriptores: Bartolomé Obrador, Juan Francisco Sánchez, Madrid.

DELGADO, FAUSTINO (Censura: DE ARGUMOSA, DIEGO)

Observacion sobre una bronquitis crónica, 87-4-A-9, no 973 y 974. 28-Enero-1836 y 4-Febrero-1836, Toboso. Papel( (1/8), No de Folios: 20. No de Fascículos: 2, Descriptores: Faustino Delgado, Diego de Argumosa, Toboso, Madrid.

BENITO GONZÁLEZ, ZACARÍAS (Censura: CALLEJO, CÁNDIDO)

Observacion sobre una enterocolitis crónica. Afectos Internos, 87-4-A-9 no 975 y 976. 11-Febrero-1836 y 18-Febrero-1836, Lillo, Papel: (1/8), № de Folios: 22 No de Fascículos: 2. Descriptores: Zacarías Benito González, Cándido Callejo, Lillo, Madrid.

HYSERN, JOAQUÍN (Censura: OBRADOR, BARTOLOMÉ)

Observacion de una oftalmia. Enfermedades de 1 os ojos, 87-4-A-9, no 977 y 978.10 y 17-Marzo-1836. Pape1: (1/8). No de Folios: 36. № de Fascículos: 2. Descriptores: Joaquín Hysern, Bartolomé Obrador, Juan Fariñas, Madrid.

CASTELLÓ, JUAN (Censura: HYSERN, JOAQUÍN)

Observacion sobre una gran contusion. Cirugía, 87-4-A-9 no 979 y 980. 7-Abril-1836 y 14-Abril-1836, Pape1: (1/8). $\mathrm{N}^{\mathrm{o}}$ de Folios: 20. $\mathrm{N}^{\mathrm{o}}$ de Fascículos: 2, Descriptores: Juan Castelló, Joaquín Hysern, Madrid.

SIERRA, ANDRÉS (Censura: CASTELLÓ, JUAN)

Historia de un parto de un feto monstruoso. Tocología y Anatomía. 87-4-A-9 no 981 y 982. 20-Febrero-1836. Villalar. $\mathrm{N}^{\circ}$ de Folios: 11 . $\mathrm{N}^{\mathrm{o}}$ de Fascículos: 2, Descriptores: Andrés Sierra, Juan Castalló, Villalar, Madrid, Real Colegio de Cirugía de San Carlos. 
TRUJILLO, RAMÓN (Censura: GUTIÉRREZ, BONIFACIO)

Observacion sobre una fiebre gástrica lenta, Afectos Internos. 87-4-A-9, no 983 y 984, 5 y 13-Mayo-1836. Papel: (1/4), $\mathrm{N}^{0}$ de Folios: 9. $\mathrm{N}^{\mathrm{o}}$ de Fascículos: 2, Descriptores: Ramón Trujillo, Bonifacio Gutiérrez. Madrid, Real Colegio de Cirugía de San Carlos.

\section{GUTIÉRREZ, BONIFACIO}

Observacion de un abceso de epilepsia durante el embrazo. Tocología y Afectos Internos. 87-4-A-9 no 985. 9-Junio-1836, Papel: (1/4), No de Folios: 4. No de Fascículos: 2. Descriptores: Bonifacio Gutierrez, Madrid, Real Colegio de Cirugía de San Carlos.

\section{ANÓNIMO}

Censura sobre un afecto escrofu1oso. Afectos Mixtos, 87-4-A-9 no 986 Papel: (1/4), $N^{\circ}$ de Folios: 4, No de Fascículos: 1 (fa1ta la Memoria). Descriptores: Real Colegio de Cirugía de San Carlos.

\section{ANÓNIMO}

Observacion sobre una erupcion herpética. Afectos Mixtos. 87-4-A-9, no 987. Papel: (1/4) , No de Folios: 4, No de Fascículos: 1 (falta la Censura). Descriptores: Ubeda, Real Colegio de Cirugía de San Carlos.

\section{ANÓNIMO}

Censura de la observacion de un caso de Hidrocefalia. Afectos Internos. 87-4-A-9 $\mathbf{n}^{\mathbf{0}}$ 988. Papel: Folio. $\mathrm{N}^{\mathrm{o}}$ de Folios: 10. $\mathrm{N}^{\mathrm{o}}$ de Fascículos: 1 (falta la Memoria). Descriptores: Sarrais, Whit, Quin, Watson, Real Colegio de Cirugía de San Carlos.

\section{ANÓNIMO}

Censura a la observacion sobre un hidrocele por derramamiento en 1a túnica vaginal. Afectos Internos, 87-4-A-9 no 989. Papel: (1/4), No de Folios: 3. No de Fascículos: 1 (falta la Memoria). Descriptores: Real Colegio de Cirugía de San Carlos.

\section{ANÓNIMO}

Observacion sobre un hidrocele doble. Afectos Internos, 87-4-A-9, $\mathbf{n}^{\mathbf{0}}$ 990, Papel: Folio, $\mathrm{N}^{\mathrm{o}}$ de Folios: 2, $\mathrm{N}^{\mathrm{o}}$ de Fascículos: 1 (falta 1a Censura), Descriptores: Real Colegio de Cirugía de San Carlos.

\section{ANÓNIMO}

Observacion sobre un hidrosarcocele, Afectos Internos. 87-4-A-9, $\mathbf{n}^{\mathbf{0}}$ 991. Papel: (1/4), $\mathrm{N}^{\mathrm{o}}$ de Folios: 2. No de Fascículos: 1. Descriptores: Real Colegio de Cirugía de San Carlos. 


\section{ANÓNIMO}

Censura a la observacion sobre una hipocondría. Afectos Internos, 87-4- A-9, no 992, Papel: Folio, $\mathrm{N}^{\mathrm{o}}$ de Folios: 1. $\mathrm{N}^{\mathrm{o}}$ de Fascículos: 1 (falta la Memoria). Descriptores: Real Colegio de Cirugía de San Carlos.

\section{ANÓNIMO}

Observacion sobre una luxacion del húmero. Enfermedades de los huesos. 87-4-A-9, no 993. Papel: (1/4), $\mathrm{N}^{\mathrm{o}}$ de Folios: 4 . $\mathrm{N}^{\mathrm{o}}$ de Fascículos: 1 (falta la Censura), Descriptores: Real Colegio de Cirugía de San Carlos de Madrid.

\section{ANÓNIMO}

Composicion del elixir para el dolor de muelas y otros medicamentos específicos, Materia Médica, 87-4-A-9 no 994, Papel: Folio. $N^{\circ}$ de Folios: 2. No de Fasciculos: 1 (falta la Censura), Descriptores: Real Colegio de Cirugía de San Carlos de Madrid.

\section{SÁNCHEZ VILLACAÑAS, JUAN ALFONSO}

Consulta sobre un caso de sordera, Afectos Internos, 87-4-A-9, no 995, Alcalá de Henares, Papel: Folio. $N^{o}$ de Folios: 1, $N^{o}$ de Fascículos: 1 (falta 1a Censura), Descriptores: Juan Alfonso Sánchez Villacañas, Cifuentes, Alcalá de Henares.

\section{ANÓNIMO}

Censura al plan de estudios quirúrgicos compuesto por Don Francisco Puig. Enseñanza Médica 87-4-A-9 no 996. Papel: (1/4) No de Folios: 6, No de Fascículos: 1 (fa1ta 1a Memoria). Descriptores: Falconnier, Heisner, Percival, Wilson, Francisco Puig, Begne de Presle, Alfonso Fermi, Duverney, Pressavin, Madrid, Barcelona, Real Colegio de Cirugía de San Carlos de Madrid, Real Colegio de Cirugía Barcelona, Escuela de Salerno.

\section{ANÓNIMO}

Observacion de una úlcera en la parte lateral del pie derecho, Afectos Mixtos, Terapéutica. no 997, 87-4-A-9, Papel; (1/4). No de Folios: 1, No de Fascículos: 1 (falta la Censura). Descriptores: Real Colegio de Cirugía de San Carlos de Madrid.

\section{ANÓNIMO}

Observacion sobre una herida penetrante con salida del epiplon, Cirugía. 87-4-A-9, no 998. Enero 1801, Papel: (1/4). No de Folios: 2, No de Fascículos: 1. 


\section{LABRADOR, JOSEF (Censura: LOCHE, SEBASTIÁN)}

Observacion sobre abortos frecuentes. Enfermedades de las Mujeres, 87-4-A-9 no 9991000. Papel: (1/4) $\mathrm{N}^{\mathrm{o}}$ de Folios: 5. $\mathrm{N}^{\mathrm{o}}$ de Fascículos: 2. Descriptores: Josef Labrador, Sebastián Loche, Boerhave, Real Colegio de Cirugía de San Carlos de Madrid.

\section{ANÓNIMO}

Censura de una observacion sobre cuatro casos de carbunco. Afectos Internos y Terapéutica, 87-4-A-9, no 1001. Papel: Folio. No de Folios: 4. Nº de Fascículos: 1.

DE VIANA, NICOLÁS

Observacion de un golpe de agua en el ojo derecho. Enfermedades de los ojos. 87-4-A9, no 1002. Papel: (1/4). $\mathrm{N}^{\mathrm{o}}$ de Folios: 2. $\mathrm{N}^{\mathrm{o}}$ de Fascículos: 1. Descriptores: Nicolás de Viana, Real Colegio de Cirugía de San Carlos de Madrid.

ANÓNIMO.

Observacion sobre una erupcion sarnosa. Materia Médica y Afectos Mixtos, 87-4-A-9 $\mathbf{n}^{\mathbf{0}}$ 1003. Pape1: (1/4). $\mathrm{N}^{\circ}$ de Folios: 2 . $\mathrm{N}^{\circ}$ de Fascículos: 1 (falta la Censura).

\section{PÉREZ, LUCAS}

Observacion sobre arrojos de cuerpos extraños por la uretra, Afectos Mixtos. 87-4A-9, no 1004, 27-Ju1io-1816. Fuente rebollo. Pape1: (1/4). No de Folios: 1. No de Fascículos: 1. Descriptores: Lucas Pérez, Josef Ribes. Fuente Rebollo.

\section{ANÓNIMO}

Observacion sobre una erisipela (...). Afectos Mixtos. 87-4-A-9, $\mathbf{n}^{\mathbf{0}} 1005$ Papel: Folio, $\mathrm{N}^{\mathrm{o}}$ de Folios: 1. $\mathrm{N}^{\mathrm{o}}$ de Fascículos: 1 (fa1ta la Censura).

\section{ANÓNIMO}

Observacion sobre una dislocacion de 1a laringe. Afectos mixtos. 87-4-A-9, $\mathbf{n}^{\mathbf{0}} 1006$ Papel: (1/4), $\mathrm{N}^{\mathrm{o}}$ de Folios: 2. $\mathrm{N}^{\mathrm{o}}$ de Fascículos: 1 (falta la Censura).

OTROS MATERIALES

ANÓNIMO

Afectos Externos y operaciones de D. Josef Ribes Espinar en el $3^{\circ}$ año de (...). Afectos Externos y Cirugía, 616 o R 39j. 1816. Papel: (1/4). No de Folios: 283. No de Fascículos: 1.

\section{ANÓNIMO}

Anatomía y Fisiología de Boerhaave. Anatomía y Fisiología. $611+612$ B 64 . No 611 y 612. Manuscritos. Papel: $1 / 4 . N^{o}$ de Folios: s.p. $N^{o}$ de Fascículos: 1. 


\section{ANÓNIMO}

Apuntaciones de Medicina. Catálogo. 61.001 Apn. 9, Papel: Folio. № de Folios: s.p. $\mathrm{N}^{\mathrm{o}}$ de Fascículos: 2 Tomos.

\section{ANÓNIMO}

Compendio de Materia Médica seguido de un formulario, Materia Médica, 615 I C 68. Manuscrito. Papel: (1/8), $\mathrm{N}^{\mathrm{o}}$ de Folios: s.p. $\mathrm{N}^{\mathrm{o}}$ de Fascículos: 1.

\section{ANÓNIMO}

El Templo del dios Esculapio y el del inmortal Hipocrates en la isla de Cos donde se enseña la historia crítica de la Medicina. 61 (09) M 54. $\mathrm{N}^{\mathrm{o}} 61, \mathrm{~N}^{\mathrm{o}}$ de Folios: s.p. $\mathrm{N}^{\mathrm{o}} \mathrm{de}$ Fascículos: 1. Encuadernado.

\section{ANÓNIMO}

Fisiología de la digestion, Fisiología, 612-F-52. Papel: (1/4), $\mathrm{N}^{\mathrm{o}}$ de Folios: $56 . \mathrm{N}^{\mathrm{o}}$ de Fascículos: 1. Encuadernación Rígida. Descriptores: Álvarez M. Canal.

\section{ANÓNIMO}

Fisiología especial. Fisiología, 612-AI-9. Papel: (1/4), No de Folios: 94, No de Fascículos: 1. Encuadernación Rígida. Descriptores: Álvarez M. Canal.

\section{ANÓNIMO}

Nosología o clasificación de las enfermedades. Afectos Internos, no 616-03-N-62. Manuscrito, 1828, Pape1: (1/4), $N^{o}$ de Folios: s.p. $N^{\circ}$ de Fascículos: 1. Encuadernación Rígida, Descriptores: Á1varez Canales.

\section{ANÓNIMO}

Obstetricia y enfermedades de Mujeres y Niños. Obstetricia y Enfermedades de Mujeres. 618-P-32. Manuscritos. Papel: (1/4). $\mathrm{N}^{\mathrm{o}}$ de Folios: s.p. $\mathrm{N}^{\mathrm{o}}$ de Fascículos: 1. Encuadernación Rígida.

\section{ANÓNIMO}

Terapéutica. Terapéutica, 615-T-34, Manuscritos. Papel: (1/4). No de Folios: s.p. $\mathrm{N}^{\mathrm{o}}$ de Fascículos: 1. Encuadernación Rígida.

\section{ANÓNIMO}

Traité de Pharmacie, Terapéutica, 615-T-55, Manuscritos. Papel: (1/4). № de Folios: s.p. $\mathrm{N}^{\mathrm{o}}$ de Fascículos: 1. Lengua francesa. Encuadernación Rígida. 


\section{ANÓNIMO}

Tratado de Medicina: De la calentura inflamatoria, Orden $1^{a}$ Angiotímicas. Calenturas biliosas, Orden $2^{\mathrm{a}}$ Meningogastricas. Calenturas esclero meningeas, Orden $3^{\mathrm{a}}$. Calenturas Adinámicas. Tifus. Calenturas Atípicas o malignas. Afectos Internos. $\mathbf{N}^{\mathbf{o}}$ 61-T-76. Manuscrito. Papel: (1/4). $\mathrm{N}^{\mathrm{o}}$ de Folios: s.p. $\mathrm{N}^{\mathrm{o}}$ de Fascículos: 1. Encuadernación rígida. Descriptores: Calleja.

\section{ASUERO VILLAESCUSA, VICENTE}

Patología Quirúrgica, no 616-89. 1858-59. Manuscrito. Papel: (1/4). No de Folios: s.p. $\mathrm{N}^{\mathrm{o}}$ de Fascículos: 1. Encuadernación rígida. Descriptores: San Martín, José Calvo Martín, Vicente Asuero Villaescusa. Madrid.

\section{DE ATAIDE, ENRIQUE}

Indices de Biblioteca de 1a Facultad Médica de Madrid. Catá1ogo 01-AT-1e. 3Junio-1845. Manuscrito. Papel: Folio. No de Folios: s.p. No de Fascículos: 1. Encuadernación rígida. Descriptores: Enrique de Ataide.

\section{CASTELLÓ, PEDRO}

Indice de la Biblioteca del Real Colegio de Cirugía Médica de San Car1os de Madrid. Catálogo. 01-C-268. 1819, Papel: Folio. Manuscrito. $\mathrm{N}^{\mathrm{o}}$ de Folios: s.p. $\mathrm{N}^{\mathrm{o}}$ de Fascículos: 1. Encuadernación rígida. Descriptores: Pedro Castelló. Madrid. Colegio de Cirugía Médica de San Carlos.

\section{CORRAL, TOMÁS}

Enfermedades de Mugeres. Obstetricia. 618-M621R. Manuscrito. Papel: (1/4). $\mathrm{N}^{\mathrm{o}}$ de Folios: 140. № de Fascículos: 1. Encuadernación rígida. Descriptores: Tomás Corral.

\section{GONZÁLEZ, PEDRO MARÍA}

Elementos de Fisiologia y de Higiene para uso de los estudiantes del Colegio de Medicina y Cirugía de Cadiz. Fisiologia e Higiene. 612-G-59P, 1815. Cádiz, Manuscrito. Papel: (1/4). $\mathrm{N}^{\mathrm{o}}$ de Folios: s.p. $\mathrm{N}^{\mathrm{o}}$ de Fascículos: 1. Encuadernación rígida. Descriptores: Miguel Canal, Pedro María González, Colegio de Medicina y Cirugía de Cádiz.

\section{GONZÁLEZ, JERÓNIMO}

Enfermedades de Mujeres por el Dr. D. Agustín Ginestá Catedrático del Real Colegio de Cirugía Médica de San Carlos y escritas por Gerónimo González Discipu1o de dicho colegio. 618-1G45a. 1820. Manuscrito. Papel: (1/4). $\mathrm{N}^{\mathrm{o}}$ de Folios: 233. $\mathrm{N}^{\mathrm{o}}$ de Fascículos: 1. Encuadernación rígida. Descriptores: Jerónimo González, Agustín Ginestá, Madrid, Real Colegio de Cirugía de San Carlos. 


\section{GONZÁLEZ, JERÓNIMO}

Enfermedades de Niños por el Dr. D. Agustín Ginestá Catedrático del Real Colegio de Cirugía Médica de San Carlos y escritas por Gerónimo González Discipulo de dicho colegio. Pediatría. 618-1G45a. 1826. Manuscrito. Papel: (1/4). No de Folios: 119. $\mathrm{N}^{\mathrm{o}}$ de Fascículos: 1. Encuadernación rígida. Descriptores: Jerónimo González, Agustín Ginestá, Madrid, Real Colegio de Cirugía de San Carlos.

\section{GONZÁLEZ, JERÓNIMO}

Tratado de Afectos externos explicados por el Dr. D. José Rives Catedrático del Real Colegio de Cirugía Médica de San Carlos de Madrid. Afectos Externos. 616R39j. 1819. Manuscrito. Papel: (1/4). No de Folios: 492. No de Fascículos: 1. Encuadernación rígida. Descriptores: Jerónimo González, Josef Ribes, Madrid, Real Colegio de Cirugía de San Carlos.

\section{GUEDEA Y CALVO, LUIS}

Programa de Anatomía topográfica, medicina operatoria y arte de los apósitos y vendages. Anatomía Topográfica, Medicina Operatoria, Arte de los Apósitos y Vendajes. 37-6-88e. Papel: (1/4), $\mathrm{N}^{\mathrm{o}}$ de Folios: s.p. $\mathrm{N}^{\mathrm{o}}$ de Fascículos: 1. Encuadernación Rígida, Descriptores: Luis Guedea, Facu1tad de Medicina de Santiago de Compostela.

\section{HERNÁNDEZ MOREJÓN, ANTONIIO}

Índice de la Biblioteca del Colegio de Cirugía de San Carlos. Catálogo, 017-M-85, 1890, Descriptores: Antonio Hernández Morejón, Madrid.

\section{CASAL, BONIFACIO}

Tratado de Anatomía. Anatomía, 611-0-6-24-m, Manuscritos, Papel: (1/4). Encuadernación Rígida, Descriptores: Bonifacio Casal, Fernández Carril, Madrid.

\section{MÉNDEZ, BARTOLOMÉ}

Enfermedades de mugeres, tratado de partos y enfermedades venéreas. 618-1-6-26p, Papel: (1/4). No de Folios: s.p. $N^{o}$ de Fascículos: 1. Encuadernación Rígida, Descriptores: Pedro Castelló, Bartolomé Méndez.

\section{MERINO, JOSÉ}

Apuntes de Patología Quirúrgica. Cirugía, 616-089-M-62-F. Manuscritos. Papel: (1/4), $\mathrm{N}^{\mathrm{o}}$ de Folios: s.p. $\mathrm{N}^{\mathrm{o}}$ de Fascículos: 1. Encuadernación Rígida, Descriptores: José Merino, Madrid. 


\section{MONTORO, ANTONIO}

Tratado de Afectos Quirúrgicos. Cirugía, 616-089 12 49i, Manuscritos, 1822. Papel: (1/4) No de Folios: s.p. No de Fascículos: 2 Tomos. Encuadernación Rígida, Descriptores: Antonio Montoro, Josef Ribes, Ribera, Madrid.

PIQUER, L.

Medicina teorico practica. Afectos Internos. 616-03 P63L. Manuscritos, Papel: (1/4), $\mathrm{N}^{\mathrm{o}}$ de Folios: s.p. $\mathrm{N}^{\mathrm{o}}$ de Fascículos: 1. Encuadernación Rígida, Descriptores: L. Piquer, Madrid.

\section{PIQUER, ANDRÉS}

Tractatus Phisico medicus de Humanis corporis mechanismo in nervis praecipue observabili et per anathomen Facile comprensibile. Anatomía. 611-P-63a. Manuscritos. 1748. Papel: (1/4), $\mathrm{N}^{\mathrm{o}}$ de Folios: s.p. $\mathrm{N}^{\mathrm{o}}$ de Fascículos: 1. Encuadernación Rígida, Lengua: Latín. Descriptores: Andrés Piquer.

\section{RIBES, JOSEF}

De 1os tumores linfáticos por congestion. Cirugía, 616-006 R 39j. Manuscritos. Pape1: (1/4). $N^{o}$ de Folios: s.p. $N^{o}$ de Fascículos: 1. Encuadernación Rígida, Descriptores: Josef Ribes.

\section{RIBES Y QUERALTO, JOSÉ}

Tratado de Afectos externos, Tomo V. Cirugía. 6177-R-49j. 1820. Pape1: (1/4). No de Folios: 217. N $^{\mathrm{o}}$ de Fascículos: 1. Encuadernación Rígida, Descriptores: José Ribes y Queraltó (Catedrático y Vicedirector del Real Colegio de Cirugía Médica de San Carlos. Madrid.

\section{RIEGO, ANTONIO}

Tratado de Cirugía de inflamaciones y operaciones. Cirugía. 617-R-44a, 1825-1828, Papel: (1/4), No de Folios: 293. No de Fascículos: 1. Encuadernación Rígida, Descriptores: Antonio Riego (Profesor de Cirugía y Medicina del Real Colegio de Cirugía Médica de San Carlos, Cirujano de los Reales Ejércitos). Barcelona. Madrid.

RODRÍGUEZ CANAMICOZAN, MANUEL

COSTE, M.

HERNÁNDEZ MOREJÓN, ANTONIO

Reglamento del Cuerpo de Cirugía Militar del 20 de julio de 1805 du service des Hospitaux Militares. Juicio imparcial sobre la reunión de la Medicina con la Cirugía. Reglamentos, 355-72 R-26. Descriptores: Manuel Rodriguez Caanamicozán, M. Coste, Antonio Hernández Morejón, Madrid, París, Valencia, Cuerpo de Cirugía Militar. 


\section{RUIZ DE LUZURIAGA, IGNACIO MARÍA}

Analisis de las Ordenanzas. Reglamento. 614, 1817. Papel: Folio, $\mathrm{N}^{\mathrm{o}}$ de Folios: 166. $\mathrm{N}^{\mathrm{o}}$ de Fascículos: 1. Encuadernación Rígida, Descriptores: Ignacio María Ruiz de Luzuriaga, Madrid.

J. R. G.

Curso de aspectos externos esplicados por D. Jose Ribes catedratico en el Colegio de San Carlos de Madrid y copiado por su discípulo J. R. G. Afectos Externos (Cirugía). 616-O R 39j. 1821, Pape1: (1/4). $\mathrm{N}^{\mathrm{o}}$ de Folios: 323. $\mathrm{N}^{\mathrm{o}}$ de Fascículos: 2 Tomos. Encuadernación Rígida, Descriptores: J. R. G., Josef Ribes, Colegio de San Carlos de Madrid.

J. R. G.

Curso de afectos externos y operaciones explicado por D. Jose Ribes, Tomo I. Afectos Externos y Cirugía. 616 o R3Tj. 1820. No de Folios: 439, $\mathrm{N}^{\circ}$ de Fascículos: 1. Descriptores: Josef Ribes, Bonifacio Montejo, Madrid.

\section{SAN GERMÁN, ANTONIO}

Afectos externos y operaciones del Dr. Ribes en su discusion por Antonio San German. Afectos Externos y Cirugía. 616 o R 37j. 1806, Papel: (1/4), No de Folios: 721, No de Fascículos: 1. Descriptores: Antonio San Germán, Josef Ribes, Madrid.

\section{SOLÍS DIONISIO}

Afectos mixtos por Bonifacio Gutiérrez, Cuaderno segundo. Afectos Mixtos. 616911-6-96b. 1829. Papel: (1/8). $\mathrm{N}^{\mathrm{o}}$ de Folios: 116, No de Fascículos: 1. Descriptores: Dionisio Solís, Bonifacio Gutiérrez.

DE LA TORRE, MARCELINO

Afectos externos por D. Marcelino de 1a Torre. Afectos Externos. 616 o T 68m. 1828. No de Folios: 163, No de Fascículos: 1. Descriptores: Marcelino de la Torre, Madrid.

GÓMEZ VALLADARES, PEDRO

Anatomía $2^{\circ}$ año. Anatomía. 611-F-79, Manuscritos 1852-1853. Papel: (1/4). $\mathrm{N}^{\mathrm{o}}$ de Folios: s.p., $\mathrm{N}^{\mathrm{o}}$ de Fascículos: 1. Descriptores: Pedro Gómez Valladares, Calleja, Juan Fararquet, Madrid.

J. V. C.

Anatomía Patologica. Oracion inaugural Curso 1826. Anatomía Patológica. 616-09l M 87j. Manuscritos. Papel: (1/8). $\mathrm{N}^{\mathrm{o}}$ de Folios: s.p., $\mathrm{N}^{\mathrm{o}}$ de Fascículos: 1. Descriptores: J.V.C., Juan Mosácula, Madrid. 